Cochrane Database of Systematic Reviews

\title{
Cervical stitch (cerclage) in combination with other treatments for preventing spontaneous preterm birth in singleton pregnancies
} (Review)

Eleje GU, Eke AC, Ikechebelu JI, Ezebialu IU, Okam PC, Ilika CP

Eleje GU, Eke AC, Ikechebelu JI, Ezebialu IU, Okam PC, Ilika CP.

Cervical stitch (cerclage) in combination with other treatments for preventing spontaneous preterm birth in singleton pregnancies.

Cochrane Database of Systematic Reviews 2020, Issue 9. Art. No.: CD012871.

DOI: 10.1002/14651858.CD012871.pub2.

www.cochranelibrary.com

Cervical stitch (cerclage) in combination with other treatments for preventing spontaneous preterm birth in singleton pregnancies (Review) 
TABLE OF CONTENTS

ABSTRAC

PLAIN LANGUAGE SUMMARY

SUMMARY OF FINDINGS

BACKGROUND

OBJECTIVES

METHODS

Figure 1.

RESULTS

Figure 2.

Figure 3.

DISCUSSION

AUTHORS' CONCLUSIONS

ACKNOWLEDGEMENTS

REFERENCES

CHARACTERISTICS OF STUDIES

DATA AND ANALYSES

Analysis 1.1. Comparison 1: Cervical cerclage in combination with antibiotic and tocolytic versus cervical cerclage alone, Outcome 1: Serious neonatal morbidity

Analysis 1.2. Comparison 1: Cervical cerclage in combination with antibiotic and tocolytic versus cervical cerclage alone, Outcome 2: Perinatal loss: all - including miscarriages and stillbirth (but no data for neonatal death)

Analysis 1.3. Comparison 1: Cervical cerclage in combination with antibiotic and tocolytic versus cervical cerclage alone, Outcome 3: Stillbirth (intrauterine fetal death at 24 weeks or more)

Analysis 1.4. Comparison 1: Cervical cerclage in combination with antibiotic and tocolytic versus cervical cerclage alone, Outcome 4: Miscarriages (perinatal loss before 24 weeks)

Analysis 1.5. Comparison 1: Cervical cerclage in combination with antibiotic and tocolytic versus cervical cerclage alone, Outcome 5: Preterm birth $<28$ weeks

Analysis 1.6. Comparison 1: Cervical cerclage in combination with antibiotic and tocolytic versus cervical cerclage alone, Outcome 6: Preterm birth $<34$ weeks

Analysis 1.7. Comparison 1: Cervical cerclage in combination with antibiotic and tocolytic versus cervical cerclage alone, Outcome 7: Preterm birth < 37 weeks

Analysis 1.8. Comparison 1: Cervical cerclage in combination with antibiotic and tocolytic versus cervical cerclage alone, Outcome 8: Serious intracranial pathology

Analysis 1.9. Comparison 1: Cervical cerclage in combination with antibiotic and tocolytic versus cervical cerclage alone, Outcome 9: Serious respiratory morbidity

Analysis 1.10. Comparison 1: Cervical cerclage in combination with antibiotic and tocolytic versus cervical cerclage alone, Outcome 10: Necrotising enterocolitis

Analysis 1.11. Comparison 1: Cervical cerclage in combination with antibiotic and tocolytic versus cervical cerclage alone, Outcome 11: Retinopathy of prematurity

Analysis 1.12. Comparison 1: Cervical cerclage in combination with antibiotic and tocolytic versus cervical cerclage alone, Outcome 12: Maternal infection, including chorioamnionitis, requiring intervention (chorioamnionitis)

Analysis 1.13. Comparison 1: Cervical cerclage in combination with antibiotic and tocolytic versus cervical cerclage alone, Outcome 13: Preterm premature rupture of membranes

APPENDICES

HISTORY

CONTRIBUTIONS OF AUTHORS

DECLARATIONS OF INTEREST

DIFFERENCES BETWEEN PROTOCOL AND REVIEW

INDEX TERMS 
[Intervention Review]

\title{
Cervical stitch (cerclage) in combination with other treatments for preventing spontaneous preterm birth in singleton pregnancies
}

\author{
George U Eleje ${ }^{1}$, Ahizechukwu C Eke², Joseph I Ikechebelu³ ${ }^{3}$ Ifeanyichukwu U Ezebialu4, Princeston C Okam ${ }^{5}$, Chito P Ilika ${ }^{5}$
}

1Effective Care Research Unit, Department of Obstetrics and Gynaecology, Faculty of Medicine, College of Health Sciences, Nnamdi Azikiwe University, Nnewi Campus, PMB 5001, Nnewi, Nigeria. 2Division of Maternal Fetal Medicine, Department of Gynecology and Obstetrics, Johns Hopkins University School of Medicine, Baltimore, Maryland, USA. ${ }^{3}$ Department of Obstetrics/Gynaecology, Nnamdi Azikiwe University Teaching Hospital, Nnewi, Nigeria. ${ }^{4}$ Department of Obstetrics and Gynaecology, Faculty of Clinical medicine, College of Medicine, Anambra State University Amaku, Awka, Nigeria. ${ }^{5}$ Department of Obstetrics and Gynaecology, Nnamdi Azikiwe University Teaching Hospital, Nnewi, Nigeria

Contact: George U Eleje, georgel21@yahoo.com.

Editorial group: Cochrane Pregnancy and Childbirth Group.

Publication status and date: New, published in Issue 9, 2020.

Citation: Eleje GU, Eke AC, Ikechebelu JI, Ezebialu IU, Okam PC, Ilika CP. Cervical stitch (cerclage) in combination with other treatments for preventing spontaneous preterm birth in singleton pregnancies. Cochrane Database of Systematic Reviews 2020, Issue 9. Art. No.: CD012871. DOI: 10.1002/14651858.CD012871.pub2.

Copyright @ 2020 The Cochrane Collaboration. Published by John Wiley \& Sons, Ltd.

\section{A B S T R A C T}

\section{Background}

Preterm birth (PTB) remains the foremost global cause of perinatal morbidity and mortality. Thus, the prevention of spontaneous PTB still remains of critical importance. In an attempt to prevent PTB in singleton pregnancies, cervical cerclage, in combination with other treatments, has been advocated. This is because, cervical cerclage is an intervention that is commonly recommended in women with a short cervix at high risk of preterm birth but, despite this, many women still deliver prematurely, as the biological mechanism is incompletely understood. Additionally, previous Cochrane Reviews have been published on the effectiveness of cervical cerclage in singleton and multiple pregnancies, however, none has evaluated the effectiveness of using cervical cerclage in combination with other treatments.

\section{Objectives}

To assess whether antibiotics administration, vaginal pessary, reinforcing or second cerclage placement, tocolytic, progesterone, or other interventions at the time of cervical cerclage placement prolong singleton gestation in women at high risk of pregnancy loss based on prior history and/or ultrasound finding of 'short cervix' and/or physical examination.

History-indicated cerclage is defined as a cerclage placed usually between 12 and 15 weeks gestation based solely on poor prior obstetrical history, e.g. multiple second trimester losses due to painless dilatation. Ultrasound-indicated cerclage is defined as a cerclage placed usually between 16 and 23 weeks gestation for transvaginal ultrasound cervical length $<20 \mathrm{~mm}$ in a woman without cervical dilatation. Physical exam-indicated cerclage is defined as a cerclage placed usually between 16 and 23 weeks gestation because of cervical dilatation of one or more centimetres detected on physical (manual) examination.

\section{Search methods}

We searched Cochrane Pregnancy and Childbirth's Trials Register, ClinicalTrials.gov and the WHO International Clinical Trials Registry Platform (ICTRP) (26 September 2019), and reference lists of retrieved studies. 


\section{Selection criteria}

We included published, unpublished or ongoing randomised controlled trial (RCTs). Studies using a cluster-RCT design were also eligible for inclusion in this review but none were identified. We excluded quasi-RCTs (e.g. those randomised by date of birth or hospital number) and studies using a cross-over design. We also excluded studies that specified addition of the combination therapy after cervical cerclage because the woman subsequently became symptomatic. We included studies comparing cervical cerclage in combination with one, two or more interventions with cervical cerclage alone in singleton pregnancies.

\section{Data collection and analysis}

Two review authors independently screened titles and abstracts of all retrieved articles, selected studies for inclusion, extracted data, assessed risk of bias, and evaluated the certainty of the evidence for this review's main outcomes. Data were checked for accuracy. Standard Cochrane review methods were used throughout.

\section{Main results}

We identified two studies (involving a total of 73 women) comparing cervical cerclage alone to a different comparator. We also identified three ongoing studies (one investigating vaginal progesterone after cerclage, and two investigating cerclage plus pessary).

One study (20 women), conducted in the UK, comparing cervical cerclage in combination with a tocolytic (salbutamol) with cervical cerclage alone in women with singleton pregnancy did not provide any useable data for this review. The other study (involving 53 women, with data from 50 women) took place in the USA and compared cervical cerclage in combination with a tocolytic (indomethacin) and antibiotics (cefazolin or clindamycin) versus cervical cerclage alone - this study did provide useable data for this review (and the study authors also provided additional data on request) but meta-analyses were not possible. This study was generally at a low risk of bias, apart from issues relating to blinding. We downgraded the certainty of evidence for serious risk of bias and imprecision (few participants, few events and wide $95 \%$ confidence intervals).

\section{Cervical cerclage in combination with an antibiotic and tocolytic versus cervical cerclage alone (one study, 50 women/babies)}

We are unclear about the effect of cervical cerclage in combination with antibiotics and a tocolytic compared with cervical cerclage alone on the risk of serious neonatal morbidity (RR $0.62,95 \% \mathrm{Cl} 0.31$ to 1.24; very low-certainty evidence); perinatal loss (data for miscarriage and stillbirth only - data not available for neonatal death) (RR $0.46,95 \% \mathrm{Cl} 0.13$ to 1.64 ; very low-certainty evidence) or preterm birth $<34$ completed weeks of pregnancy (RR $0.78,95 \% \mathrm{Cl} 0.44$ to 1.40 ; very low-certainty evidence). There were no stillbirths (intrauterine death at 24 or more weeks).

The trial authors did not report on the numbers of babies discharged home healthy (without obvious pathology) or on the risk of neonatal death.

\section{Authors' conclusions}

Currently, there is insufficient evidence to evaluate the effect of combining a tocolytic (indomethacin) and antibiotics (cefazolin/ clindamycin) with cervical cerclage compared with cervical cerclage alone for preventing spontaneous PTB in women with singleton pregnancies.

Future studies should recruit sufficient numbers of women to provide meaningful results and should measure neonatal death and numbers of babies discharged home healthy, as well as other important outcomes listed in this review.

We did not identify any studies looking at other treatments in combination with cervical cerclage. Future research needs to focus on the role of other interventions such as vaginal support pessary, reinforcing or second cervical cerclage placement, 17-alpha-hydroxyprogesterone caproate or dydrogesterone or vaginal micronised progesterone, omega-3 long chain polyunsaturated fatty acid supplementation and bed rest.

\section{PLAIN LANGUAGE SUMMARY}

\section{Cervical stitch (cerclage) in combination with other treatments for preventing premature or early birth of single babies}

We assessed randomised controlled trial evidence on the effects of cervical stitch in combination with other treatments for prolonging pregnancy in women who were at high risk of pregnancy loss and were carrying a single baby. Additional treatments were used in the same time period as when the cervical stitch was surgically inserted.

\section{What is the issue?}

The cervix is a cylinder-shaped neck of tissue connecting the vagina and uterus (womb). The cervix should stayed closed during pregnancy, but some pregnant women have cervical weakness resulting in pain-free opening of the cervix. This may lead to a late miscarriage or preterm birth before 37 weeks of pregnancy. A cervical stitch is a surgical procedure performed in the second trimester to place a stitch around the cervical neck with the intention of helping the woman carry the pregnancy until around 37 weeks. Other treatments that can 
be combined with cervical stitch include antibiotics, vaginal support inserts (pessaries), placement of a second cervical stitch, uterine relaxants (tocolytics), progesterone (hormonal drugs), omega-3 long chain polyunsaturated fatty acids and bed rest.

\section{Why is this important?}

Cervical weakness is diagnosed through a woman's history of pregnancy losses or premature births in the second trimester, ultrasound examination or physical examination. Preventing preterm birth is a healthcare priority because it is the leading cause of infant ill health and death worldwide. A cervical stitch in combination with other treatments could help prevent preterm birth in women carrying a single baby as a single stitch may not be sufficient for pregnant women with prior premature births and short cervical length or weakness.

\section{What was studied in the review?}

We wanted to know whether a cervical stitch, in addition to one of a range of treatments (antibiotics administration, a vaginal pessary, reinforcing or second cervical stitch placement, a uterine relaxant or progesterone) can prolong pregnancy for women carrying a single baby who are at high risk of pregnancy loss.

\section{What evidence did we find?}

We searched the literature for evidence from randomised controlled trials up until 26 September 2019. We identified two trials involving a total of 73 women. Only one trial with 50 mother-baby pairs had results that could be included in this review. The trial compared cervical cerclage in combination with indomethacin (tocolytic) and the antibiotics cefazolin or clindamycin with cervical cerclage alone. Women were not blinded to the treatment they received.

We are unclear about the effects of the intervention because we identified very low-certainty evidence for the main outcomes in this review: serious complications; loss of the baby (data for miscarriage and stillbirth only - data were not available for the numbers of babies who died within 28 days of being born), or preterm birth before 34 completed weeks of pregnancy. There were no stillbirths (death within the womb at 24 or more weeks).

Data for death of the newborn baby at discharge, or the number of babies discharged home healthy were not available.

\section{What does this mean?}

We found insufficient evidence to evaluate the effect of combining a tocolytic (indomethacin) and antibiotics (cefazolin/clindamycin) with inserting a cervical stitch compared with inserting a cervical stitch alone for preventing spontaneous preterm labour in women with singleton pregnancies.

We did not identify any studies looking at other treatments in combination with inserting a cervical stitch. Additional research needs to focus on the role of other interventions such as a vaginal support pessary (device), reinforcing or second cervical stitch placement, 17alpha-hydroxyprogesterone caproate, dydrogesterone or vaginal micronised progesterone, omega-3 long chain polyunsaturated fatty acid supplementation and bed rest.

Future studies should recruit sufficient numbers of women to provide meaningful results and should investigate the risk of death of the baby shortly after birth and the numbers of babies discharged home healthy. 


\section{SUMMARY OF FINDINGS}

Summary of findings 1 . Cervical cerclage in combination with antibiotics and tocolytics versus cervical cerclage alone for preventing preterm birth in singleton pregnancies

\section{Cervical cerclage in combination with antibiotics and tocolytics versus cervical cerclage alone for preventing preterm birth in singleton pregnancies}

Participants: pregnant women with singleton pregnancies in the second trimester of pregnancy and with risk factors for cervical insufficiency undergoing cervical cerclage in addition to other treatments

Settings: hospital in Chicago, USA

Intervention: cervical cerclage in combination with antibiotics (cefazolin or clindamycin) and tocolytics (indomethacin) versus cervical cerclage alone

Comparison: cervical cerclage alone

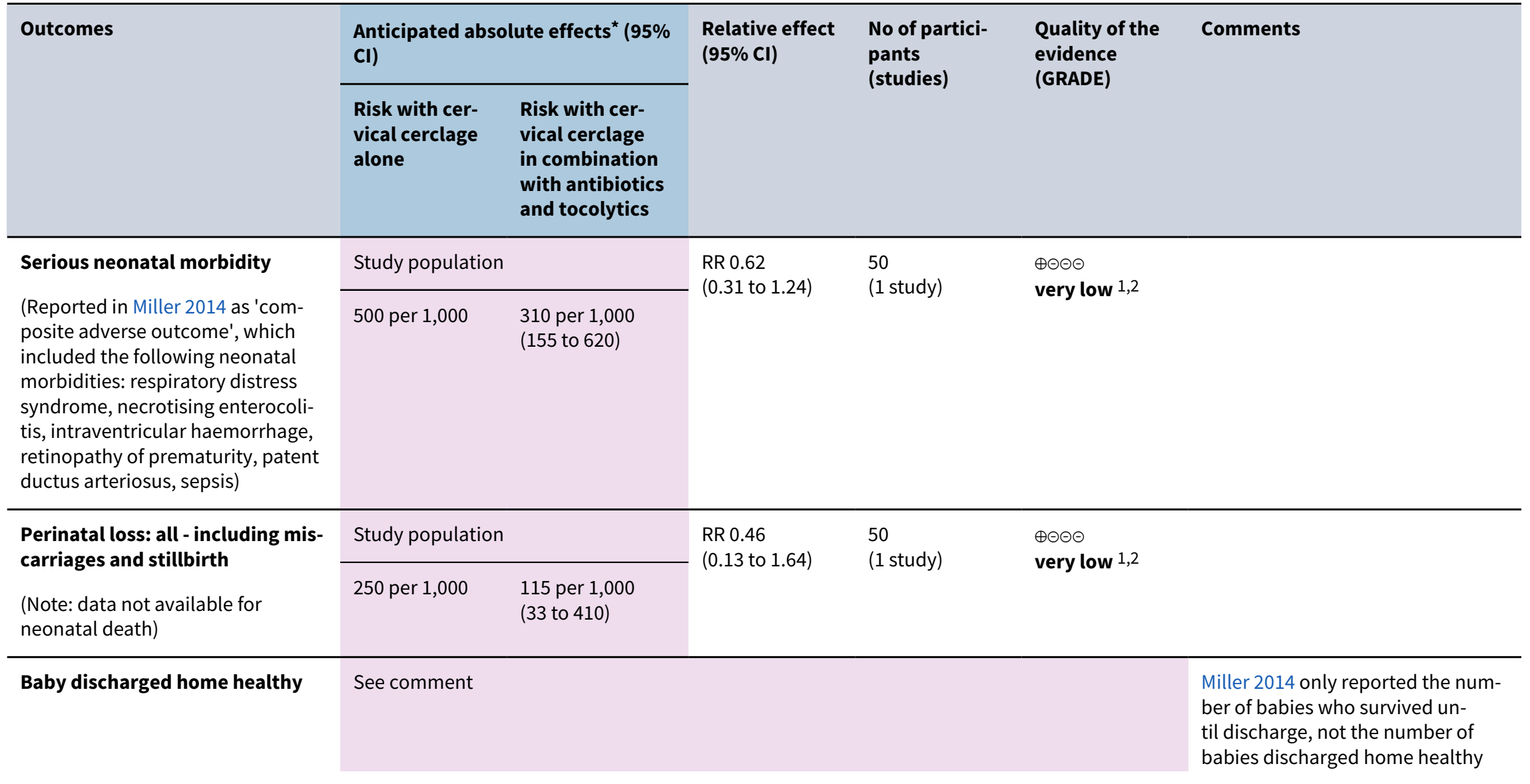




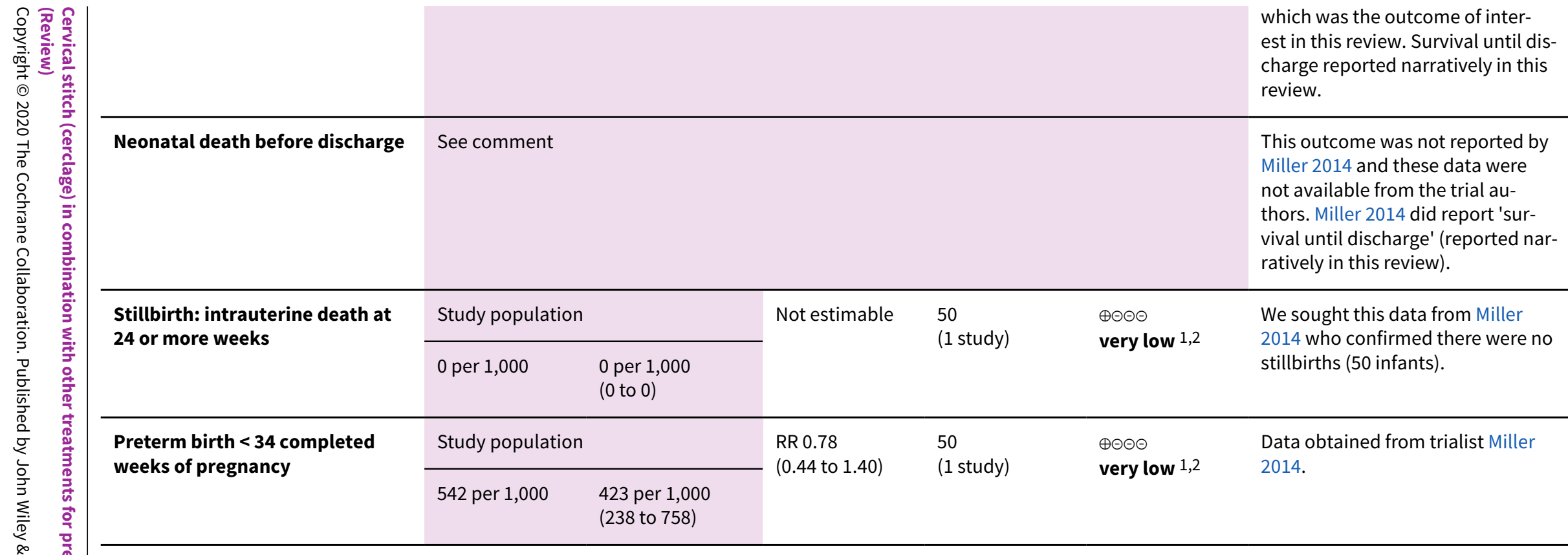

*The risk in the intervention group (and its $95 \%$ confidence interval) is based on the assumed risk in the comparison group and the relative effect of the intervention (and its $95 \% \mathrm{Cl})$.

Cl: confidence interval; RR: risk ratio;

\section{GRADE Working Group grades of evidence}

High certainty: We are very confident that the true effect lies close to that of the estimate of the effect

Moderate certainty: We are moderately confident in the effect estimate: The true effect is likely to be close to the estimate of the effect, but there is a possibility that it is substantially different

Low certainty: Our confidence in the effect estimate is limited: The true effect may be substantially different from the estimate of the effect

Very low certainty: We have very little confidence in the effect estimate: The true effect is likely to be substantially different from the estimate of effect

1 Downgraded (-1) for serious concerns around limitations in study design (risk of bias - there was no blinding of participants and personnel (risk of performance bias))

2 Downgraded (-2) for very serious concerns around imprecision (single study with a small sample size (fewer than 400 participants), few or zero events, and wide confidence intervals) 


\section{B A C K G R O U N D}

\section{Description of the condition}

The World Health Organization (WHO) has defined preterm birth as any delivery occurring prior to gestational age of 37 finished weeks or fewer than 259 days from the first day of the last menstrual period of a woman (Blencowe 2013; Eke 2019a; Eleje 2017; Marlow 2012; Umeigbo 2020; WHO 1977). In 2012, no fewer than 450,000 per 4 million newborns were affected by preterm birth, accounting for one in every nine infants born in the United States (CDC 2014). According to the recent WHO estimates of frequency of preterm deliveries worldwide, about 135 million global live births occurred in 2010, while 14.9 million of the newborns were at preterm gestation, accounting for a preterm delivery rate of $11.1 \%$ (Blencowe 2012). Overall, sub-Saharan Africa and Asia together contributed $60 \%$ of preterm births, with subSaharan Africa contributing $12.8 \%$, and Asia contributing $13.5 \%$ of all deliveries (Blencowe 2012).

For decades, births at preterm gestation remain the principal cause of both mortality and morbidity during a period immediately before and after birth (Castanon 2015; Romero 2013; Saccone 2015b; Slager 2012). Preterm birth has generated a substantial public health burden and it remains an essential element implicated as a cause of global loss of potential human resources in the surviving newborns (Umeigbo 2020). Of all direct causes of deaths in the neonatal period, preterm births constitute the greatest share, contributing up to $35 \%$ of more than 3 million annual deaths worldwide. Among the under-five-year-olds, preterm birth is the second commonest contributor of deaths, with pneumonia being the commonest cause (Blencowe 2013). In virtually all middleand high-income country settings, preterm births represent the highest share of child mortality (Liu 2012). Once a child is born at preterm gestation, the chance of it dying from other causes increases substantially, particularly from neonatal infectious morbidities (Lawn 2005). Compared with at-term newborns, infants from preterm pregnancies suffer significant risk of varying disabilities, ranging from neuro-developmental, gastrointestinal, sensory, learning, and respiratory deficits (Alijahan 2014; Dabi 2017). The associated preterm morbidities persist into adulthood, leading to enormous psychological, physical and financial costs (Alijahan 2014; Dabi 2017; Eleje 2015b; Goldenberg 2008; Petrou 2003; Petrou 2005).

Although the American College of Obstetricians and Gynecologists (ACOG) Committee on Obstetric Practice Society for Maternal-Fetal Medicine has stated that a prior clinical event of preterm birth is the strongest predictive risk influence for preterm birth (Spong 2007), a premature shortening of the cervix is also associated with an increased threat for preterm birth (Castanon 2015; Romero 2013). Structurally, the cervix sometimes may begin to shorten and dilate prematurely, and this could either lead to second trimester pregnancy loss or preterm delivery. When uterine contractions are absent, 'cervical insufficiency' is considered the cause of this pathological entity (Yorifuji 2014). Cervical insufficiency may be characterised as the inability or failure of the cervix to keep hold of the intrauterine pregnancy until term (Hershkovitz 2008). A wellknown feature of cervical insufficiency is the occurrence of habitual episodes of failure of pregnancy during the second trimester of pregnancy, manifesting clinically by pain-free dilatation of the cervix and subsequent bulging, rupture of fetal membranes and expulsion of usually live fetus(es), with little if any uterine activity
(Hershkovitz 2008). Cervical cerclage is an option for women with a history of preterm birth and short cervix less than $25 \mathrm{~mm}$ or women with a history or current evidence of cervical insufficiency (Alfirevic 2017).

One significant and important risk influencing the occurrence of recurrent episodes of preterm birth is a prior occurrence of spontaneous preterm delivery (Alijahan 2014; Castanon 2015; Goldenberg 2008). A study of various interventions for reducing preterm delivery revealed that identifying women at elevated threat for preterm delivery on the basis of the length of the cervix and past obstetric histories improves the utility of appropriate interventions using cervical cerclage and other methods to ameliorate preterm births (Newnham 2014). Various approaches directed at predicting spontaneous preterm delivery are not yet part of current prenatal care (Asiegbu 2020). Thus, preterm birth remains one of the greatest maladies facing obstetrics practice, and its aetiology remains multifactorial. It can present clinically in the midtrimester as a hushed sonographic undersized cervix (Romero 2014a), and this remains a dominant influencing predictor for preterm delivery. The focus on supplementary interventions which may be routinely useful in asymptomatic pregnant women undergoing prophylactic cervical cerclage insertion is paramount.

\section{Description of the intervention}

In an attempt at eliminating the risks of spontaneous preterm delivery during singleton pregnancies, cervical cerclage in combination with other treatments such as antibiotics, vaginal support pessaries, reinforcement or placement of second (repeat) cervical cerclage, uterine relaxants (tocolytics), progesterone, omega-3 long chain polyunsaturated fatty acids, bed rest and others are variously described in the literature (Abdel-Aleem 2013; Berghella 2006; Berghella 2009; Conde-Agudelo 2013; Defranco 2013; Dodd 2013; Rafael 2014; Saccone 2015c; Visintine 2008).

\section{Cervical cerclage}

Cervical cerclage is the surgical insertion of a suture (stitch) around the cervical neck (Alfirevic 2017; Yorifuji 2014) in pregnant women. The cervix is the lower part of the uterus that opens to the vagina. Cerclages are placed in pregnancy based on various indications as either an emergency technique in cases of threatened abortion (indicated by physical examination), a prearranged technique based on prior history, or due to a short cervical length identified via transvaginal ultrasound (Alfirevic 2017; Baxter 2005). History-indicated cervical cerclage is used for those women with one or more second-trimester losses due to documented cervical insufficiency or a history of cervical cerclage during a prior pregnancy secondary to cervical insufficiency (ACOG 2014). Ultrasound-indicated cerclage is defined as a cerclage placed usually between 16 and 23 weeks gestation for transvaginal ultrasound cervical length $<20 \mathrm{~mm}$ in a woman without cervical dilatation (Barbosa 2020). Physical examinationindicated cervical cerclage is painless cervical dilatation on sterile vaginal examination or sterile speculum examination at between 14 and 24 weeks gestation (ACOG 2014). Emergency cerclage is defined as a cerclage placed usually between 16 and 23 weeks gestation for transvaginal ultrasound cervical length less than $20 \mathrm{~mm}$ in a woman with cervical dilatation (Barbosa 2020). Based on the current role of cervical cerclage in preventing preterm birth, we note that the efficacy and safety of cervical cerclage in the management of pregnancy with associated cervical insufficiency following the

Cervical stitch (cerclage) in combination with other treatments for preventing spontaneous preterm birth in singleton pregnancies 
age of fetal viability has not been sufficiently evaluated. Cervical cerclage should be restricted to pregnancies in the second trimester prior to attainment of fetal viability.

Cervical cerclage was pioneered by VN Shirodkar (Shirodkar 1955). Shirodkar, a professor of midwifery and gynaecology in Grand Medical College in Bombay, India, developed cervical cerclage based on his discovery that some pregnant women have repeated pregnancy losses from the fourth to the seventh months of pregnancy, which are not mitigated by bed rest or treatment with hormonal therapy (Shirodkar 1955). Two years after Shirodkar's discovery of cerclage, lan McDonald, based at the Royal Melbourne Hospital, Australia, shared his knowledge involving 70 women who had cervical suture placement for inevitable abortion (McDonald 1957). A randomised controlled study of women with short cervical length and receiving cervical cerclage revealed that there was no significant dissimilarity in the prevention of preterm birth when the two methods were compared (Odibo 2007). The methods of cervical cerclage have subsequently undergone several modifications, ranging from the type of suture material to the technique and timing of the insertion of sutures (Smith 2009). Anaesthesia and theatre are needed for insertion of a cervical cerclage and this could be linked with various forms of complications. For example, the published adverse events immediately following cervical cerclage placement include traumatic rupture of membranes $(0.4 \%)$, vaginal bleeding $(1.4 \%)$, and premature rupture of fetal membranes (15.6\%) (Azem 2004; Rush 1984; Simcox 2007). A previous systematic review has reported a $2 \frac{1}{2}$-fold increased risk of chorioamnionitis (Alfirevic 2017). Other complications include suture detachment (1.4\%) (Azem 2004), preterm delivery (16.4\%) (Azem 2004), cervical lacerations (8.9\% to 25.0\%) (Jongen 1997; Simonazzi 2015), cervical dystocia (7.2\%) (Azem 2004), uterine rupture $(6.3 \%)$ (Jongen 1997), and postpartum haemorrhage (2.8\%) (Azem 2004). There was no statistically significant decline in the incidence of cervical lacerations between the women who had cervical cerclage removal planned before labour and those removed post-labour onset (Simonazzi 2015). A 1\% incidence of difficulty in cerclage removal has also been reported (MRC/ RCOG 1993). General anaesthesia is more frequently used (82.5\%) for cervical cerclage placement (Ioscovich 2015). When general anaesthesia is used, a few authorities have contended that the stress associated with endotracheal intubation may escalate the activity of uterine smooth muscles a well as stimulating spontaneous abortion, an effect cervical cerclage is intended to avert; nevertheless, the proof for this claim is conflicting (loscovich 2015; Yoon 2008). In addition, there are known contraindications to cervical cerclage, such as vaginal bleeding and premature rupture of membranes.

\section{Antibiotics}

Antibiotics are medicines to deal with diseases or infections caused by bacteria. The introduction of antibiotics in the 1940s and 1950s has saved millions of lives, including those of pregnant women and their fetuses and babies. During pregnancy, the prescription of antibiotics often presents a dilemma. The current concept and recommendation of ACOG is that pregnant women at risk of preterm birth should not be treated with antibiotics for the single aim of preventing spontaneous preterm birth (ACOG 2003). Studies have found that preconception use of antibiotics to treat women at elevated risk of spontaneous preterm birth is not efficacious in reducing the likelihood of delivering a preterm infant, and may occasionally lead to an elevated risk of subsequent preterm delivery (Andrews 2006; Tita 2007). However, antibiotic therapy could be life-saving and effective in certain circumstances (Eleje 2014; Sangkomkamhang 2015). Antibiotic use causes an antibioticmediated suppression of infection and preterm birth. Antibiotics can treat confirmed infection and could prevent ascending vaginal infection (Farr 2015; Sangkomkamhang 2015).

\section{Vaginal support pessary}

A vaginal support pessary is a medical device used to support the uterus, vagina, urinary bladder and rectum. The traditional role of the vaginal pessary is for conservative treatment of pelvic organ prolapse, such as cystocele (where the bladder bulges into the vagina) or rectocele (where part of the rectum bulges into the vagina) (Abdulaziz 2015). Vaginal pessaries are also useful in the treatment of stress urinary incontinence (Chughtai 2012). Their role at eliminating spontaneous preterm birth is therefore not standard. The vaginal pessary can be placed temporarily or permanently, and must be fitted by trained medical personnel. It can be worn during sexual intercourse. In Europe, some medical practitioners have used the vaginal pessary for prevention of spontaneous preterm births (Arabin 2003). According to some studies, pessary use is not a first-line approach but should serve as a combination treatment or co-intervention therapy following cervical cerclage procedures (Newcomer 2000; PatroMalysza 2009), or could be useful in women not needing cervical cerclage (Newcomer 2000). Another study concluded that vaginal pessary and cervical cerclage are correspondingly efficacious as methods of preventing spontaneous preterm births in pregnant women presenting with cervical insufficiency, and the decision to use one or the other method influences neither the route of delivery nor the outcome for the newborn (Antczak-Judycka 2003). A recently-published prospective randomised clinical trial (Goya 2012) involved women with an ultrasound cervical length of $25 \mathrm{~mm}$ or less, and a gestational age of 18 to 22 weeks, randomly assigned to either an expectant management arm or a vaginal pessary arm. The women had a short cervix rather than a prior preterm birth event. The trial concluded that, with a vaginal pessary, preterm birth could be prevented in a population with adequate participant selection of women at risk of preterm births, especially those already screened using midtrimester cervical length assessment. Randomised and non-randomised studies have indicated the usefulness of vaginal pessaries in preventing spontaneous preterm birth (Liem 2013). The insertion and removal of the pessary is simple and usually well tolerated by the woman (Liem 2013). However, when used as a preventive tool for preterm birth, the gestational age for removal of the vaginal pessary is usually at the 37 th week. The vaginal pessary is usually removed before 37 weeks of gestation when there is vaginal bleeding, persistent uterine contractions even in the presence of tocolysis, or when the pessary is causing discomfort (Goya 2012).

\section{Reinforcing or second or repeat cerclage placement}

Reinforcing a cerclage (also known as second or repeat cerclage placement) can be carried out with transvaginal ultrasonographic guidance following cervical surveillance post-cervical cerclage, with the repeat suture insertion performed when persistent cervical effacement (thinning of the cervix) develops (Baxter 2005; Fox 1998). This second (repeat) cerclage placement is usually performed at less than 27 weeks of gestation, following report of initial cervical cerclage suture failure, especially when cervical length was subsequently found to be less than $25 \mathrm{~mm}$ (Althuisius

Cervical stitch (cerclage) in combination with other treatments for preventing spontaneous preterm birth in singleton pregnancies 
2000). During cerclage suture reinforcement or repeat cerclage placement, the cerclage already in place is not manipulated but a second cerclage is placed to reinforce the first one (Baxter 2005; Fox 1998). The reinforcement suture is therefore the second (repeat) cerclage placement (Althuisius 2000). Although the tightening can be done vaginally, cervical cerclage sutures can be tightened under transrectal or transabdominal ultrasound guidance up to the point that the cervical canal is no longer visible. Once the suture is tightened, ultrasound can also be useful in assessing both the length and width of the cervix. Nevertheless, an hourglass appearance, as seen in the cervix at ultrasonography following reinforcement of sutures, may be a risk factor for spontaneous preterm births (Hershkovitz 2008).

\section{Tocolytics}

Tocolytics (labour repressants or anticontraction medications) are medications used to suppress premature labour. Tocolytic is derived from the Greek word tokos, (meaning childbirth) and from the word lytic, (meaning potential ability to dissolve) (Tan 2006). The therapy could be useful because it gives more time for glucocorticoid therapy to be administered, which significantly speeds up fetal lung maturity (Flenady 2014).

A number of different tocolytics are in common use as combination treatments with cervical cerclage in preventing spontaneous preterm birth and preterm labour (Eke 2016; Smith 2015). The most widely used drugs include beta-adrenoceptor agonists (e.g. ritodrine), oxytocin receptor antagonist (e.g. atosiban), prostaglandin inhibitors (indomethacin), calcium channel blockers (e.g. nifedipine), and magnesium sulphate (Van Vliet 2014; Vogel 2014). Of all the tocolytics, nifedipine, beta-agonists, atosiban and indomethacin, but not magnesium sulphate, have proven efficacy and can be given for 48 hours postoperatively, implying also that they can be given because of their steroid benefit and in-utero transfer benefit (Flenady 2014; Vogel 2014). Although each one is efficacious, each has an advantage over the others. Calcium channel blockers have been shown to have benefits over betamimetics for pregnancy elongation, severe morbidity in the neonates, and maternal adverse effects (Flenady 2014). Blockers of calcium channel could also have some therapeutic advantages over atosiban and magnesium sulphate, although atosiban results in rarer adverse effects for the mother (Flenady 2014). Magnesium sulphate is now only indicated for fetal neuroprotection (Crowther 2014). The ideal tocolytic drug should be effective in prolonging preterm labour and birth, and should have a favourable safety profile in both the women and their unborn babies, culminating in reductions in neonatal morbidity and mortality.

\section{Progesterone}

Progesterone is a sex steroid produced naturally in the ovary by the corpus luteum, and also in the placenta at a gestational age corresponding to the last two trimesters of pregnancy. Progesterone and its agents exist in various forms. Progestogens are agents that have progesterone-like action (Romero 2014a), and are now the principal agent for preventing spontaneous preterm deliveries (Likis 2012). 17- $\alpha$-hydroxyprogesterone caproate is a synthetic progestogen. The 'caproate molecule' is not made by the human body, but is produced in the laboratory when the molecule is added to 17- $a$-hydroxyprogesterone. In order to lengthen the drug's half-life, the caproate molecule is incorporated, thereby producing some structural modification of the drug molecule and resulting in pharmacological or physiological changes in the properties of the drug. One clinical study of 17-a-hydroxyprogesterone revealed a reduction in the spontaneous preterm delivery rate in women with previous history of preterm deliveries (Meis 2003). Another study showed that 17a-hydroxyprogesterone caproate injections reduced the likelihood of recurrent preterm births by approximately 30\% (Manuck 2016). However, despite prophylactic 17-alpha hydroxyprogesterone caproate, up to $30 \%$ of recipients will still have a recurrent preterm birth, as non-responders to the 17- $a$-hydroxyprogesterone (Manuck 2016a). One recent study concluded that 17-alpha hydroxyprogesterone caproate was not effective in preventing recurrent preterm birth (Nelson 2017). Although the present global protocol recommends initiation of 17-alpha hydroxyprogesterone caproate from 16 to 20 weeks, 17-alpha hydroxyprogesterone caproate could be started at any gestational age in clinical practice (Ning 2017).

The first well-conducted randomised clinical study evaluating the role of vaginally-administered progesterone in preventing spontaneous preterm birth in pregnant women with a history of short cervix was reported by Fonseca 2007. Recent studies have shown that progesterone administration by the vaginal route lowers the frequency of spontaneous birth at preterm gestation in women with a history of short cervical length, irrespective of prior histories of preterm births (Romero 2014a). However, when consideration is given to women with prior preterm births, the effectiveness of vaginal progesterone is the same as that of cervical cerclage in preventing spontaneous preterm births (Romero 2014a). Another study comparing the efficacy of 17$\mathrm{OH}$ progesterone, dydrogesterone as well as oral or vaginal micronised progesterone in combination with cervical cerclage for preventing preterm delivery in women with short cervical length, concluded that combination treatment significantly benefits pregnancy outcomes in cases of short cervical length compared with cervical cerclage, $17-\mathrm{OH}$ progesterone, dydrogesterone, or oral progesterone alone (Pustotina 2017). The safety of progesterone agents in early pregnancy is widely acknowledged; studies involving vaginal progesterone for preventing spontaneous preterm delivery have further clarified that they are safe in early pregnancy as there were no differences in adverse events between women who received progesterone and those who received inactive placebo (Slager 2012). 17-hydroxyprogesterone caproate has also been studied in the setting of prophylactic and ultrasound-indicated cerclages (Eke 2019a; Lichter 2019). In addition, a recent systematic review demonstrated that singleton pregnancies that were being administered with weekly doses of $17 a$-hydroxyprogesterone caproate for the prevention of recurrent preterm births had an exponentially greater proportion of women with anomalous glucose test results and gestational diabetes mellitus when compared with non-intervention groups, a result that did not apply to randomly assigned women receiving $17 a-$ hydroxyprogesterone caproate (Eke 2019b).

\section{Omega-3 long chain polyunsaturated fatty acid}

Reports from some randomised studies show that supplementary therapy using omega-3 long chain polyunsaturated fatty acid significantly lowers the frequency of "recurrent preterm birth" (Olsen 2000). Evidence from human- and animaldocumented reports have shown that the $n-3$ as well as the $n-6$ series of essential fatty acids, including their respective 'eicosanoid metabolites', are strongly implicated in the length of pregnancy and

Cervical stitch (cerclage) in combination with other treatments for preventing spontaneous preterm birth in singleton pregnancies 
parturition (Allen 2001). Prostaglandins of the 2-series have been shown to be involved in remodelling of parturition and connective tissue that is related to maturation of the cervix and membrane ruptures. When genital infections are absent, preterm delivery will be characterised by lower expression of prostaglandins in the tissues of the reproductive tract, with resultant lower expression of inducible cyclo-oxygenase. Pregnant women who have had premature delivery often have high blood levels of $n-6$ fatty acid but low blood levels of $n-3$ fatty acids, regardless of the decreased rate of production of prostaglandin (Allen 2001). A number of studies of $n-3$ fatty acid supports in pregnancy have revealed a marked decrease in the frequency of births at preterm gestations; however, there could be an increase in birthweight due to the associated prolonged length of pregnancy (Saccone 2015a). It has been recommended that docosahexaenoic acid ( $n-3$ fatty acids long chain molecule) as pregnancy supplementation should be used to extend the duration of pregnancy in women with high risks of spontaneous preterm births (Allen 2001).

\section{Bed rest}

The description of bed rest is two-fold, i.e. partial, which involves bed rest for some hours (but not up to 24 hours) during the day's work, or complete, which involves strict bed rest lasting up to 24 hours a day (Smith 2009). The term 'bed rest', as defined by Fox 2009, is the "limited ambulation of not more than one to two hours per day with bathroom use and bathing permitted". Although the terms 'activity restriction' and 'bed rest' are usually used synonymously in clinical practice, the two terms vary to some extent. The term 'activity restriction' is generally preferable to 'bed rest'; some women may not be confined to bed by their obstetrics care providers but restriction could be placed on some activities such as sexual intercourse, child lifting or other maternal behaviours, without restricting maternal ambulation. It is important to note that when ambulation is allowed, the problems of bed rest are diminished in accordance with the amount of ambulation.

Restriction of activity or bed rest during the antenatal period have become the central component of treatments aimed at preventing spontaneous preterm birth. Not only have such activity restrictions been used for more than 35 years, but about one million women use the intervention each year in the United States (Maloni 2010). However, evidence is lacking that this behaviour produces the desired results (Sosa 2015). In fact, there is strong evidence that bed rest or activity restriction could cause a number of adverse psychological and physiologic side effects in mothers and their newborns (Maloni 2010; Sosa 2015), but this has not impacted positively on obstetrics practice (Maloni 2010).

\section{How the intervention might work}

Interventions aimed at preventing spontaneous preterm birth will only be successful and effective if they act to break the continuity of some specific pathways that lead to preterm births.

\section{Cervical cerclage}

Cerclage is based on the hypothesis that some pregnant women have cervical weakness or malfunction contributing to the preterm delivery pathways (Althuisius 2003; Vidaeff 2009). It works by holding the cervical 'os' (opening) closed. The procedure for cervical cerclage is posited on the woman carrying the pregnancy until or close to 37 weeks' gestation.

\section{Antibiotics}

One mechanism by which untreated urinary tract infections and bacterial vaginosis cause preterm labour is through upward movement of the microorganisms from the areas of vagina and cervix and to the placenta, decidua and membranes' surfaces, and subsequent multiplication at these sites (Cram 2002; Eleje 2015a; Eleje 2020; Goldenberg 2008; Hosny 2017; Kataoka 2006). A study evaluating the role of group B streptococci activity within the amniotic fluid following inoculation revealed an increased level of cytokines (interleukin (IL)-1 $\beta$ and IL-6), and prostaglandins (PG) $\left(P E_{2}\right.$ and $P E_{2 a}$ ) within the amniotic fluid (Gravett 1994). IL-1 $\beta$ promotes IL-6 and IL-8 production, which in turn activates the synthesis of $\mathrm{PGE}_{2}$ and $\mathrm{PGF}_{2 \mathrm{a}}$, which trigger uterine contractions (Gravett 1994; Romero 2014b). Because IL-1 $\beta$ is not found in the amniotic membranes of pregnant women who are in labour at term, IL-1 $\beta$ is thought to be the key cytokine associated with intrauterine infection that can stimulate preterm labour (Sadowsky 2006). A positive response of the fetus to the infection of the amniotic cavity may also be contributory, as the intra-amniotic infection could trigger the synthesis of corticotropin-releasing hormone arising from the placenta and fetal hypothalamus, leading to elevated levels of fetal corticotropin and fetal cortisol which ultimately stimulate prostaglandin production (Gomez 1998; Romero 1998). Antibiotics work by blocking vital processes or by killing the bacteria, or stopping their multiplication. The body's natural immune system is energised in fighting the infection caused by the bacteria. Vaginal infection in early pregnancy is linked with spontaneous preterm delivery (Farr 2015; Sangkomkamhang 2015). For antibiotics to be useful in reducing spontaneous preterm labour and delivery from infectious causes, early administration of antibiotics in pregnancy is recommended (Lamont 2005). In some pregnancies, antibiotics may delay the onset of complications of labour, albeit that this is not regarded as tocolytic therapy. However, antibiotics are not currently part of standard care for the prevention of spontaneous preterm labour (ACOG 2003; Kenyon 2001). In a recent Cochrane Review assessing the effects of prophylactic antibiotics administered to women with preterm labour with intact membranes on the maternal and neonatal outcomes, Flenady 2013 concluded that there was no demonstrable benefit of using prophylactic antibiotics in women with preterm labour and intact membranes for important neonatal outcomes, although it may lead to a reduction in maternal infection. There could be harm to the children of mothers exposed to antibiotics on a short- and longer-term basis; current evidence therefore does not support the routine use of antibiotics in women with preterm labour having intact membranes unless there are clear signs of infection (Flenady 2013; Kenyon 2001; Lamont 2005). In cases with obvious signs of infection, antimicrobial agents may be beneficial in averting the onset of preterm labour (Espinoza 2006; Gibbs 1992; Goncalves 2002; Mazor 1998).

\section{Vaginal support pessary}

The vaginal support pessary works by using processes that can affect the composition of the cervix and cervical plugs (Abdel-Aleem 2013). The cervical mucus plug has 'viscoelastic' characteristics due to the presence of mucins, which are large glycoproteins (Lai 2009). The cervical mucus therefore assists the vaginal pessary by inhibiting viral replication and preventing large molecules and bacteria from ascending into the uterus (Lai 2009). Additionally, the cervical mucus has immunological characteristics such as innate and adaptive responses which make it possible

Cervical stitch (cerclage) in combination with other treatments for preventing spontaneous preterm birth in singleton pregnancies 
for the vaginal pessaries to prevent bacterial infection through their stimulation of inflammatory response pathways (Goya 2012). Ideally, the cervix is tightly closed during a normal pregnancy with the aid of a cervical mucus plug gluing the opening shut. Thus, any defect or malfunction of the cervical mucus plug by cervical effacement could enhance the ascent of infection and preterm births (Becher 2009; Liem 2013). The vaginal pessary encloses the cervix and presses on the cervical canal, to inhibit the failure of the cervical mucus plug. The pessary changes the angle of elevation of the cervical canal, thereby correcting the cervical insufficiency by pointing forward in the vaginal axis. As a result of this, direct pressure on the internal os of the cervix is relieved, since the weight of the pregnant uterus is distributed onto the vaginal floor, retrosymphyseal osteomuscular structures, and Douglas cavity. This prevents premature rupture of fetal membranes and premature labour. Furthermore, the fetal head is prevented from descending and pressing on the internal cervical os (Liem 2013).

\section{Reinforcing or second cerclage placement}

Reinforcing or second or repeat cerclage placement may be useful because suture application in the McDonald's cerclage procedures is usually at the level of the internal os of the cervix, with no allowance for possible changes in the width and shape of the cervix. The optimal tightening force for the sutures is currently unknown, and varies depending on the individual obstetrics caregiver's experience. These differences in the tightening force may account for the lack of success of cervical cerclage performed by individual obstetricians (Hershkovitz 2008). The cerclage sutures could be applied under ultrasound guidance, which may enhance the success rate in women with cervical cerclage (Hershkovitz 2008).

\section{Tocolytics}

Tocolytics work by different mechanisms following cervical cerclage procedures. For example, magnesium sulphate lowers uterine contractions, but it is not clear how it performs its tocolytic action, although it is plausible that magnesium rivals calcium for entry into the muscle cells through voltage-gated channels (Tan 2006). Antagonist therapy for calcium channels works by preventing the influx of calcium ions across the cell membrane, thereby lessening the smooth muscle vasculature tone (Sanborn 1995). Prostaglandins stimulate contractions of the uterine muscles by promoting gap junction formation in the myometrium and enhancing intracellular calcium within the cells (Van Vliet 2014). Prostaglandins are formed by cyclo-oxygenase (COX), an enzyme that enhances the level of prostaglandins. There are two distinct versions of COX, i.e. COX-1 and COX-2. COX-2 is uniquely linked with contractility of the myometrium. Prostaglandin synthetase inhibitors shorten the production of prostaglandin, thereby inhibiting a crucial labour pathway (Vogel 2014). Furthermore, intrauterine inflammation and infection play a crucial role in preterm labour, with the anti-inflammatory action of prostaglandins being one of the reasons why prostaglandin inhibitors may be efficacious in prolonging delivery (Van Vliet 2014; Vogel 2014). The use of tocolytics such as indomethacin, a nonsteroidal anti-inflammatory drug, may curb the uterine contractions precipitated by cervical manipulation and thereby prevent an accelerated stream to preterm delivery.
Tocolytics are usually given for 48 hours following cerclage placement. When a tocolytic is used, the subduing of contractions is usually partial in nature and tocolytics are often deployed to postpone delivery until some days later. Although it depends on the particular tocolytic used, the monitoring of the fetus or the mother is still paramount. For instance, the monitoring of blood pressure, especially when nifedipine is used as a tocolytic, is very important, since nifedipine lowers blood pressure. As it is unclear which of the tocolytic agents is a first-line treatment, the use of any particular agent should be individualised and should be based on a number of factors such as the condition of the mother, gestational age of the fetus and the potential adverse effects (Tan 2006).

\section{Progesterone}

One process involved in preterm birth is the ill-timed decrease in the function of progesterone, a condition that can lead to painless midtrimester shortening of the cervix (Romero 2014a). The available evidence suggests that decreased levels of plasma 17-alpha hydroxyprogesterone caproate concentration are linked with a high frequency of spontaneous preterm delivery (Caritis 2014). Although it is unclear if progesterone prevents a cervix from shortening, the fact remains that sufficient levels of progesterone can prevent the production of prostaglandin with the subsequent lowering of uterine contractions (Hollier 2005), thereby maintaining uterine quiescence. This may be especially relevant following cervical cerclage procedures. Being a principal pregnancy hormone, progesterone also works by diminishing the sensitivity of uterine musculature to oxytocin, wedges adrenergic receptors and the synthesis of prostaglandin, and excites lymphocyteassociated synthesis of progesterone-induced blocking factor. Jointly, these processes expedite uterine stillness during the antepartum period, and regulate immune tolerance and cervical functions (Pustotina 2017). In women with a previous preterm birth without symptoms of uterine contractions in their index pregnancy, one study has shown that 17-a-hydroxyprogesterone caproate prophylaxis was not correlated with an effect on cervical length shortening (Durnwald 2009), nor does it seem to influence preterm delivery in women with history-indicated cerclage (Mackeen 2013; Rafael 2011; Szychowski 2012). However, in another study, progesterone was associated with significant preservation of cervical length (O'Brien 2009). In women with preterm labour, 17- $\alpha$-hydroxyprogesterone caproate injections prevented further cervical shortening (Facchinetti 2007). In one randomised study, post hoc analysis of data revealed that the frequency of early preterm birth is lower in women who had ultrasound-indicated cerclage and hydroxyprogesterone caproate than in women who received either therapy alone (Berghella 2010).

\section{Omega-3 long chain polyunsaturated fatty acid}

It has been suggested that omega-3 long chain polyunsaturated fatty acids work by reducing gap junction formation and production of proinflammatory cytokines, thereby lowering the parturition rate among women with a prior history of spontaneous preterm delivery undergoing cervical cerclage treatment (Allen 2001; Olsen 2000; Olsen 2007). There are obvious variations in the metabolic derivatives of omega- 6 and omega- 3 polyunsaturated fatty acids, and their respective contributions in the classic Western diet provide a biological rationale for the statements that high levels of omega-3 intake could lengthen the duration of pregnancy and slow down parturition (Harper 2010). For example, in one European multicentre study among women with previous spontaneous 
preterm births, women receiving omega- 3 supplement had a significantly reduced rate of recurrent preterm birth prior to 37 weeks of gestation ( $21.3 \%$ versus $33.3 \%$, odds ratio (OR) $0.54,95 \%$ confidence interval $(\mathrm{Cl}) 0.30$ to 0.98$)$ and prior to 34 weeks of gestation (4.6\% versus $13.3 \%$, OR $0.32,95 \% \mathrm{Cl} 0.11$ to 0.89 ) (Olsen 2000).

\section{Bed rest}

Bedside advice plays an important part in reducing spontaneous preterm birth, especially following cervical cerclage procedures. The underlying mechanism of bed rest lies in the premise that strict obedience to bed rest advice often results in a reduction in preterm labour, since physical activity and hard work exhibited by pregnant women could be associated with spontaneous preterm delivery (Teitelman 1990), and in the belief that bed rest could reduce uterine contractions (Goldenberg 1994; Sosa 2015). Bed rest may account for the reduction in the prostaglandins in the blood. It is biologically plausible that high circulating prostaglandin metabolite levels might increase after cerclage placement, such that bed rest in addition to cervical cerclage may confer benefits (Novy 1987; Vitoratos 1996).

Treatments will prove successful if the relevant interventions are attuned to the definite pathophysiologic activities, and are applied at the right time for the women concerned. The use of some interventions in women who are not likely to deliver at preterm gestation is inappropriate. Understanding of the heterogeneity of preterm labour and delivery, with realistic expectations, is paramount to the process.

\section{Why it is important to do this review}

Although cervical cerclage is often a procedure performed in pregnant women with prior preterm births and short cervical length, the events leading to spontaneous preterm birth, despite placement of cerclage, are still not completely understood. A previous study has concluded that cervical cerclage alone reduces previable birth and perinatal mortality, but does not prevent spontaneous preterm birth at a gestational age of less than 35 weeks (Owen 2009). Placement of a cervical cerclage is not without complications (Azem 2004). It is an invasive procedure that can cause more harm than good in certain situations (Azem 2004; Rush 1984; Simcox 2007). Could cervical cerclage, in combination with other interventions, for preterm births be more beneficial and less harmful? In addition, the adjuvant effects of pharmacotherapy in the setting of cervical cerclage placement is important, and underscores the importance of pharmacologic research in pregnant women (Eke 2019c). Reduction of spontaneous preterm delivery is an ultimate target in every feto-maternal medicine unit, and the debate and controversy about the success of cervical cerclage alone in halting preterm birth continues (Smith 2009). The major question that arises from these statements is: why has the reduction in the rate of spontaneous preterm delivery been so difficult to achieve? We contend that this is due to the fact that preterm delivery is often regarded and described as if it were a single obstetric entity. Additionally, despite the 50-year anniversary of cerclage as a surgical technique, the evidence is unclear on its effectiveness when used alone for expected (sonographic short cervix) or prophylactic purposes (Smith 2009).

Although there is as yet no consensus about the use of cerclage, a meta-analysis of randomised controlled studies has provided some evidence to validate its use with (Defranco 2013) or without (Slager 2012) other interventions in women with previous episodes of spontaneous preterm delivery, especially in those developing a short cervix before the age of fetal viability. It remains unclear whether the effects of cervical cerclage in combination with other interventions are cumulative in pregnant women without multifetal gestations but with prior spontaneous preterm deliveries, who then develop a shortened cervical length. One study highlights the urgent need for research into preterm births and the development of novel interventions for preventing them (Chang 2013). Our review aims to assess this important clinical question: in a woman without multifetal gestations who is having cervical cerclage due to a history of preterm birth and short cervical length, are combination treatments associated with further benefits beyond those already conferred by cervical cerclage? We hypothesise that cervical cerclage in combination with other treatments can prevent more spontaneous preterm births in singleton pregnancies than cerclage alone or other treatments alone. Although previous Cochrane Reviews (Alfirevic 2017; Rafael 2014) have been published on the effectiveness of cervical cerclage in singleton (Alfirevic 2017) and multiple (Rafael 2014) pregnancies, none has evaluated the effectiveness of cervical cerclage in combination with other treatments versus cervical cerclage alone in singleton pregnancies. Our review will therefore assess cervical cerclage in combination with other treatments (both pharmacological and non-pharmacological) compared to cerclage alone for preventing singleton spontaneous preterm births, to test the link between the best current evidence and the optimal combination treatments in women undergoing a cervical cerclage procedure.

\section{O B JECT IVES}

To assess whether antibiotics administration, vaginal pessary, reinforcing or second cerclage placement, tocolytics, progesterone, or other interventions at the time of cervical cerclage placement prolong singleton gestation in women at high risk of pregnancy loss based on prior history and/or ultrasound finding of 'short cervix' and/or physical examination.

- History-indicated cerclage is defined as a cerclage placed usually between 12 and 15 weeks gestation based solely on poor prior obstetrical history, e.g. multiple second trimester losses due to painless dilatation.

- Ultrasound-indicated cerclage is defined as a cerclage placed usually between 16 and 23 weeks gestation for transvaginal ultrasound cervical length $<20 \mathrm{~mm}$ in a woman without cervical dilatation (Barbosa 2020).

- Physical-exam-indicated cerclage is defined as a cerclage placed usually between 16 and 23 weeks gestation because of cervical dilatation of one or more centimetres detected on physical (manual) examination. Emergency cerclage is defined as a cerclage placed usually between 16 and 23 weeks gestation for transvaginal ultrasound cervical length $<20 \mathrm{~mm}$ in a woman with cervical dilatation (Barbosa 2020). 


\section{METHODS}

\section{Criteria for considering studies for this review}

\section{Types of studies}

We included published, unpublished or ongoing randomised controlled trials (RCTs). Studies using a cluster-RCT design were also eligible for inclusion.

We excluded quasi-RCTs (e.g. those randomised by date of birth or hospital number) and studies using a cross-over design.

We also excluded studies that specified addition of the combination therapy after cervical cerclage because the woman subsequently became symptomatic. In future updates, we will classify potentially eligible studies presented only as abstracts as 'Studies awaiting classification' pending their full publication.

\section{Types of participants}

Pregnant women with singleton pregnancies in the second trimester of pregnancy and with risk factors for cervical insufficiency undergoing cervical cerclage in addition to other treatments. These included the following.

1. History of two or more second-trimester pregnancy losses (excluding those resulting from induced preterm labour or abruption).

2. History of losing each pregnancy at an earlier gestational age.

3. Preterm premature rupture of membranes prior to 32 weeks' gestation.

4. Short cervical length (less than $25 \mathrm{~mm}$ at 20 weeks' gestation).

5. History of cervical trauma caused by cone biopsy, forced dilatation, intrapartum cervical lacerations.

6. History of painless cervical dilatation of from $4 \mathrm{~cm}$ up to $6 \mathrm{~cm}$.

7. Congenital uterine anomalies.

8. Vaginal ultrasound evidence of cervical insufficiency, including shortening (cervical length less than $25 \mathrm{~mm}$ at 20 weeks) and funnelling of the cervix during the second trimester of pregnancy.

\section{Types of interventions}

Cervical cerclage (stitch) in singleton pregnancies in women considered to be at high risk of pregnancy loss.

\section{Comparisons}

To avoid duplication of comparisons in various reviews of interventions for preventing preterm birth, we compared trials of the intervention of interest (cervical cerclage) versus the following interventions.

1. Cervical cerclage in combination with antibiotics versus cervical cerclage alone.

2. Cervical cerclage in combination with vaginal support pessary versus cervical cerclage alone.

3. Cervical cerclage in combination with reinforcing or second cervical cerclage placement versus cervical cerclage alone.

4. Cervical cerclage in combination with tocolytics versus cervical cerclage alone.
5. Cervical cerclage in combination with 17-alphahydroxyprogesterone caproate, dydrogesterone or vaginal micronised progesterone versus cervical cerclage alone.

6. Cervical cerclage in combination with omega-3 long chain polyunsaturated fatty acid supplementation versus cervical cerclage alone.

7. Cervical cerclage in combination with bed rest versus cervical cerclage alone.

8. Cervical cerclage in combination with two or more other interventions versus cervical cerclage alone.

\section{Types of outcome measures}

We will select outcome domains based on consensus work undertaken to define core outcome measures for clinical research and evidence synthesis for pregnancy and childbirth generally (Devane 2007) and for preterm birth prevention specifically (Van 't Hooft 2016).

\section{Primary outcomes}

1. Serious neonatal morbidity (as defined by trialists).

2. Perinatal loss: all losses including miscarriages, stillbirth and neonatal deaths.

3. Baby discharged home healthy (without obvious pathology, as defined by trialists).

\section{Secondary outcomes}

\section{Neonatal}

1. Neonatal death before discharge.

2. Stillbirth: intrauterine death at 24 or more weeks; or greater than $500 \mathrm{~g}$ fetal weight or reaching viability as defined by trialists.

3. Miscarriages: perinatal loss before 24 weeks.

4. Preterm birth (birth before 28,34 and 37 completed weeks of pregnancy).

5. Serious intracranial pathology, e.g. intraventricular haemorrhage or periventricular leukomalacia (as defined by trialists).

6. Serious respiratory morbidity, e.g. respiratory distress syndrome or oxygen dependency after 28 days of life.

7. Necrotising enterocolitis requiring surgery.

8. Retinopathy of prematurity.

9. Apgar less than seven at five minutes.

Maternal

1. Caesarean section (elective and emergency).

2. Maternal infection, including chorioamnionitis, requiring intervention, e.g. antibiotics or delivery.

3. Maternal side effects (vaginal discharge, bleeding, pyrexia not requiring antibiotics).

4. Tocolysis (intravenous, oral or combined).

5. Preterm premature rupture of membranes.

\section{Search methods for identification of studies}

The following Methods section of this review was based on a standard template used by Cochrane Pregnancy and Childbirth. 


\section{Electronic searches}

We searched Cochrane Pregnancy and Childbirth's Trials Register by contacting their Information Specialist (26 September 2019).

The Register is a database containing over 25,000 reports of controlled trials in the field of pregnancy and childbirth. It represents over 30 years of searching. For full current search methods used to populate Pregnancy and Childbirth's Trials Register including the detailed search strategies for CENTRAL, MEDLINE, Embase and CINAHL; the list of handsearched journals and conference proceedings; and the list of journals reviewed via the current awareness service; please follow this link.

Briefly, Cochrane Pregnancy and Childbirth's Trials Register is maintained by their Information Specialist and contains trials identified from:

1. monthly searches of the Cochrane Central Register of Controlled Trials (CENTRAL);

2. weekly searches of MEDLINE (Ovid);

3. weekly searches of Embase (Ovid);

4. monthly searches of CINAHL (EBSCO);

5. handsearches of 30 journals and the proceedings of major conferences;

6. weekly current awareness alerts for a further 44 journals plus monthly BioMed Central email alerts.

Search results are screened by two people and the full text of all relevant trial reports identified through the searching activities described above is reviewed. Based on the intervention described, each trial report is assigned a number that corresponds to a specific Pregnancy and Childbirth review topic (or topics), and is then added to the Register. The Information Specialist searches the Register for each review using this topic number rather than keywords. This results in a more specific search set that has been fully accounted for in the relevant review sections (Included studies; Excluded studies; Ongoing studies).

In addition, we searched ClinicalTrials.gov and the WHO International Clinical Trials Registry Platform (ICTRP) for unpublished, planned and ongoing trial reports (26 September 2019) using the methods detailed in Appendix 1.

\section{Searching other resources}

We searched the reference lists of retrieved studies.

We did not apply any language or date restrictions.

\section{Data collection and analysis}

The following Methods section of this review was based on a standard template used by Cochrane Pregnancy and Childbirth.

\section{Selection of studies}

Two review authors (George Eleje (GE)) and Ahizechukwu Eke (AE)) independently assessed for inclusion all the studies we identified as a result of the search strategy. We resolved any disagreement through discussion or, if required, we consulted a third person (IE). We created a study flow diagram (Figure 1) to map out the number of records identified, included and excluded. 
Figure 1. Study flow diagram.

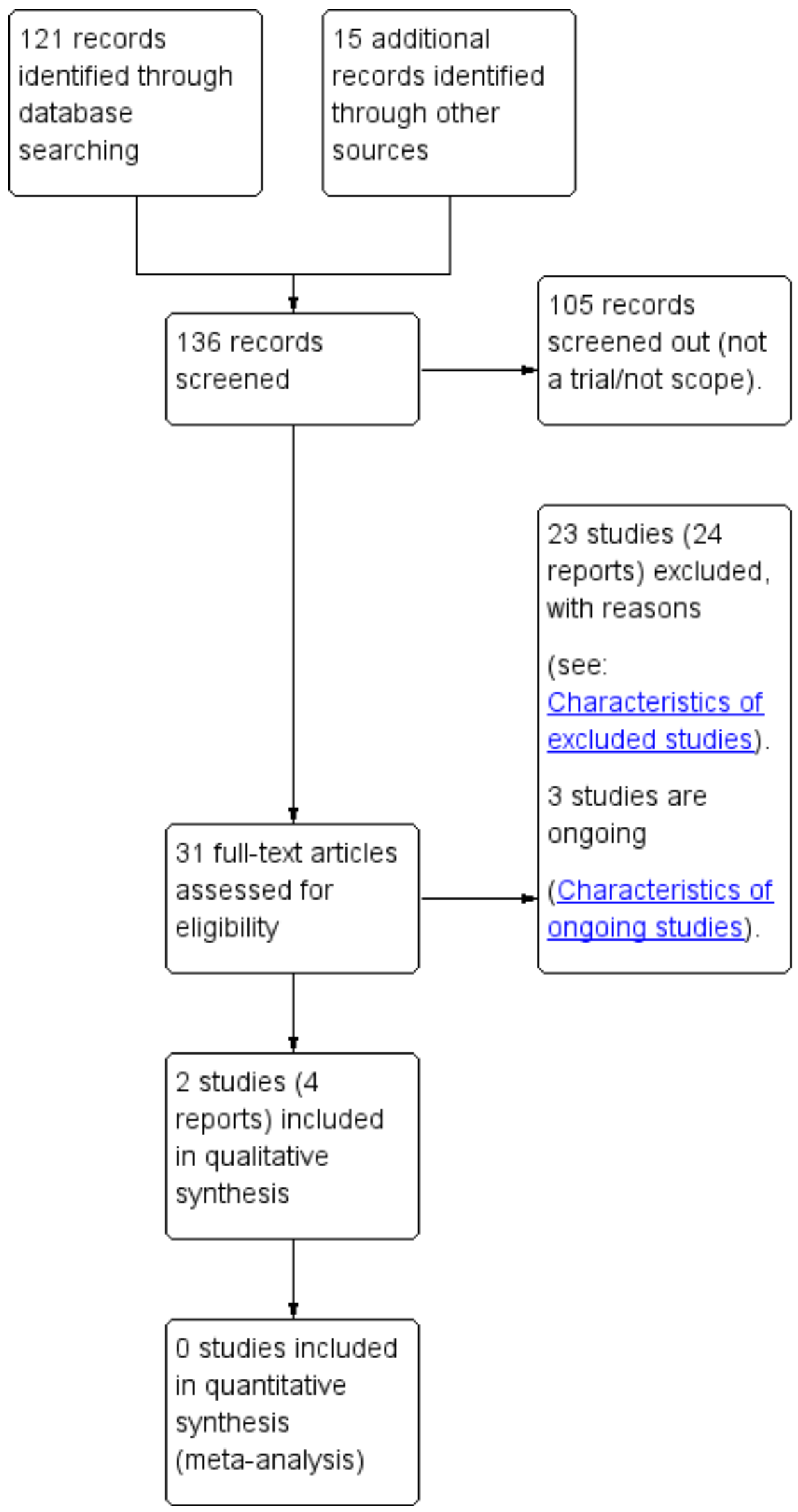




\section{Data extraction and management}

We designed a form to extract data. We extracted information on study design and setting, trial dates, participant characteristics, study eligibility criteria, details of the intervention(s) and comparison(s), the outcomes assessed, sources of trial funding, and any conflicts of interest declared by the trial investigators.

For eligible studies, at least two review authors extracted the data using the agreed form. We resolved discrepancies through discussion or, if required, we consulted a third person. We entered data into Review Manager 5 software (RevMan 2014) and checked for accuracy. When information regarding any of the above was unclear, we attempted to contact authors of the original reports to provide further details.

\section{Assessment of risk of bias in included studies}

Two review authors (GE and $A E$ ) independently assessed risks of bias for each study, using the criteria outlined in the Cochrane Handbook for Systematic Reviews of Interventions (Higgins 2011). We resolved any disagreement by discussion or by involving a third assessor.

\section{(1) Random sequence generation (checking for possible selection bias)}

We described for each included study the method used to generate the allocation sequence in sufficient detail to allow an assessment of whether it should produce comparable groups.

We assessed the method as:

- low risk of bias (any truly random process, e.g. random number table; computer random-number generator);

- high risk of bias;

- unclear risk of bias.

(2) Allocation concealment (checking for possible selection bias)

We described for each included study the method used to conceal allocation to interventions prior to assignment and assessed whether intervention allocation could have been foreseen in advance of or during recruitment, or changed after assignment.

We assessed the methods as:

- low risk of bias (e.g. telephone or central randomisation; consecutively-numbered sealed opaque envelopes);

- high risk of bias (open random allocation; unsealed or nonopaque envelopes);

- unclear risk of bias.

\section{(3.1) Blinding of participants and personnel (checking for} possible performance bias)

We described for each included study the methods used, if any, to blind study participants and personnel from knowledge of which intervention a participant received. We considered that studies were at low risk of bias if they were blinded, or if we judged that the lack of blinding would be unlikely to affect results. We assessed blinding separately for different outcomes or classes of outcomes.

We assessed the methods as:

- low, high or unclear risk of bias for participants;
- low, high or unclear risk of bias for personnel.

\section{(3.2) Blinding of outcome assessment (checking for possible detection bias)}

We described for each included study the methods used, if any, to blind outcome assessors from knowledge of which intervention a participant received. We assessed blinding separately for different outcomes or classes of outcomes.

We assessed methods used to blind outcome assessment as:

- low, high or unclear risk of bias.

\section{(4) Incomplete outcome data (checking for possible attrition bias due to the amount, nature and handling of incomplete outcome data)}

We described for each included study, and for each outcome or class of outcomes, the completeness of data including attrition and exclusions from the analysis. We stated whether attrition and exclusions were reported and the numbers included in the analysis at each stage (compared with the total randomised participants), reasons for attrition or exclusion where reported, and whether missing data were balanced across groups or were related to outcomes. Where sufficient information was reported, or could be supplied by the trial authors, we re-included missing data in the analyses which we undertook.

We assessed methods as:

- low risk of bias (e.g. no missing outcome data; missing outcome data balanced across groups);

- high risk of bias (e.g. numbers or reasons for missing data unbalanced across groups; 'as treated' analysis done with substantial departure of intervention received from that assigned at randomisation);

- unclear risk of bias.

\section{(5) Selective reporting (checking for reporting bias)}

We described for each included study how we investigated the possibility of selective outcome reporting bias and what we found.

We assessed the methods as:

- low risk of bias (where it was clear that all of the study's prespecified outcomes and all expected outcomes of interest to the review had been reported);

- high risk of bias (where not all the study's prespecified outcomes had been reported; one or more reported primary outcomes were not prespecified; outcomes of interest were reported incompletely and so could not be used; study failed to include results of a key outcome that would have been expected to have been reported);

- unclear risk of bias.

(6) Other potential bias (checking for bias due to problems not covered by (1) to (5) above)

We described for each included study any important concerns we had about other possible sources of bias.

We assessed whether each study was free of other problems that could put it at risk of bias:

Cervical stitch (cerclage) in combination with other treatments for preventing spontaneous preterm birth in singleton pregnancies 
- low risk of other bias;

- high risk of other bias;

- unclear whether there was risk of other bias.

\section{(7) Overall risk of bias}

We made explicit judgements about whether studies were at high risk of bias, according to the criteria given in the Cochrane Handbook (Higgins 2011). With reference to (1) to (6) above, we assessed the likely magnitude and direction of the bias and whether we considered it was likely to impact on the findings. We explored the impact of the level of bias through undertaking sensitivity analyses - see Sensitivity analysis.

\section{Assessing the quality of the body of evidence using the GRADE approach}

We assessed the quality of the evidence using the GRADE approach as outlined in the GRADE handbook, in order to rate the quality of the body of evidence relating to the following outcomes. We selected six outcomes for assessment by GRADE for the main comparisons.

1. Serious neonatal morbidity (as defined by trialists).

2. Perinatal loss: all losses including miscarriages, stillbirth and neonatal deaths.

3. Baby discharged home healthy, without obvious pathology (as defined by trialists).

4. Neonatal death before discharge.

5. Stillbirth: intrauterine death at 24 or more weeks; or greater than $500 \mathrm{~g}$ fetal weight or reaching viability as defined by trialists.

6. Preterm birth before 34 completed weeks of pregnancy.

We used the GRADEPro Guideline Development Tool to import data from Review Manager 5 (RevMan 2014) in order to create 'Summary of findings' tables. We produced a summary of the intervention effect and a measure of quality for each of the above outcomes, using the GRADE approach. The GRADE approach uses five considerations (study limitations, consistency of effect, imprecision, indirectness and publication bias) to assess the quality of the body of evidence for each outcome. The evidence can be downgraded from 'high quality' by one level for serious (or by two levels for very serious) limitations, depending on assessments of risk of bias, indirectness of evidence, serious inconsistency, imprecision of effect estimates or potential publication bias.

\section{Measures of treatment effect}

\section{Dichotomous data}

For dichotomous data, we presented results as the summary risk ratio (RR) with a $95 \%$ confidence interval $(\mathrm{Cl})$.

\section{Continuous data}

For continuous data, we planned to use the mean difference (MD) if outcomes were measured in the same way between trials. We planned to use the standardised mean difference (SMD) to combine trials that measured the same outcome, but use different methods.

\section{Unit of analysis issues \\ Cluster-randomised trials}

We did not identify any cluster-RCTs for inclusion in this review. Should we identify any cluster-RCTs for inclusion in future updates, we will include them in our analyses along with individually randomised trials. We will adjust their sample sizes using the methods described in the Cochrane Handbook using an estimate of the intracluster correlation co-efficient (ICC) derived from the trial (if possible), from a similar trial or from a study of a similar population. If we use ICCS from other sources, we will report this and conduct sensitivity analyses to investigate the effect of variation in the ICC. If we identify both cluster-randomised trials and individually-randomised trials, we plan to synthesise the relevant information. We will consider it reasonable to combine the results from both if there is little heterogeneity between the study designs, and the interaction between the effect of intervention and the choice of randomisation unit is considered to be unlikely.

We also acknowledged heterogeneity in the randomisation unit and performed a sensitivity analysis to investigate the effects of the randomisation unit.

\section{Cross-over trials}

We considered cross-over designs to be inappropriate for this research question.

\section{Other unit of analysis issues}

Multiple pregnancy was not eligible for inclusion in this review. We did not identify any trials that reported data for both singleton and multiple pregnancy. If we identify such trials for inclusion in future updates, we will only use data relating to the women with singleton pregnancies.

\section{Dealing with missing data}

For included studies, we noted levels of attrition. In future updates, we will explore the impact of including studies with high levels of missing data in the overall assessment of treatment effect by using sensitivity analysis.

For all outcomes, we carried out analyses, as far as possible, on an intention-to-treat basis, i.e. we attempted to include all participants randomised to each group in the analyses, and analysed all participants in the group to which they were allocated, regardless of whether or not they received the allocated intervention. The denominator for each outcome in each trial was the number randomised minus any participants whose outcomes were known to be missing.

\section{Assessment of heterogeneity}

We did not combine data in meta-analysis. In future updates, we will assess statistical heterogeneity in each meta-analysis using the $\mathrm{Tau}^{2}, \mathrm{I}^{2}$ and $\mathrm{Chi}^{2}$ statistics. We will regard heterogeneity as substantial if 12 is greater than $30 \%$ and either Tau 2 is greater than zero, or there is a low $\mathrm{P}$ value (less than 0.10 ) in the $\mathrm{Chi}^{2}$ test for heterogeneity.

\section{Assessment of reporting biases}

In future updates of this review, if there are 10 or more studies in the meta-analysis, we will investigate reporting biases (such 
as publication bias) using funnel plots. We will assess funnel plot asymmetry visually. If asymmetry is suggested by a visual assessment, we will perform exploratory analyses to investigate it.

\section{Data synthesis}

We did not combine data in meta-analysis. We carried out statistical analysis using the Review Manager 5 software (RevMan 2014).

In future updates, we will use a fixed-effect model for combining data where it is reasonable to assume that studies are estimating the same underlying treatment effect, i.e. where trials are examining the same intervention, and the trials' populations and methods are judged sufficiently similar. If there is clinical heterogeneity sufficient to expect that the underlying treatment effects differ between trials, or if we find substantial statistical heterogeneity, we will use a random-effects model to produce an overall summary if an average treatment effect across trials is considered clinically meaningful. We will consider the randomeffects summary as the average of the range of possible treatment effects and we will discuss the clinical implications of treatment effects differing between trials. If the average treatment effect is not clinically meaningful, we will not combine trials.

If we use random-effects analyses, we will present the results as the average treatment effect with a 95\% confidence interval, and the estimates of $\mathrm{Tau}^{2}$ and $\mathrm{I}^{2}$.

\section{Subgroup analysis and investigation of heterogeneity}

We did not combine data in meta-analysis. In future updates, if we identify substantial heterogeneity, we will investigate it using subgroup analyses and sensitivity analyses. We will consider whether an overall summary is meaningful, and if it is, we will use random-effects analysis to produce it.

We planned to carry out the following subgroup analyses relating to our planned comparisons.

1. Cervical cerclage in combination with antibiotics versus cervical cerclage alone

- Indication for cerclage - history-indicated cerclage versus ultrasound-indicated cerclage versus physical examinationindicated cerclage (for all outcomes)

- Type of antibiotics, such as azithromycin versus metronidazole versus erythromycin (for primary outcomes only)

2. Cervical cerclage in combination with vaginal support pessary versus cervical cerclage alone

- Indication for cerclage - history-indicated cerclage versus ultrasound-indicated cerclage versus physical examinationindicated cerclage (for all outcomes)

3. Cervical cerclage in combination with reinforcing or second cervical cerclage placement versus cervical cerclage alone

- Indication for cerclage - history-indicated cerclage versus ultrasound-indicated cerclage versus physical examinationindicated cerclage (for all outcomes)

- Gestational age of removal of pessary - less than 34 weeks versus between 34 and less than 37 weeks versus greater than or equal to 37 weeks (for primary outcomes only)
4. Cervical cerclage in combination with tocolytics versus cervical cerclage alone

- Indication for cerclage - history-indicated cerclage versus ultrasound-indicated cerclage versus physical examinationindicated cerclage (for all outcomes)

- Type of tocolytics - such as oxytocin receptor agonist versus calcium channel blockers versus magnesium sulphate, etc. (for primary outcomes only)

5. Cervical cerclage in combination with 17-alphahydroxyprogesterone caproate or dydrogesterone or vaginal micronised progesterone versus cervical cerclage alone

- Indication for cerclage - history-indicated cerclage versus ultrasound-indicated cerclage versus physical examinationindicated cerclage (for all outcomes)

- Type of progesterone support - 17-alpha-hydroxyprogesterone caproate versus dydrogesterone versus vaginal micronised progesterone (for primary outcomes only)

6. Cervical cerclage in combination with omega-3 long chain polyunsaturated fatty acid supplementation versus cervical cerclage alone

- Indication for cerclage - history-indicated cerclage versus ultrasound-indicated cerclage versus physical examinationindicated cerclage (for all outcomes)

- Supplementation dose - less than $2.7 \mathrm{~g} /$ day versus between $2.7 \mathrm{~g} /$ day and less than $6.1 \mathrm{~g} /$ day versus at least $6.1 \mathrm{~g} /$ day (for primary outcomes only)

7. Cervical cerclage in combination with bed rest versus cervical cerclage alone

- Indication for cerclage - history-indicated cerclage versus ultrasound-indicated cerclage versus physical examinationindicated cerclage (for all outcomes)

8. Cervical cerclage in combination with two or more interventions versus cervical cerclage alone

- Indication for cerclage - history-indicated cerclage versus ultrasound-indicated cerclage versus physical examinationindicated cerclage (for all outcomes)

We planned to assess subgroup differences by interaction tests available within Review Manager 5 (RevMan 2014). We planned to report the results of subgroup analyses quoting the $\mathrm{Chi}^{2}$ statistic and $P$ value, and the interaction test $\mathrm{I}^{2}$ value. However, there were insufficient data to undertake any subgroup analyses.

\section{Sensitivity analysis}

In future updates, we will carry out planned sensitivity analyses for primary outcomes, where appropriate, in order to explore the impact of trial quality, assessed as high quality if the trial reported adequate methods for sequence generation and allocation concealment and had no other clear markers of poor trial quality (for example, unacceptable attrition). We will use sensitivity analysis to investigate the effect of the randomisation unit (in cases where cluster-RCTs are included). We will also report whether or not the exclusion of studies with substantial risks of bias changed the overall effect estimate or its interpretation. 


\section{RESULTS}

\section{Description of studies}

\section{Results of the search}

See: Figure 1 We retrieved 16 trial reports from the Cochrane Pregnancy and Childbirth search, and we found (and subsequently excluded) 15 reports ourselves. The 31 reports that we assessed corresponded to a total of 28 studies. We included two studies in the review, we excluded 23 studies and three studies are ongoing.

\section{Included studies}

\section{Design}

Both of the two included trials (Miller 2014; Toplis 1980) were randomised controlled trials (RCTs).

\section{Sample sizes}

Sample sizes for the individual trials ranged from 20 (Toplis 1980) to 53 women (Miller 2014).

\section{Setting}

The trials were undertaken in Queen Charlotte's Maternity Hospital and Chelsea Hospital for Women, London, UK (Toplis 1980) and in Northwestern Memorial's Prentice Women's Hospital in Chicago, USA (Miller 2014).

\section{Dates of trials, funding and declarations of interest}

In the Miller 2014 trial, enrollment began in March 2010 and was completed in November 2012, while the follow-up was completed in March 2013. The recruitment date for the Toplis 1980 trial was not stated by trial authors.

The two trials (Miller 2014; Toplis 1980) did not report funding sources. Only one trial (Miller 2014) confirmed through correspondence that there were no potential conflicts of interest under the financial disclosure.

\section{Participants}

All participants in the Miller 2014 trial (50 participants) were women with dilated cervix devoid of regular uterine contractions or other obvious aetiology and who had consented for examinationindicated cerclage as a form of their obstetrics care in the hospital. No women in the Miller 2014 trial had a cervical cerclage placement based only on the ultrasound diagnosis of short cervical length. All participants in the Miller 2014 trial were admitted for 24 hours after the cerclage procedure and typically seen one week after hospital discharge and then thereafter at the healthcare provider's discretion. Participants in the Miller 2014 trial did not receive tocolysis as maintenance therapy or antibiotic regimen as a longerterm treatment. Antenatal corticosteroids were not administered as a routine therapy at any particular gestational age but were reserved for a clinical scenario suggesting impending preterm delivery from 24 to 34 weeks of gestation. In the Miller 2014 trial, cervical cerclage removal was effected either at suspected preterm labour or when gestational age was up to 36 or 37 weeks.

On the other hand, participants in the Toplis 1980 trial were made up of pregnant women with a singleton gestation who had a cervical cerclage under general anaesthesia from 13 to 21 weeks' gestation. In Toplis 1980, 18 women (nine in each group) had cervical cerclage performed for a history of previous spontaneous mid-trimester abortion (history-indicated cerclage); but in the remaining two women (one in each group) there was evidence of dilatation of cervix and effacement, with both women having a previous history of first trimester termination of pregnancy via vacuum extractor. All participants in the Toplis 1980 trial were admitted for 24 hours post-operation and were followed up throughout the pregnancy, labour as well as the puerperal period (see Characteristics of included studies).

The Miller 2014 trial included women with viable singleton gestation at a gestational age of 16 to 23 weeks with intact membranes, while they excluded women younger than 18 years, with major fetal congenital anomalies, with human immunodeficiency virus-positive status, with previous history of cerclage during the index pregnancy, with temperature of $100.4^{\circ} \mathrm{F}$ or higher, with allergy to both penicillin and clindamycin, or a contraindication to indomethacin. The Miller 2014 trial also excluded women who had received indomethacin or any antibiotics within seven days before presentation in the hospital. Additional inclusion and exclusion criteria are detailed in Characteristics of included studies. The authors of the Toplis 1980 trial did not state either their inclusion criteria or exclusion criteria.

\section{Interventions and comparisons}

\section{Cervical cerclage in combination with two or more interventions versus cervical cerclage alone}

In the Miller 2014 trial, participants in the intervention group received a dose of $50 \mathrm{mg}$ indomethacin orally at the immediate postoperative period (after cervical cerclage); this was followed by a 50-mg oral dose eight and 16 hours postoperatively. Additionally, women in the Miller 2014 trial intervention group received three weight-based doses of intravenous cefazolin or $600 \mathrm{mg}$ intravenous clindamycin for those with a penicillin allergy. Participants in the control (comparison) group in the Miller 2014 trial did not receive any tocolytics or antibiotics perioperatively after cervical cerclage placement.

\section{Cervical cerclage in combination with tocolytics versus cervical cerclage alone}

In the Toplis 1980 trial, participants were given intravenous salbutamol (4 mg in $500 \mathrm{~mL}$ of $5 \%$ dextrose every six hours for 24 hours) after cervical cerclage and codeine for those requiring analgesic therapy. Participants in the control (comparison) group in the Toplis 1980 trial were given $15 \mathrm{mg}$ of omnopon intramuscularly every six hours for 24 hours after cervical cerclage.

\section{Outcomes}

We could not extract useable data from the Toplis 1980 trial because the trialists did not differentiate which of the results of the outcomes belonged to which group (intervention or control) of the study participants. For instance, the authors of the Toplis 1980 trial stated: "Three patients in group A aborted between three and seven weeks after cerclage. The 24-hour plasma levels of 13,14dihydro-15-keto-prostaglandin F2 $\alpha$ (PGFM) in those patients given postoperative omnopon and those given postoperative salbutamol showed no significant difference from the basal PGFM levels. Of the 16 patients whose pregnancies continued, four had a spontaneous vertex preterm delivery (at 34, 34, 35 and 36 weeks' gestation respectively) with good fetal outcome. In the remaining 12 patients, the cervical suture was removed at 37 weeks' gestation either 
before or just after the onset of labour; all patients had healthy infants and four of them were delivered by caesarean section for reasons unrelated to the cerclage". Therefore, It should be noted that Toplis 1980 contributed no outcome data to the review.

The Miller 2014 trial report provided data for the following outcomes of interest in this review:

- Serious neonatal morbidity (a composite measure including respiratory distress syndrome, necrotising enterocolitis, intraventricular haemorrhage, retinopathy of prematurity, patent ductus arteriosus, sepsis)

- Preterm birth before 28 or 37 completed weeks of pregnancy

- Serious intracranial pathology

- Serious respiratory morbidity

- Retinopathy of prematurity

- Premature premature rupture of membranes

- Maternal infection requiring intervention (chorioamnionitis)

The outcomes of stillbirth, miscarriage (perinatal loss before 24 weeks) or preterm birth prior to 34 weeks of completed pregnancy were not mentioned in the Miller 2014 trial report but these data were sought and obtained from the study authors. Neonatal necrotising enterocolitis was reported in Miller 2014 but it was unclear whether surgery was required (data not available from the trial authors).

There were no data for neonatal death before discharge. Miller 2014 reported 'survival until discharge' but it was not appropriate to use reciprocal data. There was also no mention of caesarean section, maternal side effects, or Apgar score less than 7 at five minutes. We sought these data from the trialist but data were not available.

\section{Excluded studies}

We excluded 23 studies or trials (Althuisius 2002; Barinov 2017; Berghella 2010; Berghella 2017; Deutinger 1992; Enakpene 2018; Endl 1982; NCT03837288; Ionescu 2012; Jung 2016; Keeler 2009; Mackeen 2013; Nasr 2011; Pustotina 2018; Rafael 2011; Ragab 2015; Rebarber 2008; Roman 2018; Samson 2018; Sinkey 2018; Stetson 2016; Szychowski 2012; Yemini 1985) following full-text review, or after contacting trialists for further information to determine eligibility.

Trials were most commonly excluded because the studies were retrospective cohort studies (Enakpene 2018; Jung 2016; Mackeen 2013; Rafael 2011; Rebarber 2008; Samson 2018; Sinkey 2018; Stetson 2016) (eight trials; 35\%). Eleven trials (48\%) were RCTs but cervical cerclage was applied in only one arm of the trials (Althuisius 2002; Barinov 2017; Berghella 2010; NCT03837288; Ionescu 2012; Keeler 2009; Nasr 2011; Ragab 2015; Szychowski 2012) (nine trials; $39 \%$ ) or some of the arms of the study (Pustotina 2018) or cerclage was not applied in any arm (Yemini 1985) of the trial. One trial each was a quasi-randomised trial (Deutinger 1992), longitudinal study on twin pregnancy (Endl 1982), retrospective case-control study (Roman 2018) or letter to editor (Berghella 2017).

\section{Risk of bias in included studies}

We assessed risk of bias for both included studies - for a summary of our risk of bias judgements, see Figure 2; Figure 3. 
Figure 2. Risk of bias summary: review authors' judgements about each risk of bias item for each included study.

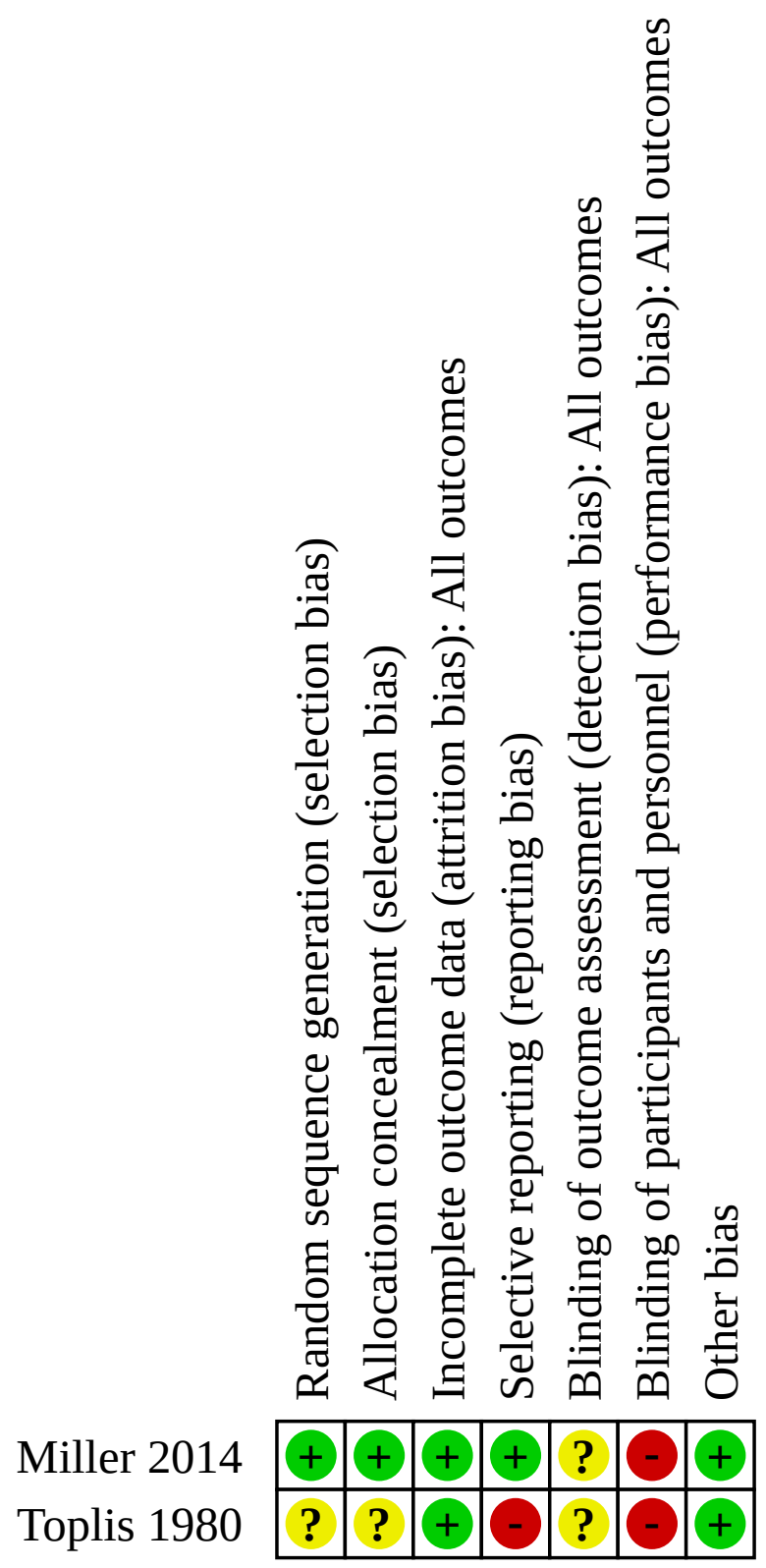


Figure 3. Risk of bias graph: review authors' judgements about each risk of bias item presented as percentages across all included studies.

$\begin{array}{r}\text { Random sequence generation (selection bias) } \\ \text { Allocation concealment (selection bias) } \\ \text { Incomplete outcome data (attrition bias): All outcomes } \\ \text { Selective reporting (reporting bias) } \\ \text { Blinding of outcome assessment (detection bias): All outcomes } \\ \text { Blinding of participants and personnel (performance bias): All outcomes } \\ \text { Other bias } \\ \hline \text { Low risk of bias }\end{array}$

\section{Allocation}

We considered the risk of bias for random sequence generation to be low for one trial reporting that random sequence generation was carried out by random number table, (though it was unclear whether this was achieved via a computer or not) and it described adequate methods for allocation concealment, including sealed, opaque, consecutively-labelled envelopes (Miller 2014). However, in the other trial, both the random sequence generation and allocation concealment were not described, therefore we considered the risk of bias for random sequence generation and allocation concealment to be unclear, given the unclear processes followed for these domains of selection bias (Toplis 1980).

\section{Blinding}

\section{Blinding of participants and personnel (performance bias)}

There was no indication in either study that participants and personnel were unaware of the intervention assignments and, given the nature of different modes of administration of the treatment agents, we considered blinding to be highly unlikely. We therefore considered the risk of performance bias to be high in both (Miller 2014; Toplis 1980) studies.

\section{Blinding of outcome assessment (detection bias)}

When considering objective outcomes only (e.g. stillbirth, neonatal death), we assessed both trials (Miller 2014; Toplis 1980) to be at unclear risk of detection bias.

\section{Incomplete outcome data}

We considered the two trials (Miller 2014; Toplis 1980) to be at low risk of attrition bias. We rated Miller 2014 and Toplis 1980 as having low risk of attrition bias because $4 \%(1 / 27)$ of women in the intervention group, and $8 \%(2 / 26)$ of women in the control group were lost to follow-up (Miller 2014), while there was no mention or evidence of sample attrition or missing data in the Toplis 1980 trial.

\section{Selective reporting}

Only the Miller 2014 trial was registered at ClinicalTrials.gov and the reported primary outcomes and secondary outcomes were consistent with the trial registration. We judged the risk of reporting bias in the Toplis 1980 trial to be high because trial registration was not stated. Also, some of the outcomes in the Toplis 1980 trial were not fully reported; for example, the authors reported no significant differences between groups and the results reported were as a whole, not according to the arm into which participants were randomised.

\section{Other potential sources of bias}

We did not identify other sources of bias for either trial.

\section{Effects of interventions}

See: Summary of findings 1 Cervical cerclage in combination with antibiotics and tocolytics versus cervical cerclage alone for preventing preterm birth in singleton pregnancies

We identified two small trials for inclusion in this review (involving a total 73 women) under two separate comparisons. Meta-analysis was not possible.

We did not identify any trials relating to the following planned comparisons.

- Cervical cerclage in combination with antibiotics versus cervical cerclage alone

- Cervical cerclage in combination with vaginal support pessary versus cervical cerclage alone

- Cervical cerclage in combination with reinforcing or second cervical cerclage placement versus cervical cerclage alone

- Cervical cerclage in combination with 17-alphahydroxyprogesterone caproate or dydrogesterone or vaginal micronised progesterone versus cervical cerclage alone

- Cervical cerclage in combination with omega-3 long chain polyunsaturated fatty acid supplementation versus cervical cerclage alone

- Cervical cerclage in combination with bed rest versus cervical cerclage alone

\section{Cervical cerclage in combination with two or more interventions versus cervical cerclage alone}

Only one trial (Miller 2014), involving 53 women (data from 50 women), compared cervical cerclage in combination with tocolytic (indomethacin) and antibiotics (cefazolin or clindamycin) with cervical cerclage alone in women with singleton pregnancy between $160 / 7$ and $236 / 7$ weeks of gestation.

Cervical stitch (cerclage) in combination with other treatments for preventing spontaneous preterm birth in singleton pregnancies 


\section{Primary outcomes}

\section{Serious neonatal morbidity (as defined by trialists)}

Miller 2014 reported a 'composite adverse outcome' which included the following neonatal morbidities: respiratory distress syndrome, necrotising enterocolitis, intraventricular haemorrhage, retinopathy of prematurity, patent ductus arteriosus, and sepsis. There were $8 / 26$ infants with serious neonatal morbidity in the cerclage in combination with tocolytic and antibiotics group and $12 / 24$ in the cerclage alone group. Very low-certainty evidence means that we are unclear about the effects of cervical cerclage in combination with tocolytic (indomethacin) and antibiotics (cefazolin or clindamycin) compared with cervical cerclage alone in terms of serious neonatal morbidity (risk ratio (RR)) 0.62, 95\% confidence interval $(\mathrm{Cl}) 0.31$ to 1.24 ; 50 women; $\mathrm{P}=0.57$; very lowcertainty evidence; Analysis 1.1).

Perinatal loss: all losses including miscarriages, stillbirth and neonatal deaths

We contacted the trialist for more information about this outcome. The authors of Miller 2014 provided data on stillbirth (intrauterine death at 24 weeks or more) and miscarriage (perinatal loss before 24 weeks) and these have been added to our analysis. There were $3 / 26$ perinatal losses in the cerclage in combination with tocolytic and antibiotics group and 6/24 in the cerclage alone group (RR 0.46, $95 \% \mathrm{Cl} 0.13$ to 1.64 , very low-certainty evidence; Analysis 1.2). Data for neonatal death before discharge were not available.

\section{Baby discharged home healthy (without obvious pathology, as defined} by trialists)

Miller 2014 did not report the number of babies discharged home healthy (without obvious pathology) but reported on the number of babies that survived until discharge. We do not know whether the babies were healthy and this information was not available from the trial authors. We have reported a narrative of the survival until discharge data here: there were $21 / 26$ babies in the cerclage in combination with tocolytic and antibiotics group and $17 / 24$ babies in the cerclage alone group who survived until discharge.

\section{Secondary outcomes - neonatal}

\section{Neonatal death before discharge}

This outcome was not reported by Miller 2014 and these data were not available from the trial authors. Miller 2014 does, however, report survival until discharge and a narrative summary of those reciprocal data are presented here: there were 5/26 babies who did not survive until discharge in the cerclage in combination with tocolytic and antibiotics group and $7 / 24$ in the cerclage alone group.

Stillbirth: intrauterine death at $\mathbf{2 4}$ or more weeks, greater than $\mathbf{5 0 0} \mathrm{g}$ fetal weight or reaching viability as defined by trialists

We sought information from the authors of Miller 2014 and they confirmed that there were no stillbirths (intrauterine fetal deaths at 24 or more weeks) (Analysis 1.3).

\section{Miscarriages: perinatal loss before 24 weeks}

We sought information from the authors of Miller 2014 who confirmed that, of the 11 deliveries born before 24 weeks, there were 9 deaths. There were 3/26 deaths in the cerclage in combination with tocolytic and antibiotics group and 6/24 in the cerclage alone group. Data from one study showed that we are unclear about the effects of cervical cerclage in combination with tocolytic (indomethacin) and antibiotics (cefazolin or clindamycin) compared with cerclage alone in terms of miscarriages (perinatal loss before 24 weeks) (RR $0.46,95 \% \mathrm{Cl} 0.13$ to $1.64 ; 50$ women; $\mathrm{P}=$ 0.23 ; very low-certainty evidence; Analysis 1.4).

\section{Preterm birth (birth before 28, 34 and 37 completed weeks of pregnancy)}

\section{Preterm birth $<28$ weeks}

There were $7 / 26$ preterm births before 28 weeks in the cerclage in combination with tocolytic and antibiotics group and $11 / 24$ preterm births before 28 weeks in the cerclage alone group. Data from one study showed that we are unclear about the effects of cervical cerclage in combination with tocolytic (indomethacin) and antibiotics (cefazolin or clindamycin) compared with cerclage alone in terms of preterm births before 28 weeks of completed weeks of pregnancy (RR $0.59,95 \% \mathrm{Cl} 0.27$ to $1.27 ; 50$ women; $\mathrm{P}=$ 0.17 ; very low-certainty evidence; Analysis 1.5 ).

\section{Preterm birth $<34$ weeks}

This outcome was not reported in Miller 2014 but we obtained data from the trialist. There were $11 / 26$ preterm births before 34 weeks in the cerclage in combination with tocolytic and antibiotics group and 13/24 preterm births before 34 weeks in the cerclage alone group. Data from this study showed that we are unclear about the effects of cervical cerclage in combination with tocolytic (indomethacin) and antibiotics (cefazolin or clindamycin) compared with cerclage alone in terms of preterm births before 34 weeks of completed weeks of pregnancy (RR $0.78,95 \% \mathrm{Cl} 0.44$ to 1.40; 50 women; $\mathrm{P}=0.40$; very low-certainty evidence; Analysis 1.6).

\section{Preterm birth $<37$ weeks}

There were 14/26 preterm births before 37 weeks in the cerclage in combination with tocolytic and antibiotics group and 15/24 preterm births before 37 weeks in the cerclage alone group. Data from the Miller study showed that we are unclear about the effects of cervical cerclage in combination with tocolytic (indomethacin) and antibiotics (cefazolin or clindamycin) compared with cerclage alone in terms of preterm births before 37 weeks of completed weeks of pregnancy (RR $0.86,95 \% \mathrm{Cl} 0.54$ to $1.38 ; 50$ women; $\mathrm{P}=$ 0.54 ; very low-certainty evidence; Analysis 1.7 ).

Serious intracranial pathology, e.g. intraventricular haemorrhage or periventricular leukomalacia (as defined by trialists)

There were no cases of serious intracranial pathology (intraventricular haemorrhage) in either the cerclage in combination with tocolytic and antibiotics group or in the cerclage alone group (very low-certainty evidence; Analysis 1.8).

\section{Serious respiratory morbidity, e.g. respiratory distress syndrome or oxygen dependency after 28 days of life}

There were $3 / 26$ cases of serious respiratory morbidity in the cerclage in combination with tocolytic and antibiotics group and $6 / 24$ cases of serious respiratory morbidity in the cerclage alone group. Very low-certainty evidence means that we are uncertain about these results (RR $0.46,95 \% \mathrm{Cl} 0.13$ to $1.64 ; 50$ women; $P=0.23$; very low-certainty evidence; Analysis 1.9).

Cervical stitch (cerclage) in combination with other treatments for preventing spontaneous preterm birth in singleton pregnancies 


\section{Necrotising enterocolitis requiring surgery}

There was $1 / 26$ case of necrotising enterocolitis in the cerclage in combination with tocolytic and antibiotics group and 2/24 cases in the cerclage alone group. However, it is not known whether these babies required surgery; this information is not available in the trial report and the trial authors did not have this information. Very lowcertainty evidence means that we are uncertain about these results (RR 0.46, 95\% Cl 0.04 to 4.77; 50 women; $\mathrm{P}=0.52$; very low-certainty evidence; Analysis 1.10).

\section{Retinopathy of prematurity}

There were 2/26 cases of retinopathy of prematurity in the cerclage in combination with tocolytic and antibiotics group and 2/24 retinopathy of prematurity in the cerclage alone group (RR 0.92, $95 \% \mathrm{Cl} 0.14$ to $6.05 ; 50$ women; $\mathrm{P}=0.93$; very low-certainty evidence; Analysis 1.11). We are uncertain about these results due to very low-certainty evidence.

\section{Apgar score less than seven at five minutes}

Not reported by Miller 2014 and data not available from the trialist.

\section{Secondary outcomes - maternal}

\section{Caesarean section (elective and emergency)}

Not reported by Miller 2014 and data not available from the trialist.

\section{Maternal infection, including chorioamnionitis, requiring} intervention, e.g. antibiotics or delivery

There were 6/26 women with infection (chorioamnionitis) requiring intervention in the cerclage in combination with tocolytic and antibiotics group and 4/24 in the cerclage alone group (RR 1.38, 95\% $\mathrm{Cl} 0.44$ to 4.32 ; 50 women; $\mathrm{P}=0.57$; very low-certainty evidence; Analysis 1.12). We are unclear about these results due to very lowcertainty evidence.

Maternal side effects (vaginal discharge, bleeding, pyrexia not requiring antibiotics)

Not reported by Miller 2014 and data not available from the trialist.

\section{Tocolysis (intravenous, oral or combined)}

Not reported by Miller 2014.

\section{Preterm premature rupture of the membranes}

There were 14/26 women with preterm premature rupture of membranes in the cerclage in combination with tocolytic and antibiotics group and 8/24 in the cerclage alone group (RR 2.08, 95\% $\mathrm{Cl} 1.12$ to 3.87 ; 50 women; $\mathrm{P}=0.57$; Analysis 1.13$)$. We are unclear about these results due to very low-certainty evidence

\section{Cervical cerclage in combination with tocolytics versus cervical cerclage alone}

A single study (Toplis 1980), involving 20 women, compared cervical cerclage in combination with tocolytic (salbutamol) with cervical cerclage alone in women with singleton pregnancy.

\section{Primary outcomes}

None of this review's primary outcomes were reported by Toplis 1980.

- Serious neonatal morbidity (as defined by trialists).
- Perinatal loss: all losses including miscarriages, stillbirth and neonatal deaths.

- Baby discharged home healthy (without obvious pathology, as defined by trialists).

\section{Secondary outcomes}

Preterm birth (birth before 34 and 37 completed weeks of pregnancy)

Toplis 1980 (20 participants) reported preterm birth rates but the data were presented in a form that we could not use.

The trial did not report on any other secondary outcomes of interest in this review.

\section{DISCUSSION}

\section{Summary of main results}

This review set out to assess the effects of cervical cerclage in combination with other different interventions or models of care at the time of cervical cerclage placement for prolonging singleton gestation in women at high risk of pregnancy loss based on prior history and/or ultrasound finding of 'short cervix' and/or physical examination.

We identified two small trials (Miller 2014; Toplis 1980) examining cervical cerclage in combination with tocolytics versus cervical cerclage alone (Toplis 1980) or cervical cerclage in combination with antibiotics and tocolytics versus cervical cerclage alone (Miller 2014) for women with singleton gestation who were at high risk of having pregnancy loss based on their prior history and/or ultrasound finding of 'short cervix' and/or physical examination. The review included data from 50 women and their babies. Metaanalysis was not possible. We do not know if cervical cerclage in combination with antibiotic and tocolytics has any effect on serious neonatal morbidity, perinatal loss, stillbirth or preterm birth because the certainty of evidence is very low. We did not identify any evidence relating to the numbers of babies discharged home health or neonatal death before discharge.

\section{Overall completeness and applicability of evidence}

The evidence around cervical cerclage in combination with other interventions to improve singleton gestation in women at high risk of pregnancy loss based on prior history and/or ultrasound finding of 'short cervix' and/or physical examination is sparse. The only evidence is on the use of indomethacin and antibiotics at the time of cervical cerclage only.

Our review set out to capture a broad range of adjunctive interventions addressing this research question. However, the two eligible trials were focused on antibiotics and tocolytics administered at the time of cervical cerclage. Other potentially beneficial interventions were not assessed, including vaginal support pessary, reinforcing or second cervical cerclage placement, 17-alpha-hydroxyprogesterone caproate or dydrogesterone or vaginal micronised progesterone, omega-3 long chain polyunsaturated fatty acid supplementation and bed rest.

With regard to the data that were available for this review, we found only one trial, with few participants. Therefore, meta-analysis was not performed. As a result, the analyses were not sufficiently powered to the extent that the we are unclear about the effects of the intervention in most of the outcomes assessed. We were

Cervical stitch (cerclage) in combination with other treatments for preventing spontaneous preterm birth in singleton pregnancies 
unable to obtain data relating to two of this review's important outcomes of interest: baby discharged home healthy (with no obvious pathology), or neonatal death before discharge (Miller 2014 reported the number of babies who survived until discharge). Miller 2014 also did not report on some of this review's secondary outcomes for the mother (e.g. caesarean section, maternal side effects) or her baby (e.g. Apgar score $<7$ at five minutes). We sought data for these outcomes from the trial authors, but data were not available.

The overall completeness and applicability of this evidence was also very limited by variation in the characteristics of the women included in the trials. There is very limited evidence on the shortor long-term effectiveness of cervical cerclage in combination with other interventions compared to cervical cerclage alone. This emphasises the urgent need for trials that specifically address various adjuncts to cervical cerclage versus cerclage alone.

\section{Quality of the evidence}

We assessed the risk of bias in terms of incomplete outcome data (attrition bias) and other bias as 'low' in both included trials (Miller 2014; Toplis 1980).

In the Miller 2014 trial, there was low risk of bias in almost all domains except blinding of outcome assessment (detection bias) which was unclear and blinding of participants and personnel (performance bias) which was high risk. However, in the Toplis 1980 trial, there was unclear risk of bias in almost all domains except incomplete outcome data and other bias which were low risk and selective reporting (reporting bias) and blinding of participants and personnel (performance bias) which were high risk. We downgraded the certainty of the evidence fom Miller 2014 once for risk of performance bias. For the Miller 2014 trial, there appeared to be low risk of attrition bias.

We used the GRADE methodology to assess the certainty of evidence provided for the comparison of cervical cerclage in combination with antibiotics and tocolytics versus cervical cerclage alone (see Summary of findings 1). The outcomes (where available) were very low-certainty. Downgrading decisions were based on serious limitations in study design (high risk of performance bias) and very serious concerns around imprecision (wide confidence intervals crossing the line of no effect, small sample sizes (less than 400 participants), and few/no events). As there was only one study for each comparison, consistency could not be assessed.

\section{Potential biases in the review process}

We conducted our review in accordance with recommendations provided in the Cochrane Handbook for Systematic Reviews of Interventions (Higgins 2011). We aimed to reduce bias wherever possible by having two review authors independently assess trial eligibility, perform data extraction, and carry out 'Risk of bias' evaluations and GRADE assessments of evidence.

We consulted with experts, handsearched conference proceedings, and searched trial registers but identified no additional unpublished studies except for the ongoing studies, which we will assess for inclusion when the authors publish the results in full.

We aimed to reduce bias in trial selection by comprehensive searches of available data. We conducted the original search for trials in this area using Cochrane Pregnancy and Childbirth's Trials
Register, and included trials directly addressing the role of cervical cerclage in combination with other treatments versus cervical cerclage alone. Our additional searches for ongoing trials within ClinicalTrials.gov and the WHO International Clinical Trials Registry Platform (ICTRP) were also comprehensive. We were unable to explore the potential for publication bias statistically, due to insufficient numbers of trials within each domain.

\section{Agreements and disagreements with other studies or reviews}

Our review is unable to offer any information about vaginal pessary, reinforcing or second cerclage placement, progesterone, omega-3 long chain polyunsaturated fatty acid, or bed rest in combination with cervical cerclage versus cervical cerclage alone. However, in a previous non-Cochrane systematic review (Defranco 2013) assessing the effectiveness of adjunctive interventions to cervical cerclage for preventing preterm births, fewer than 12 studies reported on the comparison of cervical cerclage alone and cervical cerclage and at least one intervention. However, none of the 12 studies was a randomised clinical trial with a prospective design. In this Defranco 2013 systematic review, no studies that compared cerclage alone versus cerclage and at least one intervention addressed the problems associated with use of antibiotics, bed rest, or vaginal pessary. None of the 12 studies included in the Defranco 2013 review showed an obvious advantage for the use of any of the combined interventions with cervical cerclage.

In another recent non-Cochrane systematic review and metaanalysis (Eke 2019a), aimed at assessing the need for added interventions to cervical cerclage following the administration of 17-hydroxyprogesterone caproate medication in preventing recurrent spontaneous preterm birth in women with a prophylactic cerclage, the authors indicated that five studies met the inclusion criteria and were included in their final analysis. However, the authors of the Eke 2019a systematic review stated that only one study (Yemini 1985) out of their five included studies was a randomised trial and concluded that intramuscular 17hydroxyprogesterone caproate in combination with prophylactic cerclage in women with prior preterm birth had no synergistic effect in reducing spontaneous recurrent preterm birth or improving perinatal outcomes. However, our present review excluded the Yemini 1985 trial included in the Eke 2019a review because, although it was a double-blind placebo-controlled randomised trial, treatments were randomly divided into two groups, namely either 17 alpha-hydroxyprogesterone caproate $250 \mathrm{mg}$ by intramuscular injection once a week, or a placebo, without any of the participants or arms receiving cervical cerclage.

\section{AUTHORS' CONCLUSIONS}

\section{Implications for practice}

We found insufficient evidence to evaluate the effect of combining a tocolytic (indomethacin) and antibiotics (cefazolin/clindamycin) with cervical cerclage compared with cervical cerclage alone for preventing PTB in women with singleton pregnancies. Very lowcertainty evidence means that we are unclear about these results and cannot reach any conclusions with regards to the usefulness of cervical cerclage in combination with other treatments in pregnant women with singleton pregnancies for preventing spontaneous preterm birth. 


\section{Implications for research}

We did not identify any studies looking at treatments other than tocolytics and antibiotics in combination with cervical cerclage. More research is required for comparisons of other interventions such as vaginal support pessary, reinforcing or second cervical cerclage placement, 17-alpha-hydroxyprogesterone caproate or dydrogesterone or vaginal micronised progesterone, omega-3 long chain polyunsaturated fatty acid supplementation and bed rest. Future research should report on all outcomes listed in this review.

We identified three ongoing studies (one investigating vaginal progesterone after cerclage, and two investigating cerclage plus pessary) whose results will be incorporated in a future update of this review.

\section{ACKN OWLEDGEMENTS}

We would like to thank the previous Managing Editor of the Pregancy and Childbirth Group, Sonja Henderson, for her encouragement and advice that led to the registration of the topic for this protocol. We also thank Frances Kellie, the current Managing Editor of the Pregnancy and Chilbirth Group, for her numerous encouragements and words of advice.

Special thanks to Tamara Kredo, Elizabeth Pienaar, Babalwa Zani, Joy Oliver, Solange Durao, Charles Okwundu and Kholiswa Dube of the South African Cochrane Centre for encouraging us in the writing of protocols for systematic reviews. We are grateful to the Nigerian branch of the South African Cochrane Centre (SACC) and GJ Hofmeyr of the Effective Care Research Unit, East London, for training us in the conduct of protocol writing. We would also like to thank Denise Atherton, the Administrative Assistant of the Cochrane Pregnancy and Childbirth Group for all her support towards the completion of this protocol.

GE acknowledges the Faculty of Medicine, College of Health Sciences, Nnamdi Azikiwe University, Nnewi Campus, for providing the enabling environment that allowed him to complete this review.

We would like to thank Emily Miller for answering our queries and providing additional data in relation to Miller 2014.

This project was supported by the National Institute for Health Research, via Cochrane Infrastructure funding to Cochrane Pregnancy and Childbirth. The views and opinions expressed therein are those of the authors and do not necessarily reflect those of the Systematic Reviews Programme, NIHR, NHS or the Department of Health.

As part of the pre-publication editorial process, this review has been commented on by four peers (an editor and three referees who are external to the editorial team), a member of our international panel of consumers and our Group's Statistical Adviser. The authors are grateful to the peer reviewers (who wish to remain anonymous) for their time and comments. 


\section{RE F E R E N C E S}

\section{References to studies included in this review}

Miller 2014 \{published data only\}

Miller ES, Grobman WA, Fonseca L, Robinson B. The role in emergent cerclage of indomethacin and antibiotics (RECIA). American Journal of Obstetrics and Gynecology 2014;210(1 Suppl 1):S25. [CENTRAL: CN-01012126] [EMBASE: 71275416]

* Miller ES, Grobman WA, Fonseca L, Robinson BK. Indomethacin and antibiotics in examination-indicated cerclage. Obstetrics \& Gynecology 2014;123:1311-6.

NCT01114516. Multifactorial approach to emergent cerclage [Role in emergent cerclage of indomethacin and antibiotics]. clinicaltrials.gov/show/NCT01114516 (first received 29 Apr 2010). [CENTRAL: CN-02026479]

\section{Toplis 1980 \{published data only\}}

Toplis PJ, Shepherd JH, Youssefmejadian E, Jakubowicz D, Dewhurst J. Plasma prostaglandin concentrations after cerclage in early pregnancy. British Journal of Obstetrics and Gynaecology 1980;87:669-71.

\section{References to studies excluded from this review}

\section{Althuisius 2002 \{published data only\}}

Althuisius S, Dekker G, Hummel P, Bekedam D, Kuik D, Vn Geijn H. Cervical Incompetence Prevention RAndomized Cerclage Trial (CIPRACT): effect of therapeutic cerclage with bed rest vs. bed rest only on cervical length. Ultrasound in Obstetrics \& Gynecology 2002;20(2):163-7. [PMID: 12153667]

\section{Barinov 2017 \{published data only\}}

Barinov SV, Shamina IV, Lazareva OV, Tirskaya YI, Ralko VV, Shkabarnya LL, et al. Comparative assessment of arabin pessary, cervical cerclage and medical management for preterm birth prevention in high-risk pregnancies. Journal of MaternalFetal \& Neonatal Medicine 2017;30(15):1841-6.

\section{Berghella 2010 \{published data only\}}

Berghella V, Figueroa D, Szychowski JM, Owen J, Hankins GD, lams JD, et al. 17-alpha-hydroxyprogesterone caproate for the prevention of preterm birth in women with prior preterm birth and a short cervical length. American Journal of Obstetrics and Gynecology 2010;202(4):351.e1-6. [PMID: 20350641]

\section{Berghella 2017 \{published data only\}}

Berghella V, Owen J, Szychowski JM. Outcomes with cerclage alone compared with cerclage plus 17alphahydroxyprogesterone caproate. Obstetrics and Gynecology 2017;129(2):390-1. [PMID: 28121824]

\section{Deutinger 1992 \{published data only\}}

Deutinger J, Rudelstorfer R, Pattermann A, Bernaschek G. Vaginosonographic velocimetry in uterine arteries before and after administration of beta-mimetics. British Journal of Obstetrics and Gynaecology 1992;99:417-21.
Enakpene 2018 \{published data only\}

Enakpene CA, DiGiovanni L, Jones TN, Marshalla M, Mastrogiannis D, Della Torre M. Cervical cerclage for singleton pregnant patients on vaginal progesterone with progressive cervical shortening. American Journal of Obstetrics and Gynecology 2018;219(4):397.e1-397.e10. [PMID: 30017683]

\section{Endl 1982 \{published data only\}}

Endl J, Baumgarten K. Results of prophylactic oral long term tocolysis and cerclage for the prolongation of twin pregnancy (a multi-center study) [Uber die ergebnisse der prophylaktischen oralen langzeittokolyse und cerclage zur verlangerung der zwillingsschwangerschaften (eine multicenterstudie)]. Zeitschrift fur Geburtshilfe und Perinatologie 1982;186:319-25

\section{Ionescu 2012 \{published data only\}}

Ionescu AC, Gheorghiu D, Pacu I, Davitoiu B, Dimitriu M, Haradja H. Randomized trial of cerclage and progesterone to prevent spontaneous preterm birth in high-risk women with a short cervix. Journal of Perinatal Medicine 2012;39 Suppl:Abstract no. 008.

\section{Jung 2016 \{published data only\}}

Jung EY, Oh KJ, Hong JS, Han BR, Joo JK. Addition of adjuvant progesterone to physical-exam-indicated cervical cerclage to prevent preterm birth. Journal of Obstetrics and Gynaecology Research 2016;42(12):1666-72. [PMID: 27641755]

\section{Keeler 2009 \{published data only\}}

Keeler SM, Kiefer D, Rochon M, Quinones JN, Novetsky AP, Rust O. A randomized trial of cerclage vs. 17 alphahydroxyprogesterone caproate for treatment of short cervix. Journal of Perinatal Medicine 2009;37(5):473-9. [PMID: 19492920]

\section{Mackeen 2013 \{published data only\}}

Mackeen AD, Rafael TJ, Zavodnick J, Berghella V. Effectiveness of 17-a-hydroxyprogesterone caproate on preterm birth prevention in women with history-indicated cerclage. American Journal of Perinatology 30;9:755-8.

\section{Nasr 2011 \{published data only\}}

NCT00787813. N-acetyl cysteine after cervical cerclage (NACCC). clinicaltrials.gov/ct2/show/record/NCT00787813 (first received 10 November 2008).

* Nasr A, Saman A, Zakherah M. Effect of oral N-acetyl cysteine on pregnancy outcome after cervical cerclage: a randomized controlled trial. Fertility and Sterility 2011;96(3 Suppl 1):S32.

\section{NCT03837288 \{published data only\}}

NCT03837288. Cervical cerclage for singleton pregnant on vaginal progesterone with progressive cervical length shortening. clinicaltrials.gov/ct2/show/NCT03837288 (first received 12 February 2019).

\section{Pustotina 2018 \{published data only\}}

Pustotina O. Effectiveness of dydrogesterone, $17-\mathrm{OH}$ progesterone and micronized progesterone in prevention of

Cervical stitch (cerclage) in combination with other treatments for preventing spontaneous preterm birth in singleton pregnancies 
preterm birth in women with a short cervix. Journal of Maternalfetal \& Neonatal Medicine 2018;31(14):1830-8. [PMID: 28502186]

Rafael 2011 \{published data only\}

Rafael TJ, Mackeen AD, Berghella V. The effect of $17 a-$ hydroxyprogesterone caproate on preterm birth in women with an ultrasound-indicated cerclage. American Journal of Perinatology 2011;28(5):389-94.

\section{Ragab 2015 \{published data only\}}

Ragab A, Mesbah Y. To do or not to emergency cervical cerclage (a rescue stitch) at 24-28 weeks gestation in addition to progesterone for patients coming early in labor? A prospective randomized trial for efficacy and safety. Archives of Gynecology and Obstetrics 2015;292:1255-60.

Rebarber 2008 \{published data only\}

Rebarber A, Cleary-Goldman J, Istwan NB, Rhea DJ, Desch C, Russo-Stieglitz K, et al. The use of 17 alphahydroxyprogesterone caproate (17p) in women with cervical cerclage. American Journal of Perinatology 2008;25(5):271-5. [PMID: 18401840]

\section{Roman 2018 \{published data only\}}

Roman AR, Da Silva Costa F, Araujo Junior E, Sheehan PM. Rescue adjuvant vaginal progesterone may improve outcomes in cervical cerclage failure. Geburtshilfe und Frauenheilkunde 2018;78(8):785-90. [PMID: 30140107]

\section{Samson 2018 \{published data only\}}

Samson FD, Merriman AL, Tate DL, Apostolakis-Kyrus K, Gomez LM. Adjuvant administration of 17-a-hydroxyprogesterone caproate in women with three or more second trimester pregnancy losses undergoing cervical cerclage is no more effective than cerclage alone. Journal of Perinatal Medicine 2018;46(2):155-61.

\section{Sinkey 2018 \{published data only\}}

Sinkey RG, Garcia MR, Odibo AO. Does adjunctive use of progesterone in women with cerclage improve prevention of preterm birth? Journal of Maternal-fetal \& Neonatal Medicine $31 ; 2: 202-8$

\section{Stetson 2016 \{published data only\}}

Stetson B, Hibbard JU, Wilkins I, Leftwich H. Outcomes with cerclage alone compared with cerclage plus $17 \alpha$ hydroxyprogesterone caproate. Obstetrics and Gynecology 2016;128(5):983-8.

\section{Szychowski 2012 \{published data only\}}

Szychowski JM, Berghella V, Owen J, Hankins G, lams JD, Sheffield JS, et al. Cerclage for the prevention of preterm birth in high risk women receiving intramuscular 17-alphahydroxyprogesterone caproate. Journal of Maternal-fetal \& Neonatal Medicine 2012;25(12):2686-9. [PMID: 22889234]

\section{Yemini 1985 \{published data only\}}

Yemini M, Borenstein R, Dreazen E, Apelman Z, Mogilner BM, Kessler I, et al. Prevention of premature labor by 17 alphahydroxyprogesterone caproate. American Journal Obstetrics and Gynecology 1985;151:574-7.

\section{References to ongoing studies \\ IRTC20180302038914N1 \{published data only\}}

IRCT20180302038914N1. Comparing efficacy of cerclage and adjunctive therapy (cerclage \& pessary) in prevention of preterm birth in pregnant women with cervical incompetence. en.irct.ir/trial/30016 (first received 7 May 2018).

NCT02678026 \{published data only\}

NCT02678026. Pessary as adjunctive therapy to cerclage for the prevention of preterm birth. clinicaltrials.gov/ct2/show/record/ NCT02678026 (first received 9 February 2016).

NCT02846909 \{published data only\}

NCT02846909. The effect of adjunctive use of vaginal progesterone after cerclage on prevention of 2 nd trimester miscarriage. clinicaltrials.gov/ct2/show/record/NCT02846909 (first received 27 July 2016). [NCT02846909]

\section{Additional references}

\section{Abdel-Aleem 2013}

Abdel-Aleem H, Shaaban OM, Abdel-Aleem MA. Cervical pessary for preventing preterm birth. Cochrane Database of Systematic Reviews 2013, Issue 5. Art. No: CD007873. [DOI: 10.1002/14651858.CD007873.pub3]

\section{Abdulaziz 2015}

Abdulaziz M, Stothers L, Lazare D, Macnab A. An integrative review and severity classification of complications related to pessary use in the treatment of female pelvic organ prolapse. Canadian Urological Association Journal: Journal de l'Association des Urologues du Canada 2015;9(5-6):E400-6. [PMID: 26225188]

\section{ACOG 2003}

ACOG. ACOG Practice Bulletin. Clinical management guidelines for obstetrician-gynecologist. Number 43, May 2003. Management of preterm labor. Obstetrics and Gynecology 2003;101(5 Pt 1):1039-47. [PMID: 12738177]

\section{ACOG 2014}

Anon. ACOG Practice Bulletin No.142: Cerclage for the management of cervical insufficiency. Obstetrics and Gynecology 2014;123(2 Pt 1):372-9. [PMID: 24451674]

\section{Alfirevic 2017}

Alfirevic Z, Stampalija T, Medley N. Cervical stitch (cerclage) for preventing preterm birth in singleton pregnancy. Cochrane Database of Systematic Reviews 2017, Issue 6. Art. No: CD008991. [DOI: 10.1002/14651858.CD008991.pub3]

\section{Alijahan 2014}

Alijahan R, Hazrati S, Mirzarahimi M, Pourfarzi F, Ahmadi Hadi P. Prevalence and risk factors associated with preterm birth in Ardabil, Iran. Iranian Journal of Reproductive Medicine 2014;12(1):47-56. [PMID: 24799861]

Cervical stitch (cerclage) in combination with other treatments for preventing spontaneous preterm birth in singleton pregnancies 


\section{Allen 2001}

Allen KG, Harris MA. The role of $\mathrm{n}-3$ fatty acids in gestation and parturition. Experimental Biology and Medicine 2001;226(6):498-506. [PMID: 11395920]

\section{Althuisius 2000}

Althuisius SM, Dekker GA, Van Geijn HP, Bekedam DJ, Hummel P. Cervical incompetence prevention randomized cerclage trial (CIPRACT): study design and preliminary results. American Journal of Obstetrics and Gynecology 2000;183(4):823-9. [PMID: 11035320]

\section{Althuisius 2003}

Althuisius SM, Dekker GA, Hummel P, Van Geijn HP. Cervical incompetence prevention randomized cerclage trial: emergency cerclage with bed rest versus bed rest alone. American Journal of Obstetrics and Gynecology 2003;189(4):907-10. [PMID: 14586323]

\section{Andrews 2006}

Andrews WW, Goldenberg RL, Hauth JC, Cliver SP, Copper R, Conner M. Interconceptional antibiotics to prevent spontaneous preterm birth: a randomized clinical trial. American Journal of Obstetrics and Gynecology 2006;194(3):617-23. [PMID: 16522388]

\section{Antczak-Judycka 2003}

Antczak-Judycka A, Sawicki W, Spiewankiewicz B Cendrowski K, Stelmachow J. Comparison of cerclage and cerclage pessary in the treatment of pregnant women with incompetent cervix and threatened preterm delivery [Porownanie skutecznosci leczenia szwem szyjkowym oraz pessarium kolnierzowym szyjki macicy u ciezarnych z niewydolnoscia ciesniowo-szyjkowa i zagrazajacym porodem przedwczesnym]. Ginekologia Polska 2003;74(10):1029-36. [PMID: 14669390]

\section{Arabin 2003}

Arabin B, Halbesma JR, Vork F, Hubener M, Van Eyck J. Is treatment with vaginal pessaries an option in patients with a sonographically detected short cervix? Journal of Perinatal Medicine 2003;31(2):122-33. [PMID: 12747228]

\section{Asiegbu 2020}

Asiegbu AC, Eleje GU, Ibeneme EM, Onyegbule OA, Chukwu LC, Egwim AV, et al. Combined insulin-like growth factor binding protein-1/interleukin-6 (Premaquick) versus fetal fibronectin for predicting preterm delivery among women with preterm contractions. International Journal of Gynaecology and Obstetrics 2020;149(2):171-7. [PMID: 32090329]

\section{Azem 2004}

Azem F, Blaucher A, Many A. Complications of early elective cervical cerclage. International Journal of Gynaecology and Obstetrics 2004;85(1):52-3. [PMID: 15050471]

\section{Barbosa 2020}

Barbosa M, Bek Helmig R, Hvidman L. Twin pregnancies treated with emergency or ultrasound-indicated cerclage to prevent preterm births. Journal of Maternal-fetal \& Neonatal Medicine 2020;33(19):3227-32. [PMID: 30688138]

\section{Baxter 2005}

Baxter JK, Airoldi J, Berghella V. Short cervical length after history-indicated cerclage: is a reinforcing cerclage beneficial? American Journal of Obstetrics and Gynecology 2005;193(3 Pt 2):1204-7. [PMID: 16157138]

\section{Becher 2009}

Becher N, Adams Waldorf K, Hein M, Uldbjerg N. The cervical mucus plug: structured review of the literature. Acta Obstetricia et Gynecologica Scandinavica 2009;88(5):502-13. [PMID: 19330570]

\section{Berghella 2006}

Berghella V, Rust OA, Althuisius SM. Short cervix on ultrasound: does indomethacin prevent preterm birth? American Journal of Obstetrics and Gynecology 2006;195(3):809-13. [PMID: 16949416]

\section{Berghella 2009}

Berghella V, Prasertcharoensuk W, Cotter A, Rasanen J, Mittal S, Chaithongwongwatthana $S$, et al. Does indomethacin prevent preterm birth in women with cervical dilatation in the second trimester? American Journal of Perinatology 2009;26(1):13-9. [PMID: 19021101]

\section{Blencowe 2012}

Blencowe H, Cousens S, Oestergaard MZ, Chou D, Moller AB, Narwal R, et al. National, regional, and worldwide estimates of preterm birth rates in the year 2010 with time trends since 1990 for selected countries: a systematic analysis and implications. Lancet 2012;379(9832):2162-72. [PMID: 22682464]

\section{Blencowe 2013}

Blencowe H, Cousens S, Chou D, Oestergaard M, Say L, Moller AB, et al. Born too soon: the global epidemiology of 15 million preterm births. Reproductive Health 2013;10 Suppl 1:S2. [PMID: 24625129]

\section{Caritis 2014}

Caritis SN, Venkataramanan R, Thom E, Harper M, Klebanoff MA, Sorokin Y, et al. Relationship between 17-alpha hydroxyprogesterone caproate concentration and spontaneous preterm birth. American Journal of Obstetrics and Gynecology 2014;210(2):128.e1-6. [PMID: 24113254]

\section{Castanon 2015}

Castanon A, Landy R, Brocklehurst P, Evans H, Peebles D, Singh $\mathrm{N}$, et al. Is the increased risk of preterm birth following excision for cervical intraepithelial neoplasia restricted to the first birth post treatment? BJOG 2015;122(9):1191-9. [DOI: 10.1111/1471-0528.13398] [PMID: 25854594]

\section{CDC 2014}

Preterm Birth. Reproductive Health. www.cdc.gov/ reproductivehealth/maternalinfanthealth/pretermbirth.htm) (accessed in 2015).

\section{Chang 2013}

Chang HH, Larson J, Blencowe H, Spong CY, Howson CP, Cairns-Smith $\mathrm{S}$, et al. Preventing preterm births: analysis of trends and potential reductions with interventions in 39 
countries with very high human development index. Lancet 2013;381(9862):223-34. [PMID: 23158883]

\section{Chughtai 2012}

Chughtai B, Spettel S, Kurman J, De E. Ambulatory pessary trial unmasks occult stress urinary incontinence. Obstetrics and Gynecology International 2012;2012:392027. [PMID: 21949665]

\section{Conde-Agudelo 2013}

Conde-Agudelo A, Romero R, Nicolaides K, Chaiworapongsa T, O'Brien JM, Cetingoz E, et al. Vaginal progesterone vs. cervical cerclage for the prevention of preterm birth in women with a sonographic short cervix, previous preterm birth, and singleton gestation: a systematic review and indirect comparison metaanalysis. American Journal of Obstetrics and Gynecology 2013;208(1):42.e1-18. [PMID: 23157855]

\section{Cram 2002}

Cram LF, Zapata MI, Toy EC, Baker B 3rd. Genitourinary infections and their association with preterm labor. American Family Physician 2002;65(2):241-8. [PMID: 11820488]

\section{Crowther 2014}

Crowther CA, Brown J, McKinlay CJ, Middleton P. Magnesium sulphate for preventing preterm birth in threatened preterm labour. Cochrane Database of Systematic Reviews 2014, Issue 8. Art. No: CD001060. [DOI: 10.1002/14651858.CD001060.pub2]

\section{Dabi 2017}

Dabi Y, Nedellec S, Bonneau C, Trouchard B, Rouzier R, Benachi A. Clinical validation of a model predicting the risk of preterm delivery. PIOS One 2017;12(2):e0171801. [PMID: 28182768]

\section{Defranco 2013}

Defranco EA, Valent AM, Newman T, Regan J, Smith J, Muglia LJ. Adjunctive therapies to cerclage for the prevention of preterm birth: a systematic review. Obstetrics and Gynecology International 2013;2013:528158. [PMID: 23606847]

\section{Devane 2007}

Devane D, Begley CM, Clarke M, Horey D, OBoyle C. Evaluating maternity care: a core set of outcome measures. Birth 2007;34(2):164-72. [PMID: 17542821]

\section{Dodd 2013}

Dodd JM, Jones L, Flenady V, Cincotta R, Crowther CA. Prenatal administration of progesterone for preventing preterm birth in women considered to be at risk of preterm birth. Cochrane Database of Systematic Reviews 2013, Issue 7. Art. No: CD004947. [DOI: 10.1002/14651858.CD004947.pub3]

\section{Durnwald 2009}

Durnwald CP, Lynch CD, Walker H, lams JD. The effect of treatment with 17 alpha-hydroxyprogesterone caproate on changes in cervical length over time. American Journal of Obstetrics and Gynecology 2009;201(4):410.e1-5. [PMID: 19716117]

\section{Eke 2016}

Eke AC, Chalaan T, Shukr G, Eleje GU, Okafor Cl. A systematic review and meta-analysis of progestogen use for maintenance tocolysis after preterm labor in women with intact membranes. International Journal of Gynecology and Obstetrics 2016;132(1):11-6.

\section{Eke 2019a}

Eke AC, Sheffield J, Graham EM. Adjuvant 17hydroxyprogesterone caproate in women with historyindicated cerclage: a systematic review and meta-analysis. Acta Obstetricia et Gynecologica Scandinavica 2019;98(2):139-53. [PMID: 30339274]

\section{Eke 2019b}

Eke AC, Sheffield J, Graham EM. 17a-hydroxyprogesterone caproate and the risk of glucose intolerance in pregnancy: a systematic review and meta-analysis. Obstetrics and Gynecology 2019;133(3):59-64.

\section{Eke 2019c}

Eke AC, Dooley KE, Sheffield JS. Pharmacologic research in pregnant women - time to get it right. New England Journal of Medicine 2019;380(14):1293-5.

\section{Eleje 2014}

Eleje GU, Adinma JI, Ghasi S, Ikechebelu JI, Igwegbe AO, Okonkwo JE, et al. Antibiotic susceptibility pattern of genital tract bacteria in pregnant women with preterm premature rupture of membranes in a resource-limited setting. International Journal of Gynecology and Obstetrics 2014;127(1):10-4. [PMID: 24994495]

\section{Eleje 2015a}

Eleje GU, Adinma JI, Ugwuanyi DC, Ikechebelu JI, Okafor CI, Ezeama CO, et al. Genital tract microbial isolate in women with preterm pre-labour rupture of membranes in resourceconstrained community setting. Journal of Obstetrics and Gynaecology 2015;35(5):465-8. [PMID: 25358030]

\section{Eleje 2015b}

Eleje GU, Ezugwu EC, Ogunyemi D, Eleje LI, Ikechebelu JI, Igwegbe AO, et al. Accuracy and cost-analysis of placental alpha-microglobulin-1 test in the diagnosis of premature rupture of fetal membranes in resource-limited community settings. Journal of Obstetrics and Gynaecology Research 2015;41(1):29-38. [PMID: 25164109]

\section{Eleje 2017}

Eleje GU, Ezugwu EC, Eke AC, Eleje LI, Ikechebelu JI, Ezebialu IU, et al. Accuracy of a combined insulin-like growth factor-binding protein-1/interleukin- 6 test (Premaquick) in predicting delivery in women with threatened preterm labor. Journal of Perinatal Medicine 2017;45(8):915-24. [PMID: 28236632]

\section{Eleje 2020}

Eleje GU, Ukah CO, Onyiaorah IV, Ezugwu EC, Ugwu EO, Ohayi SR, et al. Diagnostic value of Chorioquick for detecting chorioamnionitis in women with premature rupture of membranes. International Journal of Gynaecology and Obstetrics 2020;149(1):98-105. [PMID: 31907923] 


\section{Espinoza 2006}

Espinoza J, Erez O, Romero R. Preconceptional antibiotic treatment to prevent preterm birth in women with a previous preterm delivery. American Journal of Obstetrics and Gynecology 2006;194(3):630-7. [PMID: 16522390]

\section{Facchinetti 2007}

Facchinetti F, Paganelli S, Comitini G, Dante G, Volpe A. Cervical length changes during preterm cervical ripening: effects of 17-alpha-hydroxyprogesterone caproate. American Journal of Obstetrics and Gynecology 2007;196(5):453.e1-4, 421. [PMID: 17466698]

\section{Farr 2015}

Farr A, Kiss H, Hagmann M, Marschalek J, Husslein P, Petricevic L. Routine use of an antenatal infection screen-andtreat program to prevent preterm birth: long-term experience at a tertiary referral center. Birth 2015;42(2):173-80. [DOI: 10.1111/ birt.12154] [PMID: 25677078]

\section{Flenady 2013}

Flenady V, Hawley G, Stock OM, Kenyon S, Badawi N. Prophylactic antibiotics for inhibiting preterm labour with intact membranes. Cochrane Database of Systematic Reviews 2013, Issue 12. Art. No: CD000246. [DOI: 10.1002/14651858.CD000246.pub2]

\section{Flenady 2014}

Flenady V, Wojcieszek AM, Papatsonis DN, Stock OM, Murray L, Jardine LA, et al. Calcium channel blockers for inhibiting preterm labour and birth. Cochrane Database of Systematic Reviews 2014, Issue 6. Art. No: CD002255. [DOI: 10.1002/14651858.CD002255.pub2]

\section{Fonseca 2007}

Fonseca EB, Celik E, Parra M, Singh M, Nicolaides KH. Progesterone and the risk of preterm birth among women with a short cervix. New England Journal of Medicine 2007;357(5):462-9. [PMID: 17671254]

\section{Fox 1998}

Fox R, Holmes R, James M, Tuohy J, Wardle P. Serial transvaginal ultrasonography following McDonald cerclage and repeat suture insertion. Australian \& New Zealand Journal of Obstetrics \& Gynaecology 1998;38(1):27-30. [PMID: 9521385]

\section{Fox 2009}

Fox NS, Gelber SE, Kalish RB, Chasen ST. The recommendation for bed rest in the setting of arrested preterm labor and premature rupture of membranes. American Journal of Obstetrics and Gynecology 2009;200(2):165.e1-6. [PMID: 19019329]

\section{Gibbs 1992}

Gibbs RS, Romero R, Hillier SL, Eschenbach DA, Sweet RL. A review of premature birth and subclinical infection. American Journal of Obstetrics and Gynecology 1992;166:1515-28.

\section{Goldenberg 1994}

Goldenberg RL, Cliver SP, Bronstein J, Cutter GR, Andrews WW, Mennemeyer ST. Bed rest in pregnancy. Obstetrics and Gynecology 1994;84(1):131-6. [PMID: 8008308]

\section{Goldenberg 2008}

Goldenberg RL, Culhane JF, lams JD, Romero R. Epidemiology and causes of preterm birth. Lancet 2008;371(9606):75-84. [PMID: 18177778]

\section{Gomez 1998}

Gomez R, Romero R, Ghezzi F, Yoon BH, Mazor M, Berry SM. The fetal inflammatory response syndrome. American Journal of Obstetrics and Gynecology 1998;179(1):194-202. [PMID: 9704787]

\section{Goncalves 2002}

Goncalves LF, Chaiworapongsa T, Romero R. Intrauterine infection and prematurity. Mental Retardation and Developmental Disabilities Research Reviews 2002;8:3-13.

\section{Goya 2012}

Goya M, Pratcorona L, Merced C, Rodo C, Valle L, Romero A, et al. Cervical pessary in pregnant women with a short cervix (PECEP): an open-label randomised controlled trial. Lancet 2012;379(9828):1800-6. [PMID: 22475493]

\section{Gravett 1994}

Gravett MG, Witkin SS, Haluska GJ, Edwards JL, Cook MJ, Novy MJ. An experimental model for intraamniotic infection and preterm labor in rhesus monkeys. American Journal of Obstetrics and Gynecology 1994;171(6):1660-7. [PMID: 7802084]

\section{Harper 2010}

Harper M, Thom E, Klebanoff MA, Thorp J Jr, Sorokin Y, Varner MW, et al. Omega-3 fatty acid supplementation to prevent recurrent preterm birth: a randomized controlled trial. Obstetrics and Gynecology 2010;115(2 Pt 1):234-42. [PMID: 20093894]

\section{Hershkovitz 2008}

Hershkovitz R, Burstein E, Pinku A. Tightening McDonald cerclage suture under sonographic guidance. Ultrasound in Obstetrics \& Gynecology 2008;31(2):194-7. [PMID: 17935263]

\section{Higgins 2011}

Higgins JPT, Green S, editor(s). Cochrane Handbook for Systematic Reviews of Interventions Version 5.1.0 (updated March 2011). The Cochrane Collaboration, 2011. Available from www.handbook.cochrane.org.

\section{Hollier 2005}

Hollier LM. Preventing preterm birth: what works, what doesn't. Obstetrical \& Gynecological Survey 2005;60(2):124-31. [PMID: $15671901]$

\section{Hosny 2017}

Hosny AE, El-Khayat W, Kashef MT, Fakhry MN. Association between preterm labor and genitourinary tract infections caused by Trichomonas vaginalis, Mycoplasma hominis, Gramnegative bacilli, and coryneforms. Journal of the Chinese Medical Association 2017;80(9):575-81. [PMID: 28094234] 


\section{loscovich 2015}

Ioscovich A, Popov A, Gimelfarb Y, Gozal Y, Orbach-Zinger S, Shapiro J, et al. Anesthetic management of prophylactic cervical cerclage: a retrospective multicenter cohort study. Archives of Gynecology and Obstetrics 2015;291(3):509-12. [PMID: 25103960]

\section{Jongen 1997}

Jongen VH, Van Roosmalen J. Complications of cervical cerclage in rural areas. International Journal of Gynecology and Obstetrics 1997;57(1):23-6. [PMID: 9175665]

\section{Kataoka 2006}

Kataoka S, Yamada T, Chou K, Nishida R, Morikawa M, Minami M, et al. Association between preterm birth and vaginal colonization by mycoplasmas in early pregnancy. Journal of Clinical Microbiology 2006;44(1):51-5. [PMID: 16390947]

\section{Kenyon 2001}

Kenyon SL, Taylor DJ, Tarnow-Mordi W, ORACLE Collaborative Group. Broad-spectrum antibiotics for spontaneous preterm labour: the ORACLE II randomised trial. Lancet 2001;357(9261):989-94. [PMID: 11293641]

\section{Lai 2009}

Lai SK, Wang YY, Wirtz D, Hanes J. Micro- and macrorheology of mucus. Advanced Drug Delivery Reviews 2009;61(2):86-100. [PMID: 19166889]

\section{Lamont 2005}

Lamont RF. Can antibiotics prevent preterm birth - the pro and con debate. BJOG 2005;112 Suppl 1:67-73. [PMID: 15715599]

\section{Lawn 2005}

Lawn JE, Cousens S, Zupan J. 4 million neonatal deaths: when? where? why? Lancet 2005;365(9462):891-900. [PMID: 15752534]

\section{Lichter 2019}

Lichter KE, Sheffield J, Graham EM, Eke AC. Adjuvant 17hydroxyprogesterone caproate in women with ultrasoundindicated cerclage: a systematic review and meta-analysis. Journal of Maternal-fetal \& Neonatal Medicine 2019;1:18-22. [DOI: 10.1080/14767058.2019.1568406]

\section{Liem 2013}

Liem SM, Van Pampus MG, Mol BW, Bekedam DJ. Cervical pessaries for the prevention of preterm birth: a systematic review. Obstetrics and Gynecology International 2013;2013:576723. [PMID: 23606848]

\section{Likis 2012}

Likis FE, Edwards DR, Andrews JC, Woodworth AL, Jerome RN, Fonnesbeck $\mathrm{CJ}$, et al. Progestogens for preterm birth prevention: a systematic review and meta-analysis. Obstetrics and Gynecology 2012;120(4):897-907. [PMID: 22955308]

\section{Liu 2012}

Liu L, Johnson HL, Cousens S, Perin J, Scott S, Lawn JE, et al. Global, regional, and national causes of child mortality: an updated systematic analysis for 2010 with time trends since 2000. Lancet 2012;379(9832):2151-61. [PMID: 22579125]

\section{Maloni 2010}

Maloni JA. Antepartum bed rest for pregnancy complications: efficacy and safety for preventing preterm birth. Biological Research for Nursing 2010;12(2):106-24. [PMID: 20798159]

\section{Manuck 2016}

Manuck TA, Esplin MS, Biggio J, Bukowski R, Parry S, Zhang H, et al. Predictors of response to 17-alpha hydroxyprogesterone caproate for prevention of recurrent spontaneous preterm birth. American Journal of Obstetrics and Gynecology 2016;214(3):376.e1-8. [PMID: 26692181]

\section{Manuck 2016a}

Manuck TA, Stoddard GJ, Fry RC, Esplin MS, Varner MW. Nonresponse to 17-alpha hydroxyprogesterone caproate for recurrent spontaneous preterm birth prevention: clinical prediction and generation of a risk scoring system. American Journal of Obstetrics and Gynecology 2016;215(5):622.e1-8. [PMID: 27418444]

\section{Marlow 2012}

Marlow N. Full term; an artificial concept. Archives of Disease in Childhood. Fetal and Neonatal Edition 2012;97(3):F158-9. [PMID: 22262663]

\section{Mazor 1998}

Mazor M, Chaim W, Maymon E, Hershkowitz R, Romero R. The role of antibiotic therapy in the prevention of prematurity. Clinical Perinatology 1998;25:659-85.

\section{McDonald 1957}

McDonald IA. Suture of the cervix for inevitable miscarriage. Journal of Obstetrics and Gynaecology of the British Empire 1957;64(3):346-50. [PMID: 13449654]

\section{Meis 2003}

Meis PJ, Klebanoff M, Thom E, Dombrowski MP, Sibai B, Moawad AH, et al. Prevention of recurrent preterm delivery by 17 alpha-hydroxyprogesterone caproate. New England Journal of Medicine 2003;348(24):2379-85. [PMID: 12802023]

\section{MRC/RCOG 1993}

MRC/RCOG Working Party on Cervical Cerclage. Final report of the Medical Research Council/Royal College of Obstetricians and Gynaecologists multicentre randomised trial of cervical cerclage. British Journal of Obstetrics and Gynaecology 1993;100(6):516-23. [PMID: 8334085]

\section{Nelson 2017}

Nelson DB, McIntire DD, McDonald J, Gard J, Turrichi P, Leveno KJ. 17-alpha Hydroxyprogesterone caproate did not reduce the rate of recurrent preterm birth in a prospective cohort study. American Journal of Obstetrics and Gynecology 2017;216(6):600.e1-9. [PMID: 28223163]

\section{Newcomer 2000}

Newcomer J. Pessaries for the treatment of incompetent cervix and premature delivery. Obstetrical \& Gynecological Survey 2000;55(7):443-8. [PMID: 10885649]

Cervical stitch (cerclage) in combination with other treatments for preventing spontaneous preterm birth in singleton pregnancies 


\section{Newnham 2014}

Newnham JP, Dickinson JE, Hart RJ, Pennell CE, Arrese CA, Keelan JA. Strategies to prevent preterm birth. Frontiers in Immunology 2014;5:584. [PMID: 25477878]

\section{Ning 2017}

Ning A, Vladutiu CJ, Dotters-Katz SK, Goodnight WH, Manuck TA. Gestational age at initiation of 17-alpha hydroxyprogesterone caproate and recurrent preterm birth. American Journal of Obstetrics and Gynecology 2017;217(3):371.e1-7. [PMID: 28526452]

\section{Novy 1987}

Novy MJ, Ducsay CA, Stanczyk FZ. Plasma concentrations of prostaglandin F2 alpha and prostaglandin E2 metabolites after transabdominal and transvaginal cervical cerclage. American Journal of Obstetrics and Gynecology 1987;156:1543-52.

\section{Odibo 2007}

Odibo AO, Berghella V, To MS, Rust OA, Althuisius SM, Nicolaides KH. Shirodkar versus McDonald cerclage for the prevention of preterm birth in women with short cervical length. American Journal of Perinatology 2007;24(1):55-60. [PMID: 17195146]

\section{Olsen 2000}

Olsen SF, Secher NJ, Tabor A, Weber T, Walker JJ, Gluud C, Fish Oil Trials In Pregnancy (FOTIP) Team. Randomised clinical trials of fish oil supplementation in high risk pregnancies. BJOG 2000;107(3):382-95. [PMID: 10740336]

\section{Olsen 2007}

Olsen SF, Osterdal ML, Salvig JD, Weber T, Tabor A, Secher NJ. Duration of pregnancy in relation to fish oil supplementation and habitual fish intake: a randomised clinical trial with fish oil. European Journal of Clinical Nutrition 2007;61(8):976-85. [PMID: 17299499]

\section{Owen 2009}

Owen J, Hankins G, lams JD, Berghella V, Sheffield JS, PerezDelboy A, et al. Multicenter randomized trial of cerclage for preterm birth prevention in high-risk women with shortened midtrimester cervical length. American Journal of Obstetrics and Gynecology 2009;201(4):375.e1-8. [PMID: 19788970]

\section{O’Brien 2009}

O'Brien JM, DeFranco EA, Adair CD, Lewis DF, Hall DR, How H, et al. Effect of progesterone on cervical shortening in women at risk for preterm birth: secondary analysis from a multinational, randomized, double-blind, placebo-controlled trial. Ultrasound in Obstetrics \& Gynecology 2009;34:653-9.

\section{Patro-Malysza 2009}

Patro-Malysza J, Leszczynska-Gorzelak B, Marciniak B, Bartosiewicz J, Oleszczuk J. The use of pessaries in the treatment of incompetent cervix [Zastosowanie pessarow w leczeniu niewydolnosci ciesniowo-szyjkowej]. Ginekologia Polska 2009;80(1):54-8. [PMID: 19323061]

\section{Petrou 2003}

Petrou S, Mehta Z, Hockley C, Cook-Mozaffari P, Henderson J, Goldacre M. The impact of preterm birth on hospital inpatient admissions and costs during the first 5 years of life. Pediatrics 2003;112(6 Pt 1):1290-7. [PMID: 14654599]

\section{Petrou 2005}

Petrou S. The economic consequences of preterm birth during the first 10 years of life. BJOG 2005;112 Suppl 1:10-5. [PMID: 15715587]

\section{Pustotina 2017}

Pustotina O. Effectiveness of dydrogesterone, 17-OH progesterone and micronized progesterone in prevention of preterm birth in women with a short cervix. Journal of MaternalFetal \& Neonatal Medicine 2017;31(14):1830-8. [PMID: 28502186]

\section{Rafael 2014}

Rafael TJ, Berghella V, Alfirevic Z. Cervical stitch (cerclage) for preventing preterm birth in multiple pregnancy. Cochrane Database of Systematic Reviews 2014, Issue 9. Art. No: CD009166. [DOI: 10.1002/14651858.CD009166.pub2]

\section{RevMan 2014 [Computer program]}

Nordic Cochrane Centre, The Cochrane Collaboration Review Manager 5 (RevMan 5). Version 5.3. Copenhagen: Nordic Cochrane Centre, The Cochrane Collaboration, 2014.

\section{Romero 1998}

Romero R, Gomez R, Ghezzi F, Yoon BH, Mazor M, Edwin SS, et al. A fetal systemic inflammatory response is followed by the spontaneous onset of preterm parturition. American Journal of Obstetrics and Gynecology 1998;179(1):186-93. [PMID: 9704786]

\section{Romero 2013}

Romero R, Yeo L, Miranda J, Hassan SS, Conde-Agudelo A, Chaiworapongsa T. A blueprint for the prevention of preterm birth: vaginal progesterone in women with a short cervix. Journal of Perinatal Medicine 2013;41(1):27-44. [PMID: 23314512]

\section{Romero 2014a}

Romero R, Yeo L, Chaemsaithong P, Chaiworapongsa T, Hassan SS. Progesterone to prevent spontaneous preterm birth. Seminars in Fetal \& Neonatal Medicine 2014;19(1):15-26. [PMID: 24315687]

\section{Romero 2014b}

Romero R, Dey SK, Fisher SJ. Preterm labor: one syndrome, many causes. Science 2014;345(6198):760-5. [PMID: 25124429]

\section{Rush 1984}

Rush RW, Isaacs S, McPherson K, Jones L, Chalmers I, Grant A. $A$ randomized controlled trial of cervical cerclage in women at high risk of spontaneous preterm delivery. British Journal of Obstetrics and Gynaecology 1984;91(8):724-30. [PMID: 6380564]

\section{Saccone 2015a}

Saccone G, Berghella V. Omega-3 supplementation to prevent recurrent preterm birth: a systematic review and metaanalysis 
of randomized controlled trials. American Journal of Obstetrics and Gynecology 2015;213(2):135-40. [PMID: 25757636]

\section{Saccone 2015b}

Saccone G, Rust O, Althuisius S, Roman A, Berghella V. Cerclage for short cervix in twin pregnancies: systematic review and meta-analysis of randomized trials using individual patientlevel data. Acta Obstetricia et Gynecologica Scandinavica 2015;94(4):352-8. [PMID: 25644964]

\section{Saccone 2015c}

Saccone G, Berghella V. Omega-3 long chain polyunsaturated fatty acids to prevent preterm birth: a systematic review and meta-analysis. Obstetrics and Gynecology 2015;125(3):663-72. [PMID: 25730231]

\section{Sadowsky 2006}

Sadowsky DW, Adams KM, Gravett MG, Witkin SS, Novy MJ. Preterm labor is induced by intraamniotic infusions of interleukin-1beta and tumor necrosis factor-alpha but not by interleukin- 6 or interleukin-8 in a nonhuman primate model. American Journal of Obstetrics and Gynecology 2006;195(6):1578-89. [PMID: 17132473]

\section{Sanborn 1995}

Sanborn BM. Ion channels and the control of myometrial electrical activity. Seminars in Perinatology 1995;19(1):31-40. [PMID: 7538700]

\section{Sangkomkamhang 2015}

Sangkomkamhang US, Lumbiganon P, Prasertcharoensuk W, Laopaiboon M. Antenatal lower genital tract infection screening and treatment programs for preventing preterm delivery. Cochrane Database of Systematic Reviews 2015, Issue 2. Art. No: CD006178. [DOI: 10.1002/14651858.CD006178.pub3]

\section{Shirodkar 1955}

Shirodkar VN. A new method of operative treatment for habitual abortions in the second trimester of pregnancy. Antiseptic 1955;52:299-300.

\section{Simcox 2007}

Simcox R, Shennan A. Cervical cerclage: a review. International Journal of Surgery 2007;5(3):205-9. [PMID: 17509504]

\section{Simonazzi 2015}

Simonazzi G, Curti A, Bisulli M, Seravalli V, Saccone G, Berghella V. Cervical lacerations in planned versus labor cerclage removal: a systematic review. European Journal of Obstetrics, Gynecology, and Reproductive Biology 2015;193:19-22. [PMID: 26209805]

\section{Slager 2012}

Slager J, Lynne S. Treatment options and recommendations to reduce preterm births in women with short cervix. Journal of Midwifery \& Women's Health 2012;57 Suppl 1:S12-8. [PMID: 22776244]

\section{Smith 2009}

Smith V, Devane D, Begley CM, Clarke M, Higgins S. A systematic review and quality assessment of systematic reviews of randomised trials of interventions for preventing and treating preterm birth. European Journal of Obstetrics, Gynecology, and Reproductive Biology 2009;142(1):3-11. [PMID: 18996637]

\section{Smith 2015}

Smith J, DeFranco EA. Tocolytics used as adjunctive therapy at the time of cerclage placement: a systematic review. Journal of Perinatology 2015;35(8):561-5. [PMID: 25905689]

\section{Sosa 2015}

Sosa CG, Althabe F, Belizan JM, Bergel E. Bed rest in singleton pregnancies for preventing preterm birth. Cochrane Database of Systematic Reviews 2015, Issue 3. Art. No: CD003581. [DOI: 10.1002/14651858.CD003581.pub3]

\section{Spong 2007}

Spong CY. Prediction and prevention of recurrent spontaneous preterm birth. Obstetrics and Gynecology 2007;110(2 Pt 1):405-15. [PMID: 17666618]

\section{Tan 2006}

Tan TC, Devendra K, Tan LK, Tan HK. Tocolytic treatment for the management of preterm labour: a systematic review. Singapore Medical Journal 2006;47(5):361-6. [PMID: 16645683]

\section{Teitelman 1990}

Teitelman AM, Welch LS, Hellenbrand KG, Bracken MB. Effect of maternal work activity on preterm birth and low birth weight. American Journal of Epidemiology 1990;131(1):104-13. [PMID: 2293743]

\section{Tita 2007}

Tita AT, Cliver SP, Goepfert AR, Conner M, Goldenberg RL, Hauth JC, et al. Clinical trial of interconceptional antibiotics to prevent preterm birth: subgroup analyses and possible adverse antibiotic-microbial interaction. American Journal of Obstetrics and Gynecology 2007;197(4):367.e1-6. [PMID: 17904962]

\section{Umeigbo 2020}

Umeigbo BC, Modebe IA, Iloghalu IC, Eleje GU, Okoro CC, Umeononihu OS, et al. Outcomes of preterm labor and preterm births: a retrospective cross-sectional analytical study in a Nigerian single center population. Obstetrics and Gynecology Research 2020;3(1):17-28.

\section{Van 't Hooft 2016}

Van 't Hooft J, Duffy JM, Daly M, Williamson PR, Meher S, Thom E, et al. A core outcome set for evaluation of interventions to prevent preterm birth. Obstetrics and Gynecology 2016;127(1):49-58. [PMID: 26646133]

\section{Van Vliet 2014}

Van Vliet EO, Boormans EM, De Lange TS, Mol BW, Oudijk MA. Preterm labor: current pharmacotherapy options for tocolysis. Expert Opinion on Pharmacotherapy 2014;15(6):787-97. [PMID: 24533566]

\section{Vidaeff 2009}

Vidaeff AC, Ramin SM. Management strategies for the prevention of preterm birth: Part II - Update on cervical 
cerclage. Current Opinion in Obstetrics \& Gynecology 2009;21(6):485-90. [PMID: 19779339]

\section{Visintine 2008}

Visintine J, Airoldi J, Berghella V. Indomethacin administration at the time of ultrasound-indicated cerclage: is there an association with a reduction in spontaneous preterm birth? American Journal of Obstetrics and Gynecology 2008;198(6):643.e1-3. [PMID: 18221923]

\section{Vitoratos 1996}

Vitoratos N, Hassiakos D, Louridas C, Limuris G, Zourlas PA. Prostaglandin $\mathrm{F} 1 \mathrm{a}$ and prostaglandin E2 plasma levels after transvaginal cervical cerclage. Clinical and Experimental Obstetrics \& Gynecology 1996;23:21-5.

\section{Vogel 2014}

Vogel JP, Nardin JM, Dowswell T, West HM, Oladapo OT. Combination of tocolytic agents for inhibiting preterm labour. Cochrane Database of Systematic Reviews 2014, Issue 7. Art. No: CD006169. [DOI: 10.1002/14651858.CD006169.pub2]

\section{WHO 1977}

WHO. Recommended definitions, terminology and format for statistical tables related to the perinatal period and use of a

\section{CHARACTERISTICS OFSTUDIES}

Characteristics of included studies [ordered by study ID] new certificate for cause of perinatal deaths. Acta Obstetricia et Gynecologica Scandinavica 1977;56:247-53.

\section{Yoon 2008}

Yoon HJ, Hong JY, Kim SM. The effect of anesthetic method for prophylactic cervical cerclage on plasma oxytocin: a randomized trial. International Journal of Obstetric Anesthesia 2008;17(1):26-30. [PMID: 17698336]

\section{Yorifuji 2014}

Yorifuji T, Makino S, Yamamoto Y, Tanaka T, Itakura A, Takeda S. Effectiveness of delayed absorbable monofilament suture in emergency cerclage. Taiwanese Journal of Obstetrics \& Gynecology 2014;53(3):382-4. [PMID: 25286795]

\section{References to other published versions of this review \\ Eleje 2017a}

Eleje GU, Ikechebelu JI, Eke AC, Okam PC, Ezebialu IU, Ilika CP. Cervical cerclage in combination with other treatments for preventing preterm birth in singleton pregnancies. Cochrane Database of Systematic Reviews 2017, Issue 11. Art. No: CD012871. [DOI: 10.1002/14651858.CD012871]

* Indicates the major publication for the study

Miller 2014

\section{Study characteristics}

\begin{tabular}{|c|c|}
\hline Methods & Randomised controlled trial \\
\hline \multirow[t]{5}{*}{ Participants } & $\begin{array}{l}\text { Women older than } 18 \text { years of age with a singleton pregnancy between } 160 / 7 \text { and } 236 / 7 \text { weeks of ges- } \\
\text { tation undergoing an examination-indicated cerclage }\end{array}$ \\
\hline & Setting: Northwestern Memorial's Prentice Women's Hospital in Chicago, USA \\
\hline & $\begin{array}{l}\text { Dates of recruitment: enrollment began in March } 2010 \text { and was completed in November 2012. The fol- } \\
\text { low-up was completed in March } 2013 .\end{array}$ \\
\hline & $\begin{array}{l}\text { Inclusion criteria: a viable singleton gestation between } 16 \text { weeks } 0 / 7 \text { days to } 23 \text { weeks } 6 / 7 \text { days with in- } \\
\text { tact membranes who had opted for examination indicated cerclage }\end{array}$ \\
\hline & $\begin{array}{l}\text { Exclusion criteria: less than } 18 \text { years of age, HIV-infected pregnant women, major congenital anomalies } \\
\text { noted on anatomy ultrasound, temperature of } 100.4 \text { degrees Farenheit or greater, history of a prior cer- } \\
\text { clage during pregnancy, any contraindication to indomethacin, allergy to penicillin and clindamycin, or } \\
\text { if women had received indomethacin or any other antibiotics within } 1 \text { week }\end{array}$ \\
\hline
\end{tabular}

Interventions Experimental intervention: administration of indomethacin and antibiotics in addition to cerclage placement. 27 women were randomised to the intervention arm.

Comparison intervention: cerclage placement only. 26 women were randomised to the comparison (non-intervention arm).

Outcomes Gestational latency after cerclage placement, gestational age at delivery, preterm delivery (less than 24 weeks, less than 28 weeks, and less than 36 weeks of gestation), preterm premature rupture of membranes, gestational age at preterm premature rupture of membranes, chorioamnionitis at the time of 
Miller 2014 (Continued)

delivery, birthweight, neonatal intensive care admission, neonatal intensive care days, and neonatal survival until discharge

We contacted the trialist to ask for further data for all of our prespecified outcomes and obtained unpublished data relating to stillbirth, miscarriage, and preterm birth $<34$ weeks. Data for our other outcomes were not available.

$\begin{array}{ll}\text { Notes } & \text { Funding: source of study funding not clear } \\ \text { Study authors' declarations of interest: stated that authors had no potential conflicts of interest }\end{array}$

\section{Risk of bias}

Bias Authors' judgement Support for judgement

Random sequence genera- Low risk tion (selection bias)

Quote: "Those who consented to participate were randomized according to a random numbers table (though it was unclear whether this was achieved via a computer or not). Block sizes of 10 were used to prevent gross imbalances between study arms."

Allocation concealment Low risk
(selection bias)

Quote: "Allocation concealment used sealed, sequentially numbered opaque envelopes; once consent was obtained, the next sequentially numbered envelope was opened to reveal the card inside that indicated whether a woman was placed in the control (cerclage placement only) or intervention (administration of indomethacin and antibiotics in addition to cerclage placement) group."

\begin{tabular}{lll}
$\begin{array}{l}\text { Incomplete outcome data } \\
\text { (attrition bias) } \\
\text { All outcomes }\end{array}$ & Low risk & $\begin{array}{l}\text { Attrition from intervention group at follow-up was 4\% (1/27), and the attrition } \\
\text { from the control group was } 8 \%(2 / 26) .\end{array}$ \\
\hline $\begin{array}{l}\text { Selective reporting (re- } \\
\text { porting bias) }\end{array}$ & Low risk & $\begin{array}{l}\text { Trial registration available. Trial outcomes were fully reported between the } 2 \\
\text { groups. }\end{array}$ \\
\hline $\begin{array}{l}\text { Blinding of outcome as- } \\
\begin{array}{l}\text { sessment (detection bias) } \\
\text { All outcomes }\end{array}\end{array}$ & Unclear risk & Not described \\
\hline $\begin{array}{l}\text { Blinding of participants } \\
\text { and personnel (perfor- } \\
\text { mance bias) } \\
\text { All outcomes }\end{array}$ & High risk & $\begin{array}{l}\text { No attempt at blinding and women and staff would be aware of treatment al- } \\
\text { location because of different modes of administration }\end{array}$ \\
\hline $\begin{array}{l}\text { Other bias } \\
\text { L }\end{array}$ & Low risk & $\begin{array}{l}\text { Groups appeared similar at baseline and no other sources of bias were appar- } \\
\text { ent. }\end{array}$ \\
\hline
\end{tabular}

Toplis 1980

\section{Study characteristics}

\begin{tabular}{ll}
\hline Methods & Randomised control trial \\
\hline Participants & Women with a singleton pregnancy who had a cervical cerclage under general anaesthesia at 13 to \\
& 21 weeks' gestation. All women had a AFP level estimation at 16 weeks' gestation. In 18 women ( 9 in \\
each group), cervical cerclage was performed for a history of previous spontaneous mid-trimester abor- \\
tion; but in the remaining 2 women ( 1 in each group) there was cervical dilatation and effacement, both \\
women previously having had a first trimester vacuum termination of pregnancy. All women were kept
\end{tabular}

Cervical stitch (cerclage) in combination with other treatments for preventing spontaneous preterm birth in singleton pregnancies 
Toplis 1980 (Continued)

in bed for 24 hours after operation and were followed throughout the pregnancy, labour and the puerperium.

Setting: Queen Charlotte's Maternity Hospital and Chelsea Hospital for Women, London.

Dates of recruitment: not stated

Inclusion criteria: not stated

Exclusion criteria: not stated

Interventions

Experimental intervention: patients (mean gestation $16.3 \pm 0.5$ (SEM) weeks) were given intravenous salbutamol ( $4 \mathrm{mg}$ in $500 \mathrm{~mL}$ of $5 \%$ dextrose every 6 hours for 24 hours) after cervical cerclage and codeine if they required analgesia.

Comparison intervention: patients (mean gestation $14.9 \pm 0.4$ (SEM) weeks) were given $15 \mathrm{mg}$ of omnopon by intramuscular injection every 6 hours for 24 hours after cervical cerclage.

$\begin{array}{ll}\text { Outcomes } & \text { Levels of 13,14-dihydro-15-keto-prostaglandin F2a (PGFM) in } 2 \text { groups of women } \\ & \text { Number of abortion cases between } 3 \text { and } 7 \text { weeks after cerclage } \\ \text { Number of cases with spontaneous preterm delivery } \\ \text { Number of cases with cervical suture removed at } 37 \text { weeks' gestation } \\ \text { Number of cases with healthy infants after delivery } \\ \text { Notes } & \begin{array}{l}\text { Funding: not reported } \\ \text { Study authors' declarations of interest: not stated in the published report }\end{array}\end{array}$

\section{Risk of bias}

\begin{tabular}{lll} 
Bias & Authors' judgement & Support for judgement \\
\hline $\begin{array}{l}\text { Random sequence genera- } \\
\text { tion (selection bias) }\end{array}$ & Unclear risk & Not described \\
\hline $\begin{array}{l}\text { Allocation concealment } \\
\text { (selection bias) }\end{array}$ & Unclear risk & Not described \\
\hline $\begin{array}{l}\text { Incomplete outcome data } \\
\text { (attrition bias) } \\
\text { All outcomes }\end{array}$ & Low risk & There was no mention of sample attrition or missing data \\
\hline
\end{tabular}

$\begin{array}{ll}\begin{array}{l}\text { Selective reporting (re- } \\ \text { porting bias) }\end{array} & \text { High risk } \\ & \begin{array}{l}\text { Trial registration was not stated. Some of the outcomes were not fully report- } \\ \text { ed, e.g. reported as no significant differences between groups. The results re- } \\ \text { ported were as a whole, not according to the arm into which each participant } \\ \text { was randomised. }\end{array}\end{array}$

Blinding of outcome as- Unclear risk Not described
sessment (detection bias) All outcomes

\begin{tabular}{|c|c|c|}
\hline $\begin{array}{l}\text { Blinding of participants } \\
\text { and personnel (perfor- } \\
\text { mance bias) } \\
\text { All outcomes }\end{array}$ & High risk & $\begin{array}{l}\text { No attempt at blinding and women and staff would be aware of treatment al- } \\
\text { location because of different modes of administration. }\end{array}$ \\
\hline Other bias & Low risk & No other sources of bias were identified. \\
\hline
\end{tabular}

Cervical stitch (cerclage) in combination with other treatments for preventing spontaneous preterm birth in singleton pregnancies 
AFP: serum alpha-fetoprotein HIV: human immunodeficiency virus

PGFM: 13,14-dihydro-15-keto-prostaglandin F2a

SEM:Standard error of mean

Characteristics of excluded studies [ordered by study ID]

\begin{tabular}{ll}
\hline Study & Reason for exclusion \\
\hline Althuisius 2002 & $\begin{array}{l}\text { The study was a randomised trial of women allocated to therapeutic cerclage and bed rest versus } \\
\text { just bed rest and with the aim of comparing the effects of therapeutic cerclage and bed rest versus } \\
\text { just bed rest on cervical length with respect to the risk of preterm delivery. Therefore, cervical cer- } \\
\text { clage placement was applied to only } 1 \text { arm of the study. }\end{array}$
\end{tabular}

Barinov 2017

This study was a randomised study of the use of Arabin pessary versus cervical cerclage versus progesterone with progesterone-only management of pregnant women at high risk of preterm birth. Only 1 arm out of the 3 arms of the study received cervical cerclage. The study did not specify what type of progesterone was used (vaginal progesterone or intramuscular 17-alpha-hydroxyprogesterone caproate). droxyprogesterone caproate for prevention of preterm birth in women with prior spontaneous preterm birth and cervical length $<25 \mathrm{~mm}$. The effect of 17-alpha-hydroxyprogesterone caproate was analysed separately for cerclage and no-cerclage groups.

Therefore, cervical cerclage placement was applied to only 1 arm of the study.

This was a letter to the editor following the Stetson 2016 study, which was a retrospective cohort study aimed at examining the differences in perinatal outcomes among women with a prior preterm birth who received cerclage compared with cerclage plus 17-alpha-hydroxyprogesterone caproate. ter-randomised trial) aimed at investigating the effect of surgical procedures at 15 weeks' gestation (amniocentesis or cervical cerclage), with or without postoperative ritodrine prophylaxis, on uterine blood flow velocity waveforms and maternal heart rate. aimed at determining whether cerclage with vaginal progesterone will: (1) reduce the overall spontaneous preterm birth rate, (2) prolong pregnancy latency, and (3) improve neonatal outcomes compared to vaginal progesterone alone.

\section{Endl 1982 \\ This study was a longitudinal study (not a randomised controlled trial or cluster-randomised trial) on prophylactic oral long-term use of tocolysis and cerclage for the prolongation of twin pregnan- cy. The study did not include singleton pregnancies.}

\section{Ionescu 2012}

The study was a randomised trial of women with prior spontaneous preterm birth at 16-33 6/7 weeks, singleton gestation and cervical length of $<25 \mathrm{~mm}$ between 16 and $226 / 7$ weeks who received 17-alpha-hydroxyprogesterone caproate and were randomised to cerclage or no cerclage. Therefore, cervical cerclage placement was applied to only 1 arm of the study.

\begin{tabular}{ll}
\hline Jung 2016 & $\begin{array}{l}\text { The study was a retrospective cohort study (not a randomised controlled trial or cluster-ran- } \\
\text { domised trial) that assessed the effect of vaginal progesterone as an adjuvant therapy to physi- } \\
\text { cal-exam-indicated cervical cerclage. }\end{array}$ \\
\hline Keeler 2009 & $\begin{array}{l}\text { This was a randomised controlled trial aiming to determine pregnancy outcome in patients with } \\
\text { short cervix on transvaginal ultrasound between } 16 \text { and } 24 \text { weeks' gestation treated with Mc- } \\
\text { Donald cerclage compared to weekly intramuscular injections of } 17 \text {-alpha-hydroxyprogesterone } \\
\text { caproate, but cervical cerclage placement was applied to only } 1 \text { arm of the study. }\end{array}$
\end{tabular}

Cervical stitch (cerclage) in combination with other treatments for preventing spontaneous preterm birth in singleton pregnancies (Review)

Copyright $\odot 2020$ The Cochrane Collaboration. Published by John Wiley \& Sons, Ltd. 


\section{Study \\ Reason for exclusion}

Mackeen 2013

This was a retrospective cohort study (not a randomised controlled trial or cluster-randomised trial) of women aimed at determining whether 17-alpha-hydroxyprogesterone caproate reduces the incidence of preterm birth in women with a history-indicated cerclage.

Nasr 2011

This study was a prospective randomised controlled trial of 58 women with a history and ultrasound findings suggestive of cervical insufficiency, randomised to receive $0.6 \mathrm{mg}$ of $\mathrm{N}$ acetyl-cysteine (intervention group), while the group that did not receive $\mathrm{N}$ acetyl cysteine served as controls. $\mathrm{N}$ acetyl cysteine use in this trial was not as an adjunctive therapy to cervical cerclage.

NCT03837288

This study is an ongoing randomised controlled trial of vaginal progesterone with and without cervical cerclage for singleton pregnancy in women with progressive cervical length shortening; the intervention arm received cervical cerclage plus vaginal progesterone while the control group received vaginal progesterone alone. Therefore, only $1 \mathrm{arm}$ is receiving cervical cerclage.

Pustotina 2018

This was a randomised controlled trial aimed at comparing the efficacy of dydrogesterone, 17-alpha-hydroxyprogesterone caproate and oral or vaginal micronised progesterone with cerclage for the prevention of preterm birth in women with a short cervix. Women were randomised to receive dydrogesterone, 17-alpha-hydroxyprogesterone caproate or oral/vaginal micronised progesterone to which 15 women underwent cerclage after 1 week of therapy. Cervical cerclage placement was applied to only 15 out of 95 women that took part in the study but no arm in the study received cervical cerclage placement only.

Rafael 2011 The study was a retrospective cohort study (not a randomised controlled trial or cluster-randomised trial) of women with a previous spontaneous preterm birth and current ultrasound-indicated cerclage with the study group consisting of women treated with 17-alpha-hydroxyprogesterone caproate and the control group consisting of women not treated with 17-alpha-hydroxyprogesterone caproate.

Ragab 2015

The study was a randomised study aimed at measuring the outcome of emergency cervical cerclage combined with progesterone versus progesterone alone in pregnancy prolongation for preterm labour at 24-28 weeks, but cervical cerclage placement was applied to only 1 arm of the study.

Rebarber 2008

The study was a retrospective cohort study (not a randomised controlled trial or cluster-randomised trial) of singleton gestations aimed at comparing the incidence of recurrent spontaneous preterm delivery in patients with cervical cerclage treated with weekly 17-alpha-hydroxyprogesterone caproate injections versus daily outpatient nursing surveillance without 17-alpha-hydroxyprogesterone caproate.

Roman 2018

This was a retrospective case control study (not a randomised controlled trial or cluster-randomised trial) aimed at evaluating the effect of rescue adjuvant vaginal progesterone in women with ongoing, transvaginal ultrasound-confirmed cervical shortening despite cervical cerclage.

Samson 2018

The study was a retrospective cohort study (not a randomised controlled trial or cluster-randomised trial) aimed at investigating the role of adjuvant 17-alpha-hydroxyprogesterone caproate in reducing the risk of preterm delivery $<34$ weeks and adverse perinatal outcomes in women with cervical insufficiency undergoing prophylactic cerclage with a cohort receiving adjuvant 17 -alpha-hydroxyprogesterone caproate $(n=43)$, and controls with cerclage alone $(n=59)$.

Sinkey 2018

This was a retrospective cohort study (not a randomised controlled trial or cluster-randomised trial) aimed at evaluating the outcomes among pregnancies with cerclage as compared to cerclage and adjunctive progesterone.

Stetson 2016

This was a retrospective cohort study (not a randomised control trial or cluster-randomised trial) aimed at examining the differences in perinatal outcomes among women with a prior preterm birth who received cerclage compared with cerclage plus 17-alpha-hydroxyprogesterone caproate. 


\begin{tabular}{ll}
\hline Study & Reason for exclusion \\
\hline Szychowski 2012 & $\begin{array}{l}\text { This was a randomised controlled trial aiming to assess cerclage benefit in women with short } \\
\text { cervix also receiving 17-alpha-hydroxyprogesterone caproate to prevent recurrent preterm birth, } \\
\text { but cervical cerclage placement was applied to only } 1 \text { arm of the study. }\end{array}$ \\
\hline Yemini 1985 & $\begin{array}{l}\text { This was a double-blind placebo-controlled randomised trial where treatments were randomly di- } \\
\text { vided into } 2 \text { groups, viz: either 17-alpha-hydroxyprogesterone caproate, } 250 \text { mg by intramuscular } \\
\text { injection once a week, or a placebo, without any of the participants or arms receiving cervical cer- } \\
\text { clage. }\end{array}$
\end{tabular}

Characteristics of ongoing studies [ordered by study ID]

\section{IRTC20180302038914N1}

\begin{tabular}{|c|c|}
\hline Study name & $\begin{array}{l}\text { Comparing efficacy of cerclage and adjunctive therapy (cerclage \& pessary) in prevention of } \\
\text { preterm birth in pregnant women with cervical incompetence }\end{array}$ \\
\hline Methods & Randomised controlled trial \\
\hline Participants & $\begin{array}{l}\text { Women between } 18 \text { to } 42 \text { years of age with cervical insufficiency } \\
\text { Setting: Royal Institute for Treatment, No 2, Hafez Street, Tehran, Iran } \\
\text { Dates of recruitment: April 10th } 2018 \text { to October } 22 \text { nd } 2018 \\
\text { Inclusion criteria: } \\
\text { - Gestational age of } 14+0 \text { to } 26+0 \text { weeks } \\
\text { - Singleton gestation } \\
\text { - Presence of cervical insufficiency } \\
\text { - Intact membranes } \\
\text { Exclusion criteria: } \\
\text { - Age < } 18 \text { years } \\
\text { - Age }>42 \text { years } \\
\text { - Multiple pregnancy } \\
\text { - Cervical dilatation }>4 \mathrm{~cm} \\
\text { - Uterine contractions in the patient with a cerclage } \\
\text { - Vaginal bleeding } \\
\text { - Vaginal discharge }\end{array}$ \\
\hline
\end{tabular}

Interventions: cerclage and adjunctive therapy (cerclage and pessary)

Control group: includes pregnant women with cervical insufficiency who have had cerclage surgery (routine care)

\begin{tabular}{ll}
\hline Outcomes & Primary outcome: gestational age at delivery greater than 34 weeks of gestation \\
& Secondary outcome: patient satisfaction \\
\hline Starting date & The actual trial starting date was not stated. The stated expected start date was 2018-04-10. \\
\hline Contact information & Mitra Arjmandi Far: E-mail: m-arjmandifar@razi.tums.ac.ir \\
\hline Notes & The results of this study are yet to be reported. \\
\hline
\end{tabular}




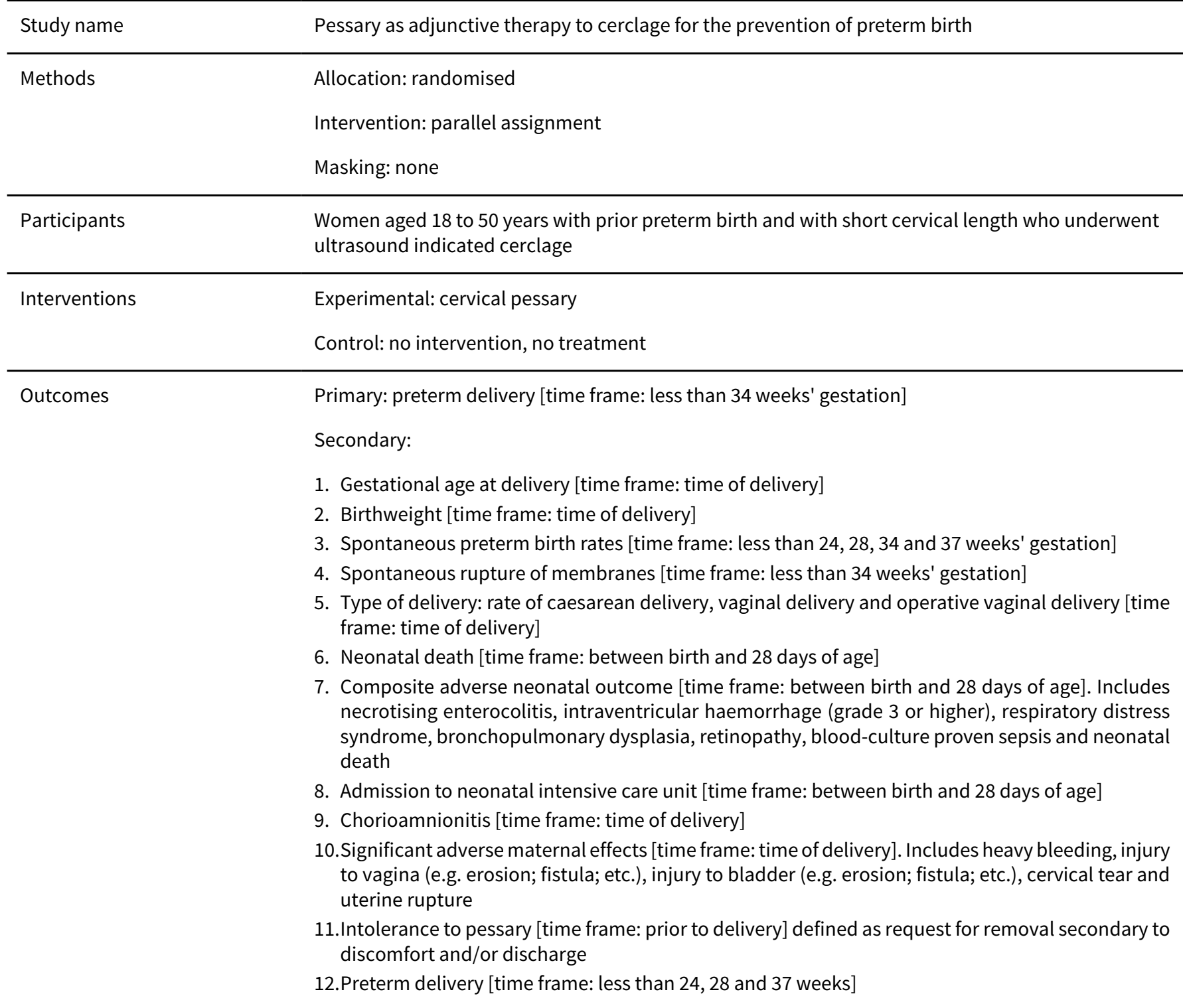

\begin{tabular}{ll}
\hline Starting date & January 2016 \\
\hline Contact information & Trial author contacted and responded. The trial has not started yet. \\
\hline Notes & We will reassess and include results in the next update. \\
\hline
\end{tabular}

\section{NCT02846909}

$\begin{array}{ll}\text { Study name } & \begin{array}{l}\text { The effect of adjunctive use of vaginal progesterone after cerclage on prevention of } 2 \text { nd trimester } \\ \text { miscarriage }\end{array}\end{array}$

Methods

Allocation: randomised.

Intervention: parallel assignment. 
NCT02846909 (Continued)

Masking: none

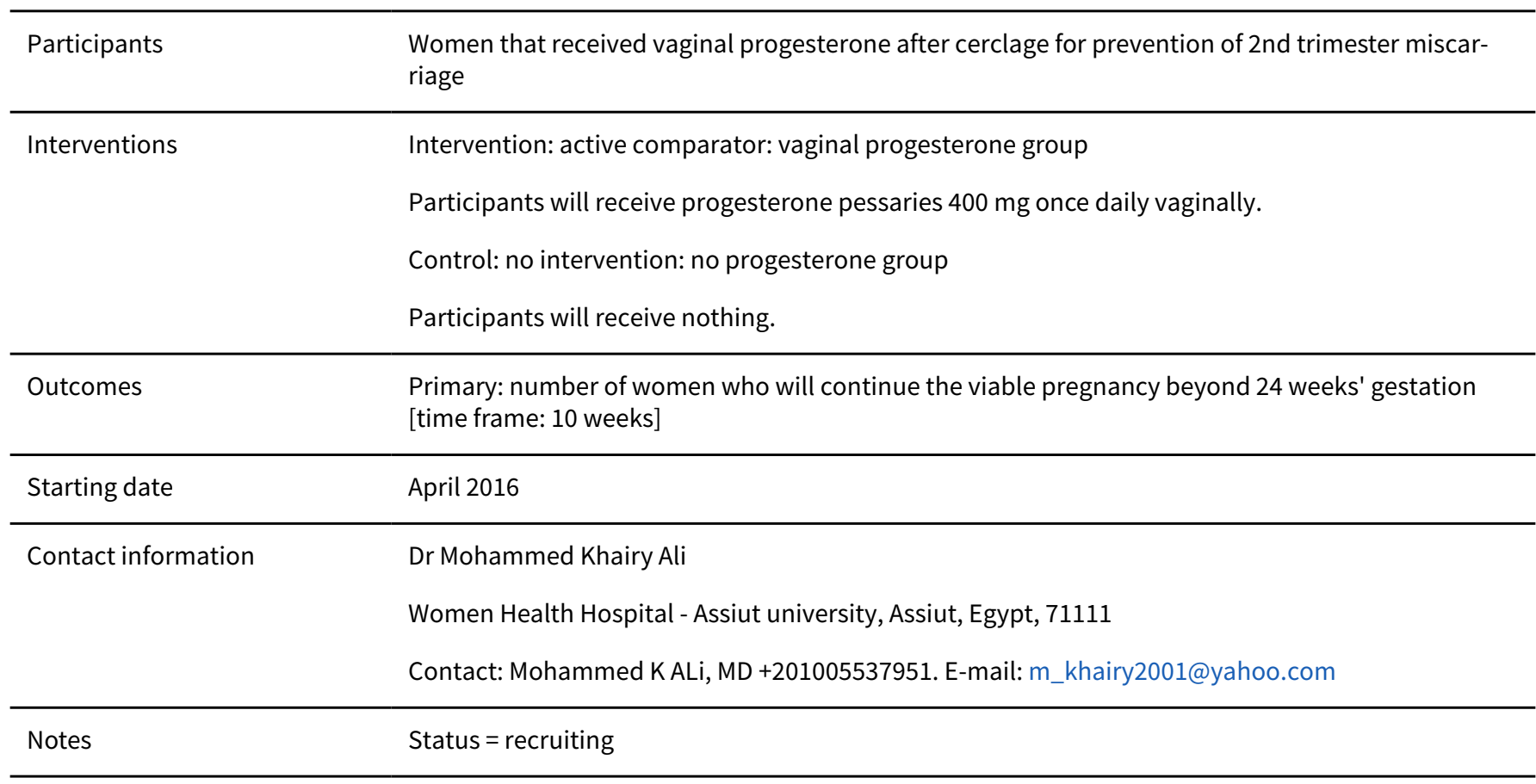

DATA AND ANALYSES

Comparison 1. Cervical cerclage in combination with antibiotic and tocolytic versus cervical cerclage alone

\begin{tabular}{|c|c|c|c|c|}
\hline Outcome or subgroup title & No. of studies & $\begin{array}{l}\text { No. of partici- } \\
\text { pants }\end{array}$ & Statistical method & Effect size \\
\hline 1.1 Serious neonatal morbidity & 1 & 50 & $\begin{array}{l}\text { Risk Ratio (M-H, Random, } \\
95 \% \mathrm{Cl} \text { ) }\end{array}$ & $0.62[0.31,1.24]$ \\
\hline $\begin{array}{l}\text { 1.2 Perinatal loss: all - including mis- } \\
\text { carriages and stillbirth (but no data for } \\
\text { neonatal death) }\end{array}$ & 1 & 50 & $\begin{array}{l}\text { Risk Ratio (M-H, Random, } \\
95 \% \mathrm{Cl})\end{array}$ & $0.46[0.13,1.64]$ \\
\hline $\begin{array}{l}1.3 \text { Stillbirth (intrauterine fetal death } \\
\text { at } 24 \text { weeks or more) }\end{array}$ & 1 & 50 & $\begin{array}{l}\text { Risk Ratio (M-H, Fixed, 95\% } \\
\mathrm{Cl} \text { ) }\end{array}$ & Not estimable \\
\hline $\begin{array}{l}1.4 \text { Miscarriages (perinatal loss before } \\
24 \text { weeks) }\end{array}$ & 1 & 50 & $\begin{array}{l}\text { Risk Ratio (M-H, Random, } \\
95 \% \mathrm{Cl} \text { ) }\end{array}$ & $0.46[0.13,1.64]$ \\
\hline 1.5 Preterm birth $<28$ weeks & 1 & 50 & $\begin{array}{l}\text { Risk Ratio (M-H, Random, } \\
95 \% \mathrm{Cl} \text { ) }\end{array}$ & $0.59[0.27,1.27]$ \\
\hline 1.6 Preterm birth $<34$ weeks & 1 & 50 & $\begin{array}{l}\text { Risk Ratio (M-H, Fixed, 95\% } \\
\mathrm{Cl})\end{array}$ & $0.78[0.44,1.40]$ \\
\hline 1.7 Preterm birth $<37$ weeks & 1 & 50 & $\begin{array}{l}\text { Risk Ratio (M-H, Random, } \\
95 \% \mathrm{Cl} \text { ) }\end{array}$ & $0.86[0.54,1.38]$ \\
\hline
\end{tabular}

Cervical stitch (cerclage) in combination with other treatments for preventing spontaneous preterm birth in singleton pregnancies 


\begin{tabular}{|c|c|c|c|c|}
\hline Outcome or subgroup title & No. of studies & $\begin{array}{l}\text { No. of partici- } \\
\text { pants }\end{array}$ & Statistical method & Effect size \\
\hline 1.8 Serious intracranial pathology & 1 & 50 & $\begin{array}{l}\text { Risk Ratio (M-H, Random, } \\
95 \% \mathrm{Cl})\end{array}$ & Not estimable \\
\hline 1.9 Serious respiratory morbidity & 1 & 50 & $\begin{array}{l}\text { Risk Ratio (M-H, Random, } \\
95 \% \mathrm{Cl} \text { ) }\end{array}$ & $0.46[0.13,1.64]$ \\
\hline 1.10 Necrotising enterocolitis & 1 & 50 & $\begin{array}{l}\text { Risk Ratio (M-H, Random, } \\
95 \% \mathrm{Cl})\end{array}$ & $0.46[0.04,4.77]$ \\
\hline 1.11 Retinopathy of prematurity & 1 & 50 & $\begin{array}{l}\text { Risk Ratio (M-H, Random, } \\
95 \% \mathrm{Cl})\end{array}$ & $0.92[0.14,6.05]$ \\
\hline $\begin{array}{l}1.12 \text { Maternal infection, including } \\
\text { chorioamnionitis, requiring interven- } \\
\text { tion (chorioamnionitis) }\end{array}$ & 1 & 50 & $\begin{array}{l}\text { Risk Ratio (M-H, Random, } \\
95 \% \mathrm{Cl})\end{array}$ & $1.38[0.44,4.32]$ \\
\hline $\begin{array}{l}\text { 1.13 Preterm premature rupture of } \\
\text { membranes }\end{array}$ & 1 & 50 & $\begin{array}{l}\text { Risk Ratio (M-H, Fixed, 95\% } \\
\mathrm{Cl})\end{array}$ & $2.08[1.12,3.87]$ \\
\hline
\end{tabular}

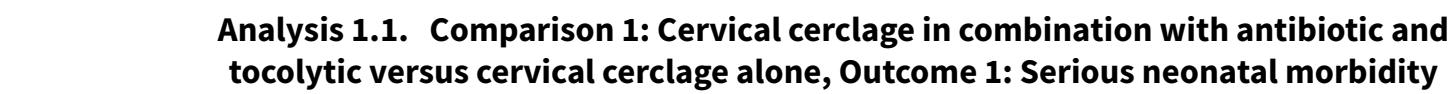

\begin{tabular}{|c|c|c|c|c|c|c|c|}
\hline & Cerclage & or more & Cercla & alone & & Risk Ratio & Risk Ratio \\
\hline tudy or Subgroup & Events & Total & Events & Total & Weight & M-H, Random, 95\% CI & M-H, Random, 95\% C \\
\hline
\end{tabular}

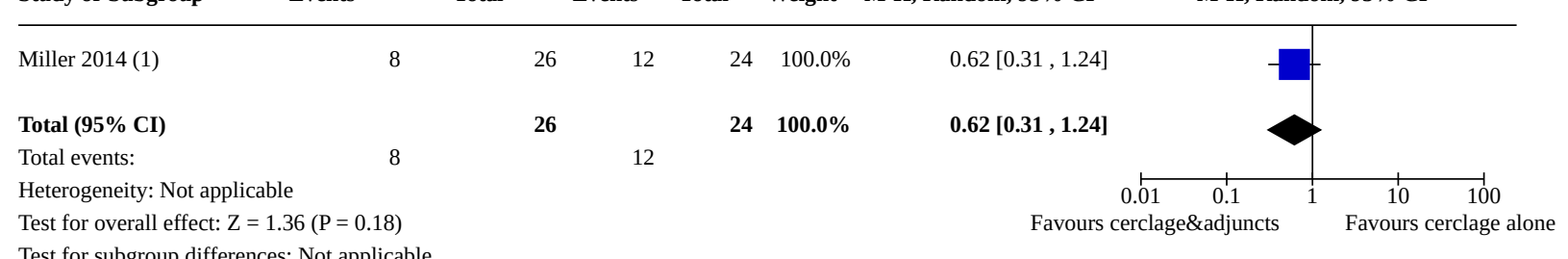

Test for subgroup differences: Not applicable

Footnotes

(1) Note: Table 3 in Miller 2014 reports composite adverse outcome included respiratory distress syndrome, necrotizing enterocolitis, intraventricular hemorrhage, retinopath

Analysis 1.2. Comparison 1: Cervical cerclage in combination with antibiotic and tocolytic versus cervical cerclage alone, Outcome 2: Perinatal loss: all - including miscarriages and stillbirth (but no data for neonatal death)

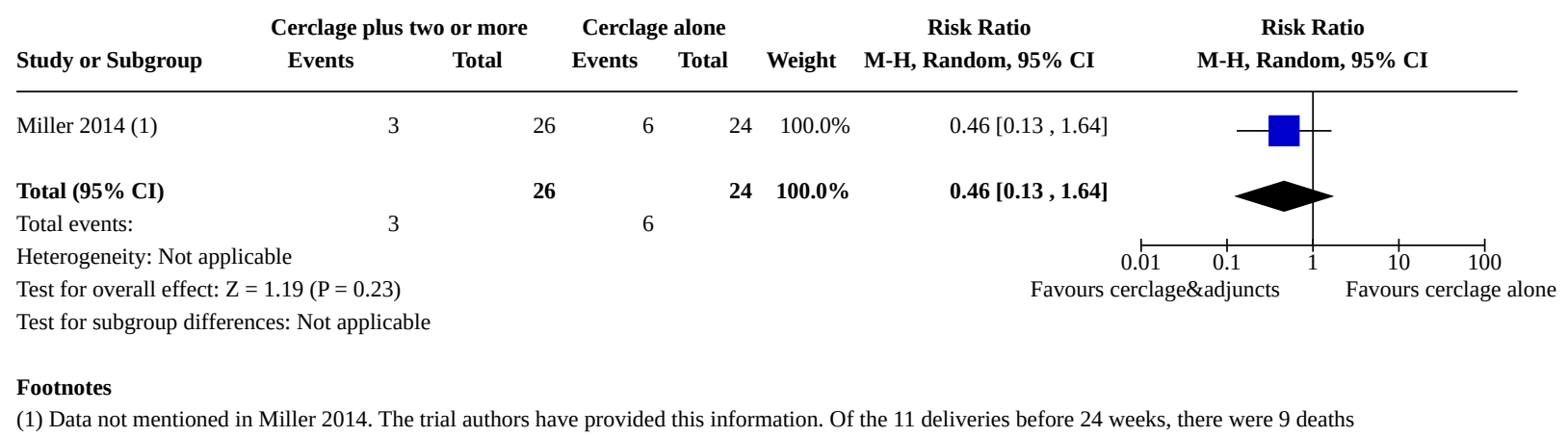

Cervical stitch (cerclage) in combination with other treatments for preventing spontaneous preterm birth in singleton pregnancies 
Analysis 1.3. Comparison 1: Cervical cerclage in combination with antibiotic and tocolytic versus cervical cerclage alone, Outcome 3: Stillbirth (intrauterine fetal death at 24 weeks or more)

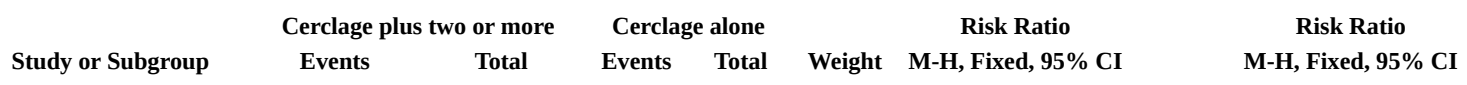

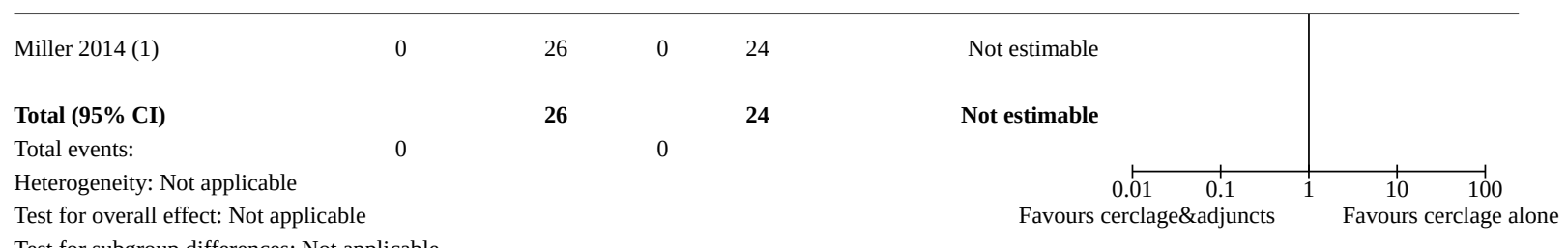

Footnotes

(1) Information not in publihsed trial report for Miller 2014. We requested additional information from the trialist and they confirmed that there were no intra-uterine feta.

\section{Analysis 1.4. Comparison 1: Cervical cerclage in combination with antibiotic and tocolytic versus cervical cerclage alone, Outcome 4: Miscarriages (perinatal loss before 24 weeks)}

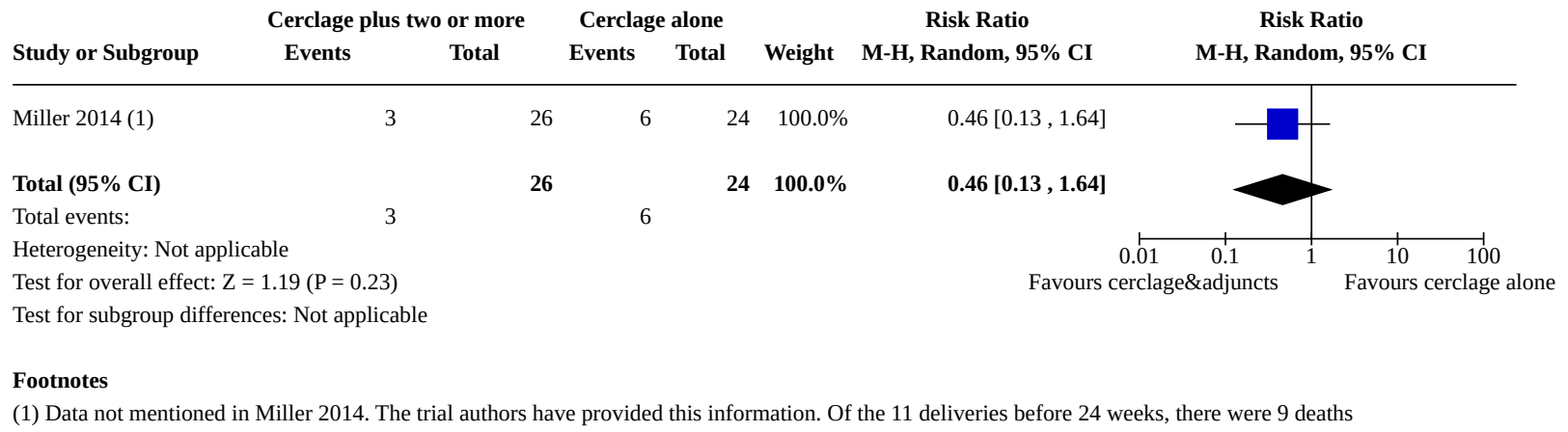

\section{Analysis 1.5. Comparison 1: Cervical cerclage in combination with antibiotic and tocolytic versus cervical cerclage alone, Outcome 5: Preterm birth $<28$ weeks}

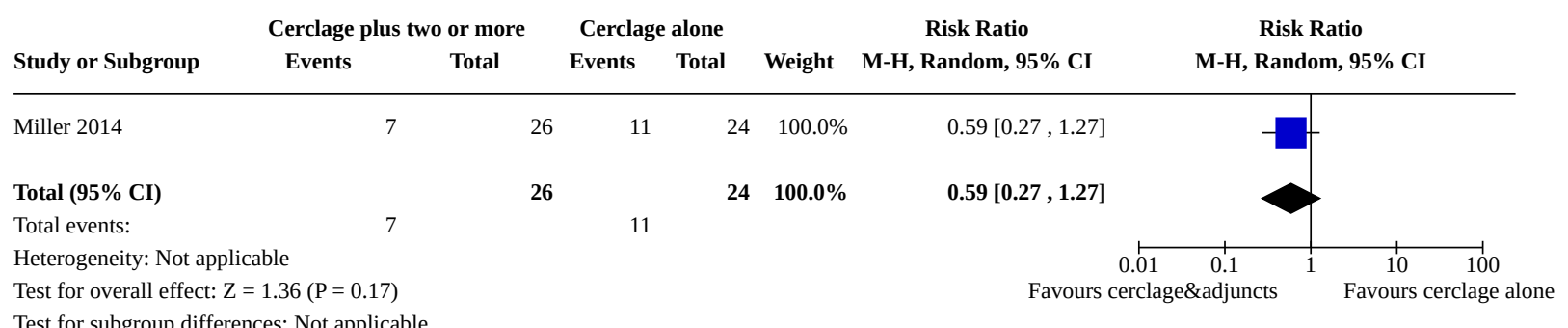


Analysis 1.6. Comparison 1: Cervical cerclage in combination with antibiotic and tocolytic versus cervical cerclage alone, Outcome 6: Preterm birth $<34$ weeks

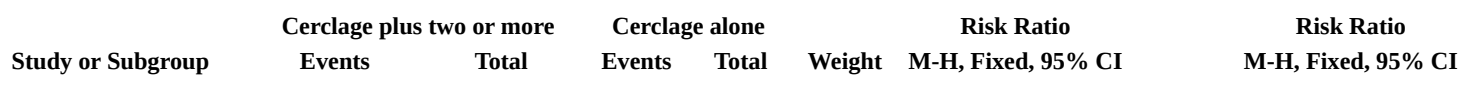

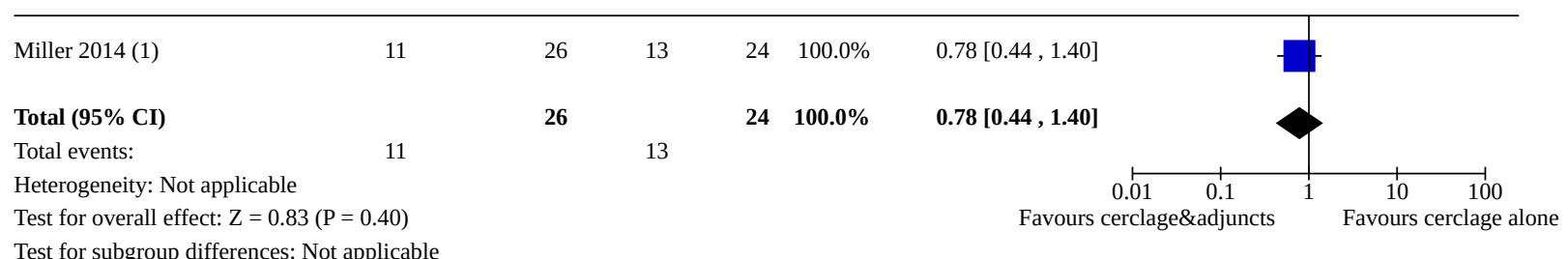

Footnotes

(1) Information not available in trial report (Miller 2014) - information provided by the trialist.

\section{Analysis 1.7. Comparison 1: Cervical cerclage in combination with antibiotic and tocolytic versus cervical cerclage alone, Outcome 7: Preterm birth $<37$ weeks}

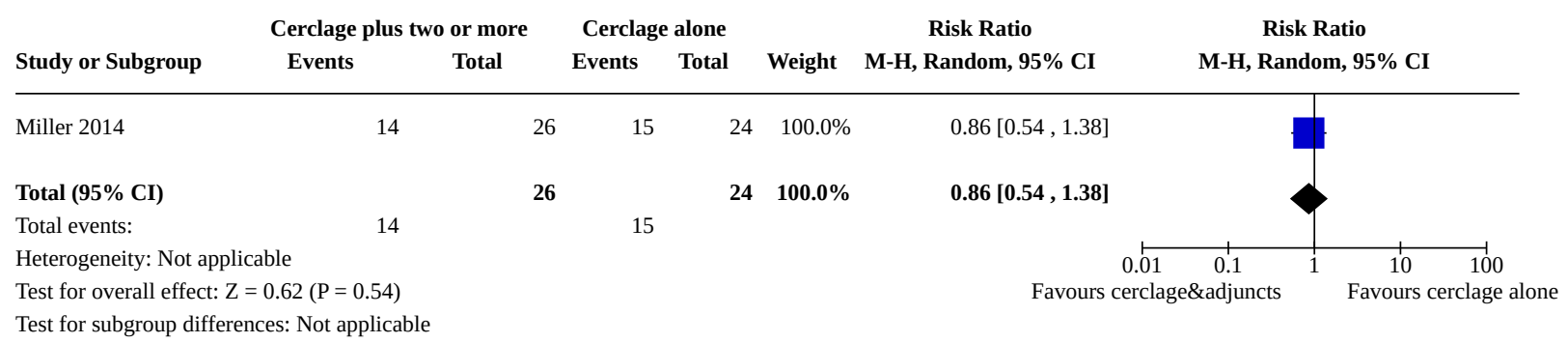

Analysis 1.8. Comparison 1: Cervical cerclage in combination with antibiotic and tocolytic versus cervical cerclage alone, Outcome 8: Serious intracranial pathology

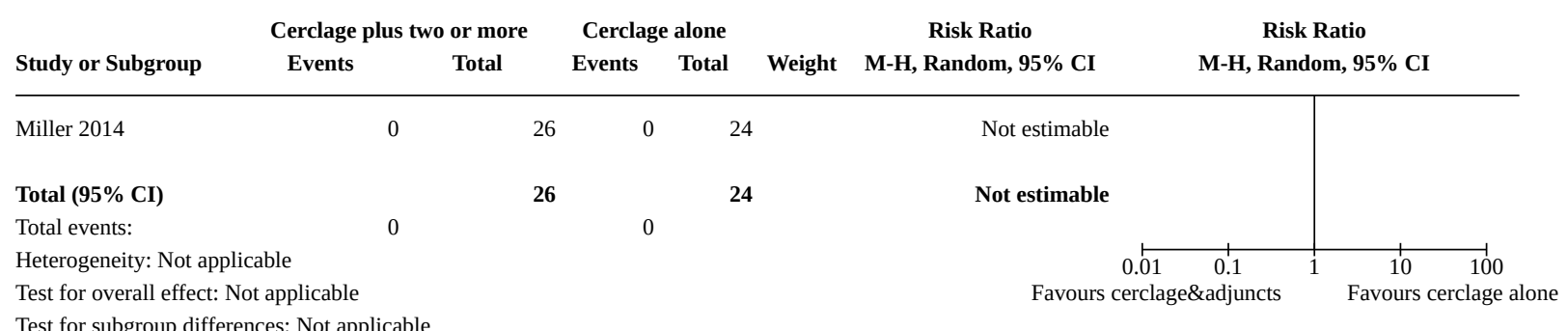

Test for subgroup differences: Not applicable

Analysis 1.9. Comparison 1: Cervical cerclage in combination with antibiotic and tocolytic versus cervical cerclage alone, Outcome 9: Serious respiratory morbidity

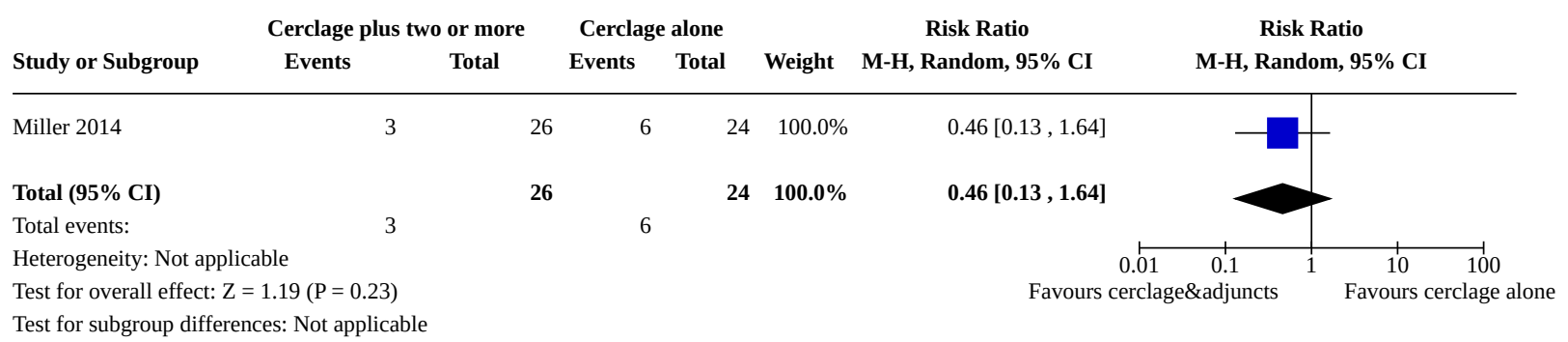

Cervical stitch (cerclage) in combination with other treatments for preventing spontaneous preterm birth in singleton pregnancies 


\section{Analysis 1.10. Comparison 1: Cervical cerclage in combination with antibiotic and tocolytic versus cervical cerclage alone, Outcome 10: Necrotising enterocolitis}

\begin{tabular}{lccccccc} 
& \multicolumn{2}{c}{ Cerclage plus two or more } & Cerclage alone & & \multicolumn{2}{c}{ Risk Ratio } & Risk Ratio \\
Study or Subgroup & Events & Total & Events & Total & Weight & M-H, Random, 95\% CI & M-H, Random, 95\% CI
\end{tabular}

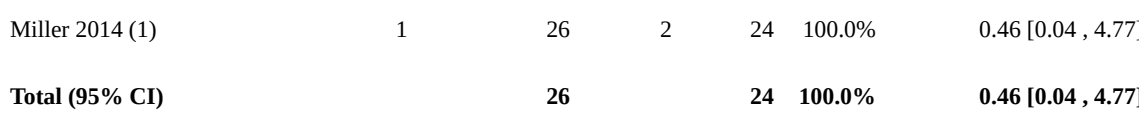

Total events:

1 2

(1) Not applicable

Test for overall effect: $\mathrm{Z}=0.65(\mathrm{P}=0.52)$

Test for subgroup differences: Not applicable

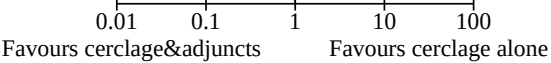

Footnotes

(1) It is not known whether the babies required surgery for necrotizing enterocolitis, we sought clarification from the trial authors but this information was not available.

\section{Analysis 1.11. Comparison 1: Cervical cerclage in combination with antibiotic and} tocolytic versus cervical cerclage alone, Outcome 11: Retinopathy of prematurity

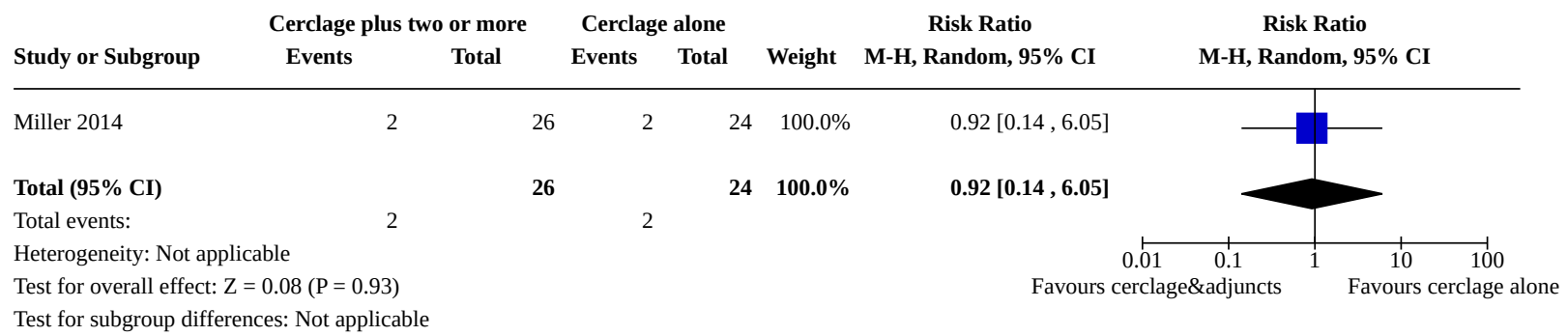

Analysis 1.12. Comparison 1: Cervical cerclage in combination with antibiotic and tocolytic versus cervical cerclage alone, Outcome 12: Maternal infection, including chorioamnionitis, requiring intervention (chorioamnionitis)

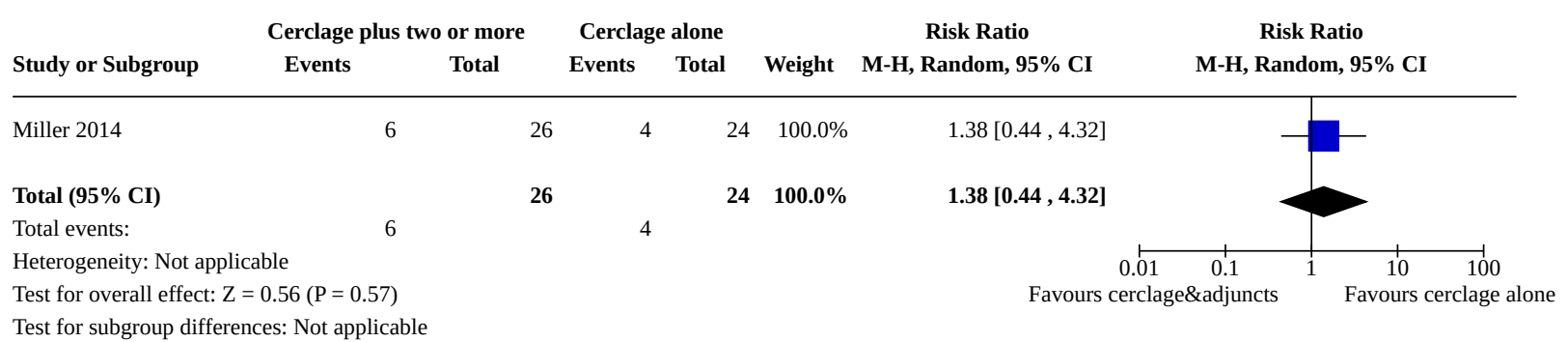

Cervical stitch (cerclage) in combination with other treatments for preventing spontaneous preterm birth in singleton pregnancies 


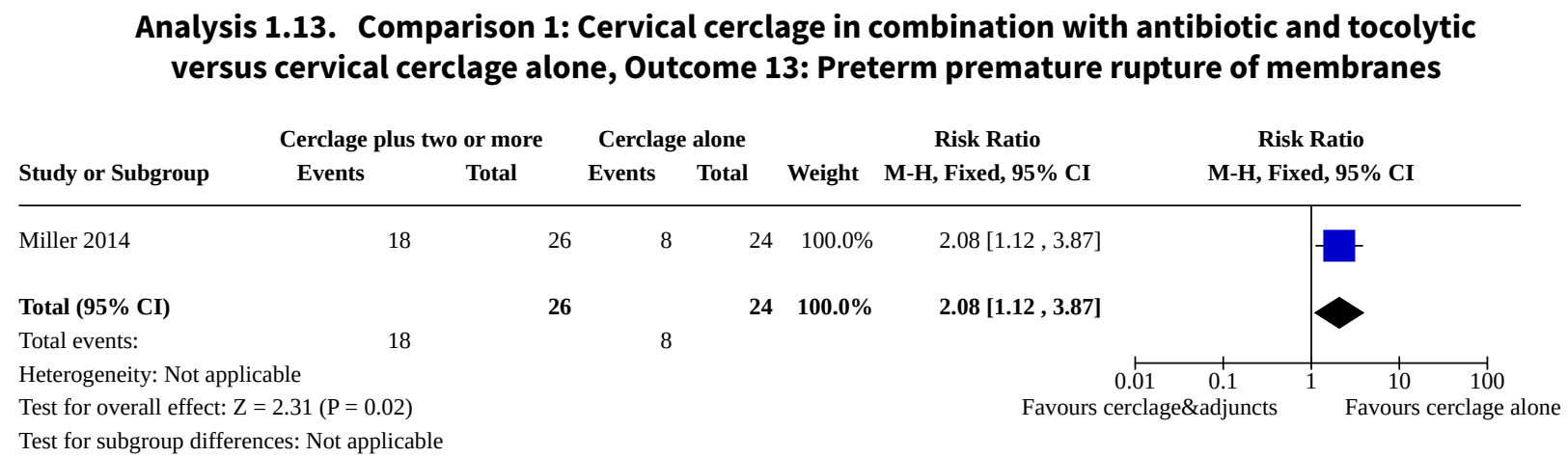

\section{APPENDICES}

\section{Appendix 1. Search terms for ClinicalTrials.gov and ICTRP}

cerclage

\section{HIST O R Y}

Protocol first published: Issue 11, 2017

Review first published: Issue 9, 2020

\section{CONTRIBUTIONS OF AUTHORS}

George Eleje conceived the review question and protocol, assessed studies for inclusion, extracted data, assessed risk of bias, carried out GRADE assessments, contributed to writing the review and approved the final draft.

Ahizechukwu Eke assessed studies for inclusion, assessed risk of bias, carried out GRADE assessments, contributed to writing the review and approved the final

draft.

Joseph Ikechebelu extracted data, contributed to writing the review and approved the final draft.

Princeston Okam searched for studies, screened studies, contributed to writing the review and approved the final draft.

Ifeanyichukwu Ezebialu assessed studies for inclusion, extracted data, assessed risk of bias, carried out GRADE assessments, contributed to writing the review and approved the final draft.

Chito Ilika searched for studies, screened studies, contributed to writing the review and approved the final draft.

\section{DECLARATIONS OF INTEREST}

George U Eleje: none known.

Joseph I lkechebelu: none known.

Ahizechukwu C Eke: none known.

Princeston C Okam: none known.

Ifeanyichukwu U Ezebialu: none known.

Chito P Ilika: none known.

\section{DIFFERENCES BETWEEN PROTOCOLANDREVIEW}

The differences between our published protocol (Eleje 2017a) and the full review are outlined below.

In our protocol, we stated that we would exclude studies published in abstract form only. No abstracts were identified or excluded in this version of the review. However, in future updates, we will classify potentially eligible studies presented only as abstract as 'Studies awaiting classification' pending their full publication.

Review title: we have edited the review title from 'cervical cerclage' to 'cervical stitch (cerclage)' to clarify the intervention for the reader. Methods/types of outcomes: our protocol included three outcomes listed separately as 'not prespecified outcomes'. The outcomes were:

Cervical stitch (cerclage) in combination with other treatments for preventing spontaneous preterm birth in singleton pregnancies 
- Any intravenous, oral or combined tocolysis - now listed as 'tocolysis (intravenous, oral or combined)'

- Preterm premature rupture of the membranes - now listed as 'preterm premature rupture of membranes'

- Chorioamnionitis - now incorporated into the edited secondary outcome, 'maternal infection, including chorioamnionitis, requiring intervention, e.g. antibiotics or delivery'

\section{NDEX TERMS}

\section{Medical Subject Headings (MeSH)}

Albuterol [therapeutic use]; Analgesics, Opioid [therapeutic use]; Anti-Bacterial Agents [therapeutic use]; Bias; Cefazolin [therapeutic use]; Cerclage, Cervical [ ${ }^{\star}$ methods]; Clindamycin [therapeutic use]; Indomethacin [therapeutic use]; Opium [therapeutic use]; Premature Birth [epidemiology] [*prevention \& control]; Randomized Controlled Trials as Topic; Stillbirth [epidemiology]; Tocolytic Agents [therapeutic use]

\section{MeSH check words}

Female; Humans; Pregnancy 